\title{
norden
}

\section{Marine Ecosystem Services}

Marine ecosystem services in Nordic marine waters and the Baltic Sea - possibilities for valuation 

Uli norden 



\section{Marine Ecosystem Services}

Marine ecosystem services in Nordic marine waters and the Baltic Sea - possibilities for valuation

Berit Hasler, Heini Ahtiainen, Linus Hasselström,

Anna-Stiina Heiskanen, Åsa Soutukorva and Louise Martinsen

TemaNord 2016:501 
Marine Ecosystem Services

Marine ecosystem services in Nordic marine waters and the Baltic Sea - possibilities for valuation

Berit Hasler, Heini Ahtiainen, Linus Hasselström, Anna-Stiina Heiskanen, Åsa Soutukorva and Louise Martinsen

ISBN 978-92-893-4444-9 (PRINT)

ISBN 978-92-893-4445-6 (PDF)

ISBN 978-92-893-4446-3 (EPUB)

http://dx.doi.org/10.6027/TN2016-501

TemaNord 2016:501

ISSN 0908-6692

(c) Nordic Council of Ministers 2016

Layout: Hanne Lebech

Cover photo: ImageSelect

Print: Rosendahls-Schultz Grafisk

Printed in Denmark

This publication has been published with financial support by the Nordic Council of Ministers. However, the contents of this publication do not necessarily reflect the views, policies or recommendations of the Nordic Council of Ministers.

\section{www.norden.org/nordpub}

\section{Nordic co-operation}

Nordic co-operation is one of the world's most extensive forms of regional collaboration, involving Denmark, Finland, Iceland, Norway, Sweden, and the Faroe Islands, Greenland, and Åland.

Nordic co-operation has firm traditions in politics, the economy, and culture. It plays an important role in European and international collaboration, and aims at creating a strong Nordic community in a strong Europe.

Nordic co-operation seeks to safeguard Nordic and regional interests and principles in the global community. Common Nordic values help the region solidify its position as one of the world's most innovative and competitive.

\section{Nordic Council of Ministers}

Ved Stranden 18

DK-1061 Copenhagen K

Phone (+45) 33960200

\section{www.norden.org}




\section{Content}

Executive summary ……................................................................................................... 7

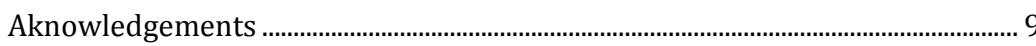

Comprehensive summary and conclusions ..............................................................11

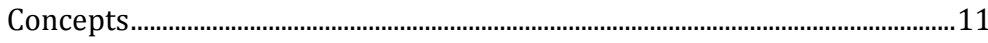

Choice of ecosystem services as examples...........................................................11

Links between ecosystem functions, processes and services complexities and potential solutions? ........................................................12

Use of descriptors for the assessment...............................................................12

The valuation experiences and usefulness for ecosystem services assessment....................................................................................................13

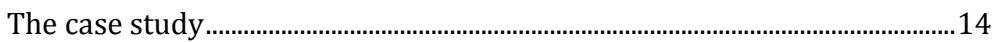

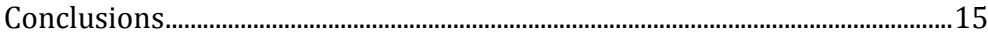

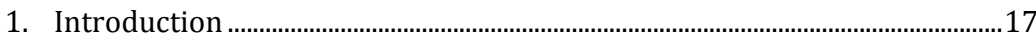

1.1 Background and focus of the report.........................................................17

1.2 The steps of marine ecosystem services assessments ........................19

1.3 The content and approaches used in this report ...................................21

1.4 The outline of the report..........................................................................21

2. Classification of marine ecosystem services ..................................................23

2.1 The need for classification systems and concepts for ecosystem services assessments.....................................................................................23

2.2 Classification systems used for ecosystem services..............................25

3. Ecosystem Services provided by the Baltic Sea - choice of examples ........39

3.1 Choice of ecosystem services for the analyses in the report.............39

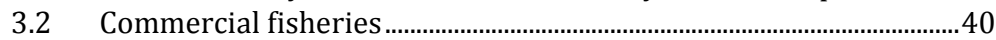

3.3 Mitigation of eutrophication and sediment retention .........................41

3.4 Marine and coastal tourism and recreation .............................................42

4. Ecosystem Services, ecosystem structures and processes in the Baltic

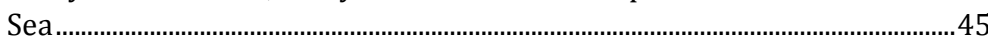

4.1 Introduction ............................................................................................. 45

4.2 Marine ecosystem components providing eutrophication mitigation service.....................................................................................46

4.3 Marine ecosystem components providing the flow of ecosystem service "wild fish for food'.......................................................................50

4.4 Possibilities and proposals for mapping the ecosystem services...51

5. Linking selected ecosystem goods and services to descriptors and indicators of good environmental status ............................................................5

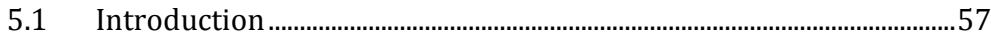

5.2 Cultural service: Recreation ....................................................................60

5.3 Provisioning service: Wild fish for Food ...............................................63

5.4 Maintenance/regulating services: Sediment retention .......................67

5.5 Concluding remarks and discussion .........................................................68 
6. Literature study on the value of marine ecosystem services.........................69

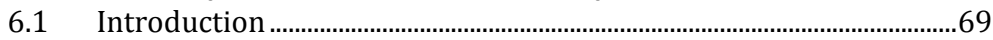

6.2 Previous reviews of the value of marine ecosystem services............70

6.3 Valuation of ecosystem services ...........................................................72

6.4 From goods to values and benefits ........................................................75

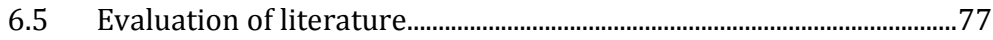

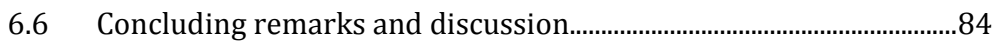

7. Case study on seaside recreation in Denmark and Sweden.............................87

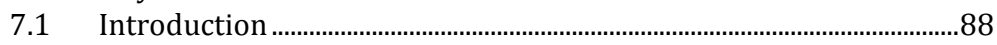

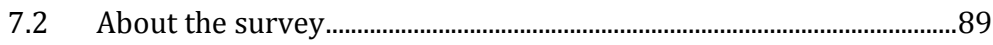

7.3 Implementation of the Danish case study ……......................................99

7.4 Results from the Danish case study ......................................................100

7.5 Implementation of the Swedish case study ……................................105

7.6 Results from the Swedish case study .................................................106

7.7 Conclusions and discussion ....................................................................111

8. Conclusions and discussions ..........................................................................113

References....................................................................................................... 115

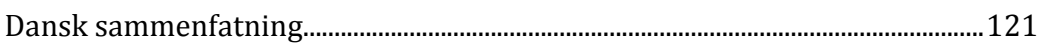

Udvidet dansk sammendrag med konklusioner............................................122

Appendix - The questionnaire used in the case study .........................................129

Questionnaire ............................................................................................................129 


\section{Executive summary}

MARECOS (Marine Ecosystem Services) is an interdisciplinary study that provides relevant information for national, Nordic and international ecosystem services assessments and valuation in the implementation of marine policy. The report aims to provide suggestions on how the ecosystem condition assessments, being based on the Marine Strategy Framework Directive (MSFD), and the HELCOM indicator based assessments for the Baltic Sea, could be used for the assessment of ecosystem services. The guidance report includes:

- definitions and description of the common concepts for ecosystem services assessments

- a proposal on how to conduct marine ecosystem services assessments

- suggestions and examples on how the MSFD descriptors and indicators for environmental status assessment can be linked with selected ecosystem services and how these data can be used for ecosystem services assessments

- a presentation and discussion of valuation study results that can be used for practical ecosystem services assessments

- a discussion of knowledge gaps related to the valuation of ecosystem services and to descriptors and indicators of good environmental status

- a case study filling some of these gaps by demonstrating how recreation (a cultural ecosystem service) can be valued.

By describing the potentials of linking data and knowledge describing the status of marine ecosystems and water quality to the values of the services and goods provided, the report offers useful information for policy and decision makers in the domain of the policies mentioned. 


\section{Aknowledgements}

This report has used knowledge and results from the authors' institutions previous work and from consultancy of colleagues. We will especially aknowledge the contributions from Harri Kuosa, Mia Olsen, Soile Oinonen and Eija Pouta. 


\section{Comprehensive summary and conclusions}

The aim of the Marecos study is to define and discuss classification methods to assess marine ecosystem services and their value, and to explore how existing knowledge and data with respect to ecosystem processes, functions, descriptors and valuation results can be used for the assessment. A case study on coastal recreation is presented as an example of an important marine ecosystem service, which has been studied to a varying degree across the Nordic countries.

\section{Concepts}

Several concepts for the valuation of ecosystem services exist, and they are all valuable and useful for different contexts. The conclusion in Marecos is that the chosen concept should include the possibility to study the effects and trade-offs between ecosystem services when policies and other drivers change. The concept used in Marecos is inspired both by MAES and the UKNEA concepts, and the focus is mainly on analysing and assessing the possibilities to describe and quantify the links between ecosystem processes and functions, ecosystem services and their values.

\section{Choice of ecosystem services as examples}

To simplify the analysis, three ecosystem services were chosen as examples of how data on ecosystem processes, functions, descriptors of the quality and the final valuation of the ecosystem services might be linked, and of the data availability in the Baltic and Nordic region. The ecosystem services chosen for further analysis are fish provision for food, ability of marine ecosystems to regulate nutrients, sediments and water purification, and coastal recreation and tourism, which all are regarded important for the Baltic Sea area and the Nordic countries. 


\section{Links between ecosystem functions, processes and services - complexities and potential solutions?}

Potential use of existing data for assessing the linkages between ecosystem function and processes on the one hand, and the ecosystem services on the other hand is illustrated for the mentioned ecosystem services. The marine bentic ecosystem of the Northern Atlantic was used as an example of how the information on predominant benthic habitats and ecosystem services could be used for establishing maps of the capacity of the benthic ecosystems to provide ecosystem services. The relationships between functions, processes and services in the marine ecosystems are very complex and the current understanding of the linkages between biodiversity, ecosystem processes, functions, and services is incomplete and lagging behind that of terrestrial ecosystems. Further research on how the ecosystem services depend on ecosystem structures (such as species and habitats), processes and functions is therefore necessary in order to be able to map and assess the condition and distribution of marine ecosystem services, as well as to pave the way for increased understanding of the potential value of the ecosystem services.

\section{Use of descriptors for the assessment}

The HELCOM CORESET I and II projects have developed core indicators. These indicators form a set of state- and pressure indicators to follow up on the progress towards achieving a Good Environmental Status (GES) in the Baltic Sea. ${ }^{1}$ The core indicators have a scientific basis and reflect changes in the marine environment due to anthropogenic pressure, and based on examples of indicators a common understanding of how the descriptors and indicators can be used in the assessment of the ecosystem health of the Baltic Sea has been developed and presented. - In the present report examples of the potential linkages between selected ecosystem services and the state of the marine environment and the EU Marine Strategy Framework Directive (MSFD) descriptors are presented. To illustrate how the use of different sets of indicators may affect the results of analyses of the links between ecosystem services and the state of the marine environment an analysis similar to the one conducted with the MSFD descriptors is repeated using the HELCOM CORESET indicators.

\footnotetext{
1 The HELCOM Baltic Sea Action Plan (BSAP) aims to reach GES in 2021, and the EU Marine Strategy Framework Directive (MSFD) aims to reach GES by 2020.
} 
The CORESET indicators are particularly suitable for Baltic-wide assessments, as they are developed to comply with the MSFD, and as they are agreed by all the Baltic contracting parties and EU member states. Therefore it is crucial to develop further linkages between the HELCOM assessment system and the mapping and assessment of the marine ecosystem services in the Baltic Sea.

There is no MSFD descriptor that is directly linked to the provision of recreational services. Hence, the analysis has focused on identifying the most relevant intermediate services, and then subsequently identifying, the descriptors and indicators most suitable to describe the status of these intermediate services. Thus, the identified indicators can indirectly be used to predict the perceived benefits of recreational activities. These indicators might be usable also for other cultural services, such as aesthetic values.

The analysis is limited to the descriptors and indicators that have an effect on particularly important intermediate ecosystem services, and to the indicators that represents ecological endpoints for these services.

\section{The valuation experiences and usefulness for ecosystem services assessment}

The economic part of the ecosystem services assessments requires monetary valuation of the changes in the provision of ecosystem services for different scenarios. Although there are several studies on the monetary benefits of changes in the Baltic Sea marine environment, the existingknowledge base of valuation studies pertaining to assessment of the value of ecosystem services is fragmented. In most cases, it is straightforward to link the valuation studies to the GES descriptors of the EU MSFD and to the HELCOM CORESET indicators and Baltic Sea Action Plan strategic goals. However, when these goals are defined further with ecological objectives and core indicators, the links are more complex.

The valuation studies are clearly concentrated on some descriptors of GES, namely biodiversity maintenance, healthy fish populations, eutrophication and contaminants and litter. Non-indigenous species are studied to a very modest extent.

When the environmental changes required by the MSFD or the BSAP differ substantially from those evaluated in the studies, it may be difficult to extrapolate the results to match the changes in the ecosystem required by the MSFD or the BSAP; but many of the studies are designed to address these issues, so we are not on totally bare field. Another challenge in using the results of valuation studies for assessing the benefits of the MSFD or 
the BSAP is that most of the studies are tied to a specific geographical location and context. This is a benefit in terms of ensuring spatial explicteness, but it represents a challenge when wanting to extend the spatial scale, e.g. if the results are to be used for estimating the aggregate benefits of reaching a good status with regard to a certain descriptor in a sub-basin or the entire Baltic Sea.

The situation is most promising for assessing the benefits of reduced eutrophication. These have been studied both at the regional, national and international levels throughout the Baltic Sea, and the changes in the level of eutrophication which have been valued correspond reasonably well with the target of reaching good environmental status.

Many studies have not considering the spatial distribution of ecosystem services and benefits, and ecosystem services capacity maps constructed based on the results of existing studies may consequently fail to reflect the true spatial variability of values. Therefore, if ecosystem services assessment is considered important to guide policy development, more emphasis should be put on incorporating spatial aspects in valuation studies, both in terms of where the ecosystem services are located (the capacity mapping) but also where the benefits accrue. One way to do this could be to identify so called marine and coastal "hotpots", which designate locations that are very important to human well-being, for example, due to their extensive use or importance in terms of providing other cultural ecosystem services. Despite the limitations of existing valuation estimates in terms of spatial explicitness it is believed that existing valuation results and benefit transfer could be used to point out some hotspots in the Baltic Sea area, e.g. in relation to recreation or fisheries. This would be especially useful for marine spatial planning.

There are no value estimates related to ecological thresholds, i.e. abrupt and dramatic changes in the ecosystem. Incorporating these to valuation studies requires careful consideration of how to describe these threshold effects, especially if there is ecological uncertainty about their occurrence.

\section{The case study}

Finally, a case study has been conducted as part of the Marecos project illustrating how a valuation study of marine ecosystem services can be conducted. The study focuses on assessing the extent to which the value of coastal recreation is dependent on water quality, the presence of litter on the coast and the number of other visitors at the site. The case study is a pilot study preceding a larger survey which later will be submitted to 
representative samples of households in Sweden and Denmark. Based on the results of the pilot, a number of important changes have been made in the main survey questionnaire. The willingness to pay results from the pilot are not included in the present report, but descriptive statistics related to the Swedish and Danish sample's use of the coastal areas for recreational purposes are summarised in the report.

The analysis and the examples may indicate potential starting points for further analysis related to identifying how the ecosystem service approach can be used to connect the "environmental" dimension of marine policy with the economic dimension. By starting in the environmental dimension, and using indicators that are already in place (or will be in place in the near future) the economic dimension can potentially be attached to existing analytical frameworks. This may provide analytical efficiency and possibilities for holistic assessments. It may also provide the base for broader sustainability assessments, where the state of the environment represents the logical central node to which the economic impacts of changes subsequently can be related to.

The implicit assumption behind the framework used is that measures are implemented in order to improve the environmental status. These measures, in turn, affect the flow of ecosystem services, and this has economic consequences. This analytical framework may oversimplify the analysis of economic consequences, since measures themselves, regardless of their effect on the environmental status, have economic consequences. For example, restrictive fishery policies may lead to increasing fish stocks, which affects the ecosystem service food provision and is likely to generate long-term economic benefits. However, the measure will also have a direct, short-term economic impact on fisheries, regardless of whether the measure entails long-term effects or not. This is an example of why ecosystem services assessments should focus on both trade-offs and synergies, thereby acknowledging potential conflicts, between the provisions of different ecosystem services.

\section{Conclusions}

Knowledge from both economic and marine science represents necessary inputs for the mapping and assessment of the condition and distribution of marine ecosystem services, which may serve to increase our understanding of the potential socioeconomic value of ecosystem services. This study has not provided an exhaustive list of "final" or "recommended" links between these domains, which can be used in future assessments of 
ecosystem service provisioning; instead focus has been on providing examples. The examples may serve as potential starting points for further analysis of how the ecosystem service approach can be used as to link between the environment and the economy, and as inspiration for holistic assessments and broader sustainability assessments.

The conclusions are that:

- Existing monitoring systems, data and results can be used to link the understanding of ecosystem health and status to the economic values of the services provided by the ecosystems.

- The descriptors and indicators of the MSFD and HELCOMs BSAP can be used to assess the current status of ecosystems, and to clarify future objectives related to ecosystem health. The descriptors and indicators can also be used to link the ecosystem health information to the drivers of change.

- It would be useful to have more valuation studies that use GES as the policy scenario, so that the benefit estimates can be directly linked to the goals of the MSFD.

- Preferebaly benefits should be assessed in a manner that allows them to be linked to measurable indicators of environmental status thereby facilitating the assessment of benefits at different levels of environmental change (and also at GES).

International studies that provide comparable benefit estimates for several countries would be useful, and such future studies of ecosystem service values should be spatially explicit. Spacial explicitness is important in order to be able to reflect how ecosystem services and their benefits varies between different coastal areas. Information on ecological thresholds, and the magnitude of value changes induced when crossing them, would also be valuable. Assessing the values may however be difficult as such changes might be outside the scope of valuation methods. The conclusion is, however, that if ecosystem services assessment is considered important to guide policy development future valuation studies need to put more emphasis on the spatial aspects of ecosystem provisioning. Hence spatial information is important for judging where the capacities and potentials are highest, and it is also important in relation to more specific assessments of how benefits are geographically distributed. One way ahead could be to identify so called marine and coastal "hotspots", which represent locations where the amount of ecosystems provided or the value of the provided ecosystem services are particularly high compared to other more generic locations. This approach can in particular be useful for marine spatial planning. 


\section{Introduction}

This report describes approaches and methodologies for mapping and valuing marine ecosystem services (ES), including the possibility of using existing data for these assessments. Additionally, the report analyses and discusses potentials and barriers for the development of common approaches to quantify and value marine ES in the three Nordic countries: Sweden, Finland and Denmark, with specific focus on these countries'shared marine areas: the Baltic Proper, Kattegat and the Belt Sea.

\subsection{Background and focus of the report}

Following the Nordic Environmental Action Plan 2013-2018 (Nordic Council of Ministers, 2013), the promotion of sustainable development makes it more and more necessary to find alternative ways of quantifying welfare. The broader welfare perspective should include the valuation of natural capital and ecosystem services (ES). This is also called for in the EU Biodiversity Strategy 2020 (EBS) ${ }^{2}$ and UN Biodiversity Convention, as well as in relation to the Marine Strategy Framework Directive (MSFD) 3 (COM, 2011) and the national implementations of this directive. The Baltic Marine Environment Protection Commission Helsinki Commission (HELCOM) has also indicated interest in initiating work to attribute economic values to marine and coastal ecosystem services, as well as to assessments of the contribution these services make to societal, cultural and ecological wellbeing (HELCOM; 2013, section (F)).

Marine and coastal ecosystems influence human welfare both through their use, and via the impacts these services have on other parts of the environment. The marine and coastal services are under pressure from overfishing, eutrophication, contamination, habitat destruction and loss of biodiversity (UNEP-WCMC 2011). By documenting the consequences of these impacts on human welfare, the understanding of coastal and marine ecosystems can be improved, and a sound base for national and international decision-making can be created.

2 COM(2011) 244 final.

3 DIRECTIVE 2008/56/EC. 
Marine areas deliver important ecosystem services to society, such as the provision of fish and shellfish for food; sea water; raw materials (such as algae, salt, sand and gravel); amber and other biotic items for decoration; space for delivering energy from offshore windfarms; transport ways for ship traffic; cultural services such as recreational opportunities for local visitors and tourists; as well as biodiversity. The marine environment also delivers maintenance and regulating services, such as the regulation and sequestration of nutrients and toxic substances, as well as climate regulation. These intermediate services also have a large economic value even if they are more difficult to monetize and assess than other more tangible services. Services like food, raw materials, and energy provision and recreational possibilities are called final services which affect human welfare directly, while the maintenance and regulating services are intermediate services and affect welfare indirectly (cf. Zaucha 2014, Boyd and Banzhaf 2007; Boyd and Krupnick 2009).

The ecosystem services mentioned above are all of importance for the Nordic countries, and the aim of this report is to outline and discuss approaches, methodologies and data for the assessment and valuation of marine ES, with a specific focus on evaluating the possibility of using existing data for mapping, quantification and valuation. This report also provides background information on the potentials and barriers for the development of common approaches to quantify and value marine ES in the three Nordic countries: Sweden, Finland and Denmark, with specific focus on these countries' shared marine areas: the Baltic Proper, Kattegat and the Belt Sea.

By sharing experiences in the Nordic countries, utilising literature and existing data, as well as conducting a new case study, the results from this report can support the implementation of the MSFD, the Water Framework Directive (WFD), 4 (COM, 2000), the HELCOM's Baltic Sea Action Plan (BSAP) (helCOM, 2013b) as well as the EBS 2020. The EBS sets six targets to address the main pressures on nature and ecosystem services, and one of the actions of target 2 (action 5) is to improve knowledge of ecosystems and their services by assessing the economic value. The WFD, the MSFD and the BSAP set targets for the achievement of Good Environmental Status (GES) in coastal areas (WFD only) and in the open Baltic Sea basins. As pointed out by Zaucha (2014) the ecosystem services approach is also important for marine spatial planning at the national and international levels. 
Coherent approaches for the implementation of these policies in coastal and marine areas are important to the management of human activities and to initiate measures in order to achieve good water quality and biodiversity improvements. To achieve such coherence it is necessary to obtain knowledge and approaches to assess how the marine, coastal and catchment policies affect coastal and marine ES. We provide examples of how to link the current concepts and descriptions of ES with the indicators for Good Environmental Status (GES) as well as with other water quality indicators used in the monitoring and assessment of marine and coastal waters. Furthermore, we suggest how data from the monitoring of the MSFD, WFD and HELCOM could be used for the assessment of marine ES. The assessments can be used for communication and for decision support as the approach provides information on how to compare different policies and policy options, by assessing trade-offs, synergies and conflicts between the delivery of different ecosystem services.

To exemplify how information from various sources can be used - including ecosystem health assessments, environmental quality descriptors and indicators, ecosystem services mapping and valuation - we focus on three examples of services. These comprise: fish for food, representing a provisioning service; eutrophication mitigation, representing a regulation and maintenance service; and recreation, representing a cultural service. These services are considered important for the Nordic countries, and they allow for an extensive analysis with the use of examples from each of the three ES categories.

\subsection{The steps of marine ecosystem services assessments}

In order to achieve a better understanding of marine ES, their value and the changes in value when the marine environment changes, at least three types of analyses and assessments are needed

- Identifying the ecosystem services and their provision.

- Mapping and assessing the ecosystem services and their provision.

- Valuing the monetary benefits from ecosystem services and their changes.

The identification and mapping of ES are interrelated. The ecosystem services and the provision of these should be linked to the ecosystem processes and functions that shape the flow of the services on the one hand, and to the 
demand for the services, shaping the value, on the other hand. Marine ecosystem services are provided by a combination of abiotic and biological structures and processes. Thus mapping should show where the ES are provided, in relation to the spatial distribution of the marine structures and processes that shape and influences the ES provision. However, appropriate data and knowledge of the distribution of these services are often scarce. Therefore the mapping of marine ES can in many ways be challenging, and even more challenging compared to terrestrial systems, where maps of habitat distributions are more commonly available.

There exists a substantial amount of information related to the status of the marine environment, although relatively little knowledge exists on how to link existing monitoring data and information to assessments of marine ecosystem services, and subsequently to the value of these services. Monitoring data and pressure information obtained in relation to the MSFD, the WFD and the HELCOM BSAP has been suggested to be used to retrieve information about the status of the ecosystem services (Maes et al., 2014). Various types of information would be needed to enable assessments of how the deliveries of marine ecosystem services, and the societal benefits from these, might develop in the future. In this report we present suggestions on how to use MSFD, WFD and HELCOM monitoring data, descriptors and indicators for ecosystem services assessments.

The next step after the identification and mapping is the valuation of the benefits provided by ecosystem services and their changes. Often the value of ES needs to be estimated using non-market valuation approaches because of the public good character of many ecosystem services, i.e. they are normally not traded on any market. A number of valuation studies have been conducted in the Baltic Sea area to elicit the monetary value of marine ecosystem services. The existing studies cover both ecosystem services in open marine areas and coastal areas, and we aim to make an overview of how well these studies address different ecosystem services and the extent to which they can be related to the MSFD and the HELCOM assessment systems. For instance, Ahtiainen et al. (2013) have found that coastal areas are frequently used for recreation, but information is still lacking regarding how the value of the ecosystem service "coastal recreation" is affected by ecosystem conditions, including water quality, as well as other factors, such as litter, noise and the number of visitors at the site (i.e. the level of congestion). 


\subsection{The content and approaches used in this report}

This report investigates possiblities to identify, assess and map ecosystem services, based on the information from MSFD, WFD and HELCOM assessments. In addition, it examines if it is possible to use these assessments to understand how natural and human induced changes affect the ecosystem condition and the provision of the ecosystem services, and whether monetary assessments can be linked to the ecosystem services. This chain of knowledge requires concepts that capture the linkages between values, goods, ecosystem services, ecosystem structures and ecosystem conditions based on knowledge of:

- how the ecosystems (and their structures and components) link with the provision of goods and services

- how different drivers and pressures influence changes in the ecosystem goods and services

- what are the economic benefits of these changes in the delivery of goods and services.

Descriptions of the possibilities for acquiring such knowledge for all types of ecosystem services in the Nordic marine areas and the Baltic Sea is a complex task, and the knowledge necessary for linking existing monitoring data with ecosystem services is not yet complete. The approach used here in this report is therefore that we start the assessment by identifying important ecosystem services and goods for the human society, as examples of marine ecosystem services. Thereafter we identify the intermediate services, ecosystem structures, processes and functions underlying the final services; we also identify the pressures and drivers (human activities) impacting these ecosystem function and services.

The analyses in the report use existing knowledge and experience from the consortium's previous projects, literature, as well as discussions within the research network and community.

\subsection{The outline of the report}

The work is divided into the following subtasks:

Common classification systems for assessments of ecosystem services are reviewed in Chapter 2 to describe and explain the advantages and drawbacks of the classification systems and concepts used in this study. 
Chapter 3 describes the choice of ecosystem services in focus for the analysis in the rest of the report is described.

Chapter 4 presents monitoring data and knowledge that can be used for assessments, with a focus on those datasets that are considered useful for the assessment and mapping of the marine ecosystems functions, processes and health in the Baltic Sea region.

Chapter 5 describes how the valuation of the ecosystem services can be linked to environmental status indicators used in the MSFD.

Chapter 6 presents a literature study focusing on experiences related to the valuation of marine ecosystem services. The studies are linked to the MSFD and BSAP, and the findings are discussed with specific focus on the three chosen ecosystem services.

Chapter 7 describes the case study, which is carried out to explore the value of coastal recreation and how water quality affects the value of this service. The chapter presents the study, which is performed in the western part of Sweden and the eastern part of Denmark, as well as some results.

In Chapter 8 we present our conclusions and discussion points. 


\section{Classification of marine ecosystem services}

A wide array of concepts and classifications have been developed for ecosystem services assessments, at international and EU levels and in specific countries. This chapter presents classification schemes for ecosystem services assessments, the main characteristics of the classifications, and describes some potentials and problems using the schemes for marine ecosystem services classification and assessment. As a conclusion on the presentation and discussion of the different concepts a concept intended specifically for identification of how marine ecosystem structures, processes and functions affects ecosystem services and goods, and the value of these, is presented. The concept is used in the remaining part of the report for the assessments of how available data and knowledge can be used for assessting and identifying the intermediate services, ecosystem structures, processes and functions underlying the production of the final ecosystem goods and services, as well as the value of these services from the literature review and the case study.

\subsection{The need for classification systems and concepts for ecosystem services assessments}

This chapter describes ecosystem services assessment concepts and argues for the choice of classification schemes for different purposes. As in Magnussen et al. (2014), we will not choose one specific classification scheme but rather discuss how data and existing knowledge can be used for marine ecosystem services assessment using different classifications.

From economic theory and from the present classifications and concepts the following requirements should hold for a classification system used for ES assessments (see also Figure 1):

- The concept should allow for spatially explicit assessments, as the provision of ecosystem services most often is spatially dependent.

- The concept should allow for mapping and assessments of marginal changes, as larger changes will change the wider economy, and not 
only affect the benefits provided by the ecosystem services.

Furthermore, estimates of the total value provided by ecosystems are often not meaningful.

- The concept used should allow for preventing the double counting the benefits or disbenefits from changes in ecosystems.

- The concept should also pay attention to how trade-offs, synergies and conflicts between the provision of ecosystem services might occur when policies and pressures change.

- The concept should be able to reflect non-linearities and threshold effects. Not all processes, functions, service provision and benefit deliveries are linear, and neither are the costs of delivering these services. Non-linearities can complicate the assessments of the benefits from ecosystems, and require explicit consideration.

- Threshold effects can tip ecosystems into different states, and then the functions and values retrieved from one state are no longer valid. One should therefore be aware of tipping points.

Figure 1: Challenges for ecosystem services assessments (Here adapted from Luisetti et al., 2011)

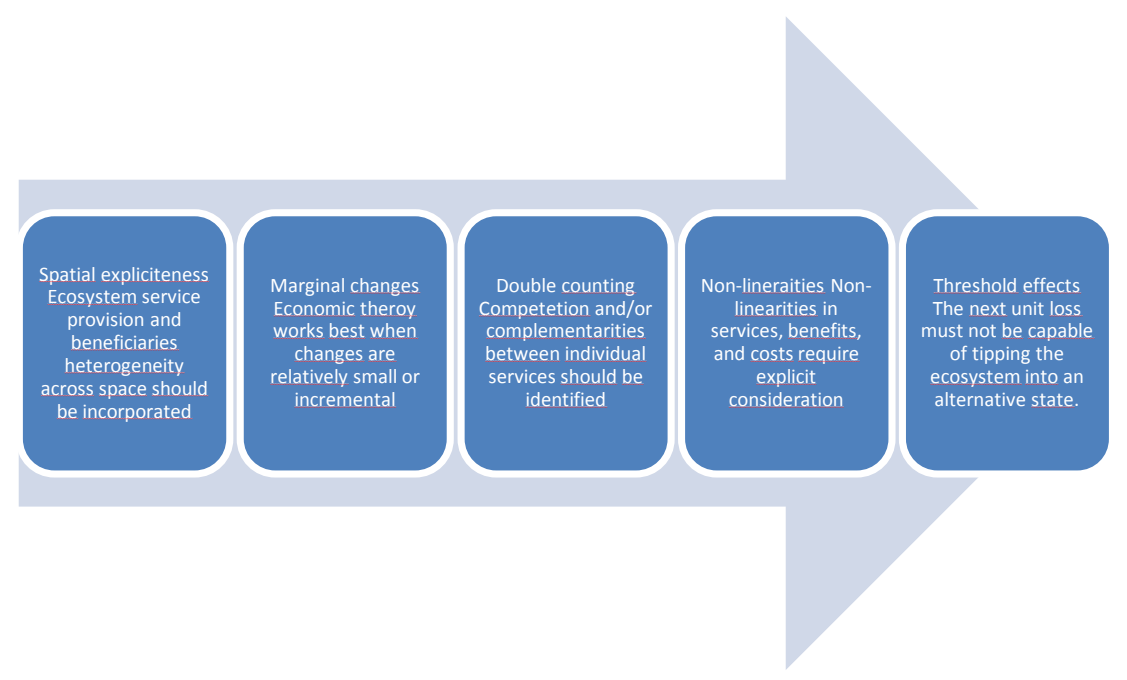

For ecosystem services in general, i.e. not specifically for marine ecosystem services, these links are captured and conceptualised in a number of classification systems. The classifications are, to different degrees, applicable for the assessments of marine ecosystem goods and services, but further discussion and analysis of the concepts is needed for decisions on which classifications to use in marine assessments, as few of them are developed to assess marine services. 


\subsection{Classification systems used for ecosystem services}

The most well-known classification systems are developed in the Millennium Ecosystem Assessment (MEA) (2005), the Economics of Ecosystems and Biodiversity (TEEB) and TEEB Oceans and Coasts (TEEB, 2012), the Common International Classification of Ecosystem Services (CICES) (EU Commission/JRC 2013) and the EU approach developed by the MAES working group; Mapping and Assessments of Ecosystem Services (Maes et al., 2014). Furthermore, the UK National Ecosystem Assessment (UK NEA) (Bateman et al., 2013) and UK National Ecosystem Assessment Follow On (UK NEAFO, Turner et al., 2014) have inspired classifications and concepts used in many other countries outside UK; e.g. the Danish assessment of ecosystem services mapping (Termansen et al., in press). The most recent application UK NEAFO also addresses specifically marine ecosystem services.

Each national ecosystem assessment has been based on adaptations of existing classifications, and common classification schemes have rarely been used (Brouwer et al., 2013). The most comprehensive national ecosystem assessment has been carried out in the UK (UKNEA), based a specific approach developed for this purpose. Furthermore, the EU Commission and the EEA have developed their own approaches. In the EU, the mentioned MAES working group has been the joint expert group forum for development of harmonized classification scheme for ecosystem services (CICES), particularly aimed for the purpose of the EU BD-strategy 2020. UNEP also addresses Ecosystem Services with a focus on Economic Valuation and Natural Wealth, Equity in Ecosystem Management and Disaster Risk Management. Cognetti et al. (2010) have developed a marine ecosystem services concept for ES provision, focusing on the providers of these services. This approach allows for linking data on marine biotopes, pressures or disturbance types to the provision of marine ecosystem services and the final goods/benefits. This type of approach can be inspiring as an example of a concept for using the existing monitoring data on biotopes and ecosystems, data on pressures and changes in water quality to the assessment of ecosystem services and final benefits. 


\subsubsection{The Millennium Ecosystem Assessment}

The Millennium Ecosystem Assessment (MEA, 2005) is a framework for relating ecosystem services to science and policy, and one of the first classification schemes developed. The MA approach divide ecosystem services into the categories supporting services, regulating services, provisioning services and cultural services, and defines the Ecosystem services as "the benefits humans obtain from ecosystems". Hereby the classification represents a way to attach values to changes in the ecosystems.

Figure 2: The classification of ecosystem services in the Millennium Ecosystem Assessment

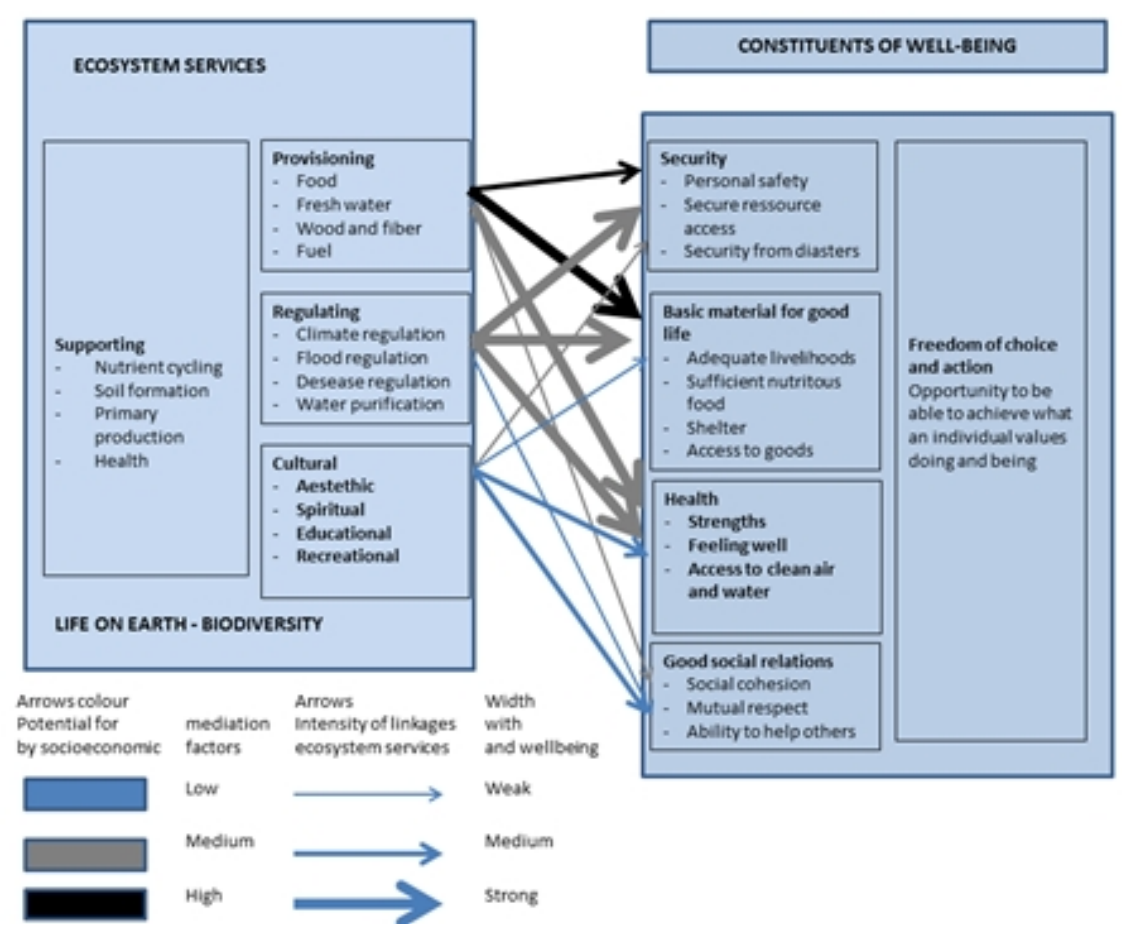

Source Millennium Ecosystem Assessment (MEA), 2005.

During the years since MEA was first published, a couple of potential problems with this framing have been identified. One problem with the approach used in the MEA is that it is not always clear whether this approach is used for valuing changes, or the total ecosystems, while the first should be the case. Another problem inherent in the MEA approach is the risk of double counting the benefits from the services. Fisher et al. (2011) describe how this can be the case for water-related services, where nutrient cycling is a supporting service, water flow regulation is a regulating 
service and recreation is a cultural service. The nutrient cycling and water-flow regulation supports, among other benefits, good water quality, and hereby the recreational services.

Fisher et al. (2011) gives this analogy as an example to illustrate the risk of double-counting using this approach: "An analogy is that when buying a live chicken you do not pay for the price of a full chicken plus the price of two legs, two wings, head, neck etc. ... you simply pay the price of a whole chicken" Fisher et al., 2011, p.5.

The double counting problem and marginal changes versus the total value are the main pitfalls of the MEA approach. These issues have been approached in the development of classification schemes following up on MEA.

\subsubsection{The Common International Classification of Ecosys- tem Services (CICES)}

The Common International Classification of Ecosystem Services (CICES) (www.cices.org) categorise the services into provisioning, regulating and cultural services, and compared to the MA the supporting services is omitted to avoid double counting.

CICES was launched in 2009 as a way of classifying and describing ecosystem services (see Haines-Young et al., 2010). The CICES classification system applies a hierarchical structure, where the highest level are the three "service themes" mentioned above, and below there are nine principle classes of service.

The aim for the development of the CICES classification is to provide a framework for linking data on ecosystem structure and dynamics and information on economic performance. CICES identifies the "final product" from an ecosystem service and, therefore, it only includes directly provisioning, regulating, and cultural services. Following the Millennium Ecosystem Assessment, the term "service" has generally been taken to include both goods and services. The structure of the CICES classification with examples related to marine ecosystem services is illustrated in Table 2. 
Table 1: Classification of marine ecosystem services adapted using the CISES terminology (based on version 4.3 available at www.cices.eu)

\begin{tabular}{|c|c|c|}
\hline $\begin{array}{l}\text { CICES Service } \\
\text { Section }\end{array}$ & CICES division & CICES Group and Class (as relevant for marine ecosystems) \\
\hline \multirow{3}{*}{$\begin{array}{l}\text { Provisioning } \\
\text { services }\end{array}$} & Nutrition & Fish, shellfish, algae and their outputs for used for food \\
\hline & Materials & $\begin{array}{l}\text { Fibres and other material from plants, algae, and animals for di- } \\
\text { rect use or processing (including agricultural use and genetic ma- } \\
\text { terials from biota) }\end{array}$ \\
\hline & Energy & Biomass based energy sources (e.g. algae for energy) \\
\hline \multirow[t]{3}{*}{$\begin{array}{l}\text { Regulating and } \\
\text { maintenance }\end{array}$} & $\begin{array}{l}\text { Meditation of waste, tox- } \\
\text { ics and other nuisances }\end{array}$ & $\begin{array}{l}\text { Mediation by biota and ecosystems (their ability to remove or } \\
\text { store pollutants, e.g. bioremediation by organisms, filtration, } \\
\text { storage and accumulation }\end{array}$ \\
\hline & Mediation of flows & $\begin{array}{l}\text { Mass stabilisation and control of erosion rates, flood protection } \\
\text { (etc.) }\end{array}$ \\
\hline & $\begin{array}{l}\text { Maintenance of physical, } \\
\text { chemical and biological } \\
\text { conditions }\end{array}$ & $\begin{array}{l}\text { Lifecycle maintenance, habitat and gene pool protection (disper- } \\
\text { sal and maintenance of nursery population and habitats, gene } \\
\text { pool protection); pest and disease control; decomposition and } \\
\text { fixing processes; chemical condition of water; climate regulation } \\
\text { (by reduction of greenhouse gas concentration) }\end{array}$ \\
\hline \multirow[t]{2}{*}{ Cultural } & $\begin{array}{l}\text { Physical and intellectual } \\
\text { interactions with biota } \\
\text { and ecosystems, and } \\
\text { seascapes }\end{array}$ & $\begin{array}{l}\text { Experiental and physical use (e.g. many activities of recreation, } \\
\text { swimming, diving, leisure fishing, etc.), scientific, educational, } \\
\text { heritage, entertainment, and aesthetic interactions }\end{array}$ \\
\hline & $\begin{array}{l}\text { Spiritual, symbolic and } \\
\text { other interactions with } \\
\text { biota, ecosystems, and } \\
\text { seascapes }\end{array}$ & $\begin{array}{l}\text { Symbolic, sacred and/ or religious, as well as existence and be- } \\
\text { quest values }\end{array}$ \\
\hline
\end{tabular}

Abiotic outputs from ecosystems were not originally included in the CICES: following the MAES framework it was argued that the generation of an ecosystem service must involve living processes (i.e. show dependency on biodiversity). Currently, however, also abiotic outputs (such as minerals, aggregates and energy sources) are also included in CICES.

The main difference between the CICES and TEEB classifications is in the treatment of 'habitat services'. While TEEB identifies them as a distinct grouping at the highest level, CICES regards them as part of a broader "regulating and maintenance" section. In CICES "habitat services" are important for the regulation and maintenance of "biotic" conditions in ecosystems (e.g. pest and disease control, pollination, gene-pool protection etc.), and are equivalent to other biophysical factors that regulate the ambient conditions such as climate regulation. 
The EU project OPENNESS has develop an ecosystem services typology translator, ${ }^{5}$ which can be used to provide a quick overview of how the different ecosystem service types used in CICES can be transferred to equivalent MA, TEEB or UK NEA services. (TEEB and UK NEA are described in the next sections, after CICES).

\begin{tabular}{|c|c|c|c|c|c|}
\hline CICES Section & CICES Division & TEEB Categories & & & \\
\hline \multirow[t]{4}{*}{ Provisioning } & Nutrition & Food & & & \multirow{4}{*}{$\begin{array}{l}\text { Ornamental } \\
\text { resources }\end{array}$} \\
\hline & & Water & & & \\
\hline & Materials & Raw materials & $\begin{array}{l}\text { Genetic re- } \\
\text { sources }\end{array}$ & $\begin{array}{l}\text { Medicinal re- } \\
\text { sources }\end{array}$ & \\
\hline & Energy & & & & \\
\hline \multirow[t]{4}{*}{$\begin{array}{l}\text { Regulating and } \\
\text { Maintenance }\end{array}$} & Meditation of waste & Air purification & $\begin{array}{l}\text { Waste treatment } \\
\text { (esp. water puri- } \\
\text { fication) }\end{array}$ & & \multirow{6}{*}{$\begin{array}{l}\text { Biological } \\
\text { control }\end{array}$} \\
\hline & Mediation of flows & $\begin{array}{l}\text { Disturbance pre- } \\
\text { vention or moder- } \\
\text { ation }\end{array}$ & $\begin{array}{l}\text { Regulation of } \\
\text { water flows }\end{array}$ & $\begin{array}{l}\text { Erosion pre- } \\
\text { vention }\end{array}$ & \\
\hline & $\begin{array}{l}\text { Maintenance of physi- } \\
\text { cal, chemical, biological } \\
\text { conditions }\end{array}$ & $\begin{array}{l}\text { Climate regula- } \\
\text { tion (incl. C-se- } \\
\text { questration) }\end{array}$ & $\begin{array}{l}\text { Maintaining soil } \\
\text { fertility }\end{array}$ & & \\
\hline & & $\begin{array}{l}\text { Gene pool protec- } \\
\text { tion }\end{array}$ & $\begin{array}{l}\text { Lifecycle mainte- } \\
\text { nance }\end{array}$ & Pollination & \\
\hline \multirow[t]{2}{*}{ Cultural } & $\begin{array}{l}\text { Physical and intellec- } \\
\text { tual interactions with } \\
\text { biota, ecosystems, and } \\
\text { land-/seascapes }\end{array}$ & $\begin{array}{l}\text { Aesthetic infor- } \\
\text { mation }\end{array}$ & $\begin{array}{l}\text { Inspiration for } \\
\text { culture, art and } \\
\text { design }\end{array}$ & \multirow[t]{2}{*}{$\begin{array}{l}\text { Recreation } \\
\text { and tourism }\end{array}$} & \\
\hline & $\begin{array}{l}\text { Spiritual, symbolic and } \\
\text { other interactions with } \\
\text { biota, ecosystems, and } \\
\text { land-/seascapes }\end{array}$ & $\begin{array}{l}\text { Spiritual experi- } \\
\text { ence }\end{array}$ & & & \\
\hline
\end{tabular}

${ }^{5} \mathrm{http}: / /$ openness.hugin.com/example/cices 


\subsubsection{The economics of Ecosystems and Biodiversity (TEEB)}

The Economics of Ecosystems and Biodiversity (TEEB) is a global initiative focused on drawing attention to the economic benefits of biodiversity and ecosystems, as well as the costs of biodiversity loss and ecosystem degradation (TEEB, 2013). The conceptual understanding of ecosystem services is the same as for CICES. TEEB identifies a "habitat service" as a separate category to highlight the importance of habitats for migratory species (e.g. as nurseries) and gene-pool "protectors" (e.g. natural habitats allowing natural selection processes to maintain the vitality of the gene pool). The availability of these services is directly dependent on the state of the habitat providing the service. The TEEB classification has also been adapted for marine ecosystems (Böhnke-Henrichs et al., 2011) and recently updated for the purpose of marine spatial planning and management (Böhnke-Henrichs et al., 2013).

Table 3: Ecosystem services categories, services and indicators used in TEEB

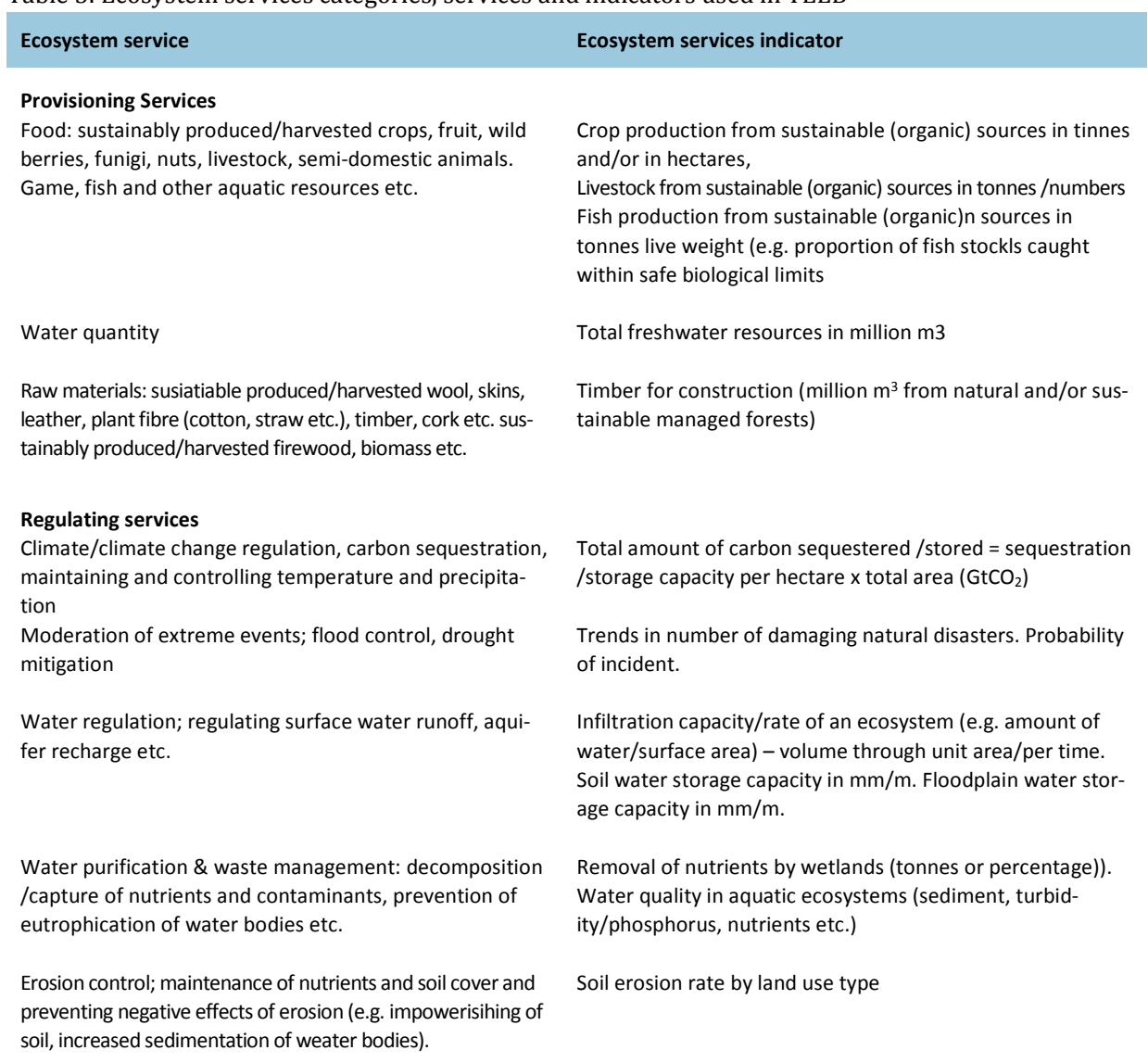




\begin{tabular}{|c|c|}
\hline Ecosystem service & Ecosystem services indicator \\
\hline \multicolumn{2}{|l|}{ Cultural \& Social services } \\
\hline $\begin{array}{l}\text { Landscape and amenity values; amenity of the ecosys- } \\
\text { tem, cultural diversity and identity, spiritual values, cul- } \\
\text { tural heritage values etc. }\end{array}$ & Changes in the number of residents and real estate values \\
\hline $\begin{array}{l}\text { Ecotourism and recreation; hiking, camping, nature } \\
\text { walks, jogging, skiing, canoing, rafting, recreational fish- } \\
\text { ing, diving, animal watching etc }\end{array}$ & $\begin{array}{l}\text { Number of visitors to sites per year } \\
\text { Amount of nature tourism }\end{array}$ \\
\hline $\begin{array}{l}\text { Cultural values and inspirational services; e.g. education, } \\
\text { art and research }\end{array}$ & $\begin{array}{l}\text { Total number of educational excursions at a site } \\
\text { Number of TV programmes, studies, books etc. featuring } \\
\text { sites and the sourrounding area; number of scientific artciles } \\
\text { and patents }\end{array}$ \\
\hline
\end{tabular}

National TEEBs have been completed in some countries (e.g. Finland: Jäppinen \& Heliölä, 2015, Norway: Lier Hansen et al., 2013; Sweden: Miljö och Energidepartementet; Denmark (partly, underway): Termansen et al., 2015 (MAES approach, see below)). The TEEB for Oceans and Coasts aims to support the mainstreaming of new policies, practices, markets and agreements to improve the ecological and economic productivity and sustainability of marine ecosystems around the world. A minimum of four ecosystem-level valuation exercises are planned as case studies to demonstrate how holistic valuation approaches can be adapted to respond to specific national policy questions. The work is still ongoing.

\subsubsection{The common framework for mapping and assess- ment of ecosystem services (MAES)}

The mandate of the Working Group on Mapping and Assessment on Ecosystems and their Services (MAES) is to coordinate the approaches for the national ecosystem (services) assessments for Target2/Action 5 of EUs Biodiversity Strategy. MAES working group developed an analytical framework, linking ecosystems, biodiversity and ecosystem services with the socio-economic systems, promoting the CICES classification for ecosystem services (Maes et al., 2013). In this framework the ecosystem services cascade model, the TEEB framework and the UK NEA approach are used together with elements of the DPSIR framework.

The recommendations from the MAES group (Maes et al., 2013; Maes et al., 2014) are suggesting that the use of the ecosystem services framework can be very helpful to assess and illustrate trade-offs between different goods and services, i.e. how different implementation strategies might lead to different results for the provision of ecosystem services, and hence also illustrate differences between implementation strategies 
when it comes to the total benefits of a strategy but also for the distribution of benefits between different users or beneficiaries.

Figure 3: The Ecosystem Services concept adapted by MAES working group (Maes et al., 2013)

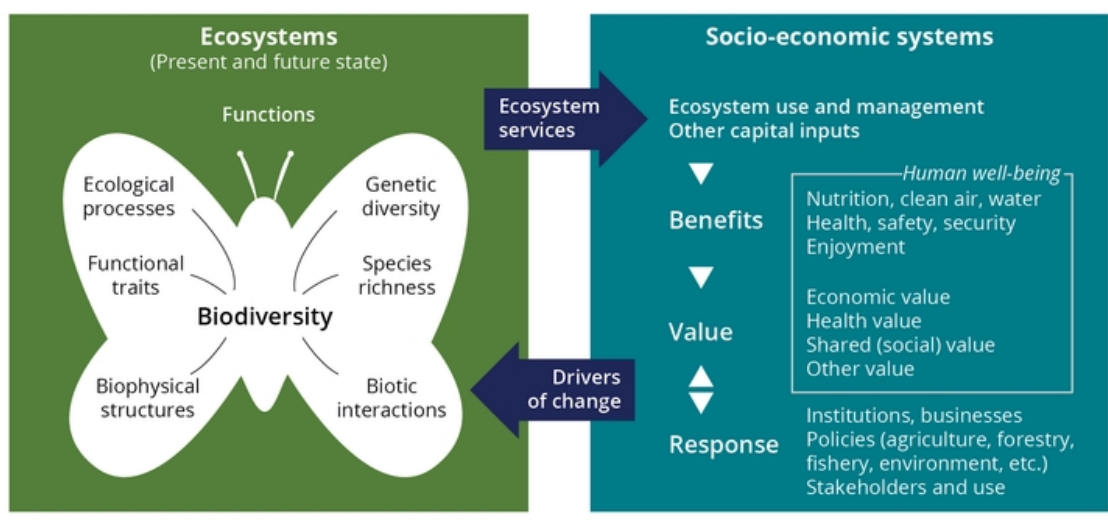

The state of the ecosystems is specifically addressed on the left side of the framework illustrated in Figure 3, and the state of the ecosystems - ecosystem condition - is important for the potential of ecosystem functions and the provisions of a number of ecosystem services beneficial for human welfare.

Ecosystems in general consist of the physio-chemical environment, which constitutes the abiotic component, and the populations of organisms, which constitutes the biotic component.

This approach has been applied to marine ecosystem services (Maes et al., 2013). Habitats and ecosystem structures and functions are important for the flow of ecosystem services.

In this application the basic marine ecosystem structures are characterized by a typology that reduced the 3-dimensional structure of the ocean to 2 dimensions: 1) seabed (benthic habitats) and 2) depth zones (pelagic habitats). The marine ecosystems are split into these typologies:

- Marine inlets and transitional waters; ecosystems on the land-water interface, influenced by tides, salinity higher than $0.5 \%$. Coastal wetlands, lagoons, estuaries and transitional waters are included.

- Coastal areas: Coastal, shallow, marine systems significantly influenced from land. Fluctuations in temperature, salinity, turbidity, wave disturbance. Depth between 50 and $70 \mathrm{~m}$. 
- The Shelf: marine systems away from coastal influence, down to the shelf break. Stable temperature and salinity compared to the coastal areas, seabed is below wave disturbance. About $200 \mathrm{~m}$ deep.

- The open sea: Very stable salinity and temperature, below $200 \mathrm{~m}$. (Maes et al., 2013, page 24).

The idea is to use the spatial distribution of marine ecosystem types and their habitats for mapping of the ecosystem services that those habitats provide. However, the MAES marine ecosystem services typology ignores the important role of the photic zone which drives the functioning of the marine food webs which would be particularly important for the shallow areas in the Baltic Sea (Maes et al., 2013). This is explained more in detail in the Chapter 3 (Ecosystem services provided by the Baltic Sea).

The ecosystem services framework from Maes et al. (2013) was further developed, and indicators for assessing for instance marine ecosystem services were suggested by Maes et al. (2014). The MAES process has been carried out in many countries in order to fulfill the EU biodiversity strategy action 5 requirements. However, the focus has been mostly in mapping and assessment of terrestrial and to some extent freshwater ecosystems.

\subsubsection{THE UK NEA-approach}

A comprehensive methodological framework for valuing ecosystem services was developed and applied for the UK NEA (UK National Ecosystem Assessment) (Bateman et al., 2013). The concept is based on the existing concepts used for the MEA (2005) and TEEB (Ring et al., 2010; Balford et al., 2010). UK NEA avoids the risk of double counting which as explained is inherent in the MEA; because the supporting services is not a class in the UK NEA, just as in TEEB, CICES and MAES. The UK NEA has a more clear emphasis on policy than the other concepts and by its focus on scenario development and assessments the UK NEA approach is especially suitable to evaluate the changes in ecosystem services delivery from both policy- and natural changes. The approach is illustrated in Figure 4. 
Figure 4: The overall concept of the UK NEA. Mace and Bateman 2011, page 13

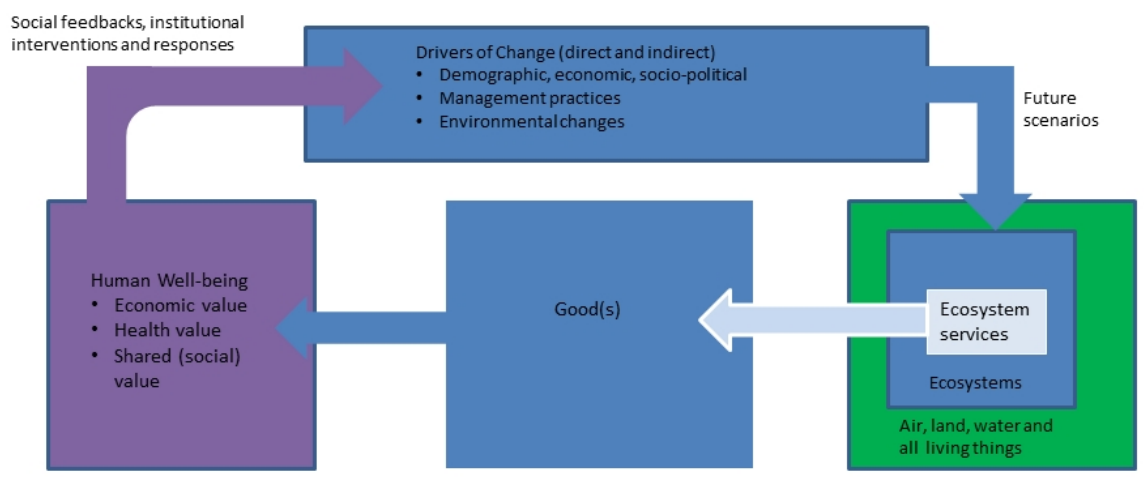

The concept is very suitable to compare policies and trade-offs between them and between different ecosystem services. This is demonstrated in e.g. Bateman et al. (2013) and Bateman et al. (2014).

\subsubsection{Other approaches}

Beside the above mentioned approaches, that are the most significant ones, there are variations in the use of them and other concepts are also developed. UNEP (Tinch \& Mathieu, 2011) has a larger focus on resource changes than many of the other concepts, and describe the relationships between environmental changes, ecosystem services and final benefits. The approach is described in Figure 5, showing the links between resource change, the effects on intermediate services such as primary production and nutrient cycling; final services such as greenhouse gas regulation and commercial fish harvest and finally, the value of the goods provided by the services, e.g. market value of fish, market and non-market value of recreation etc. 
Figure 5: The UNEP approach (UNEP 2011, page 7)

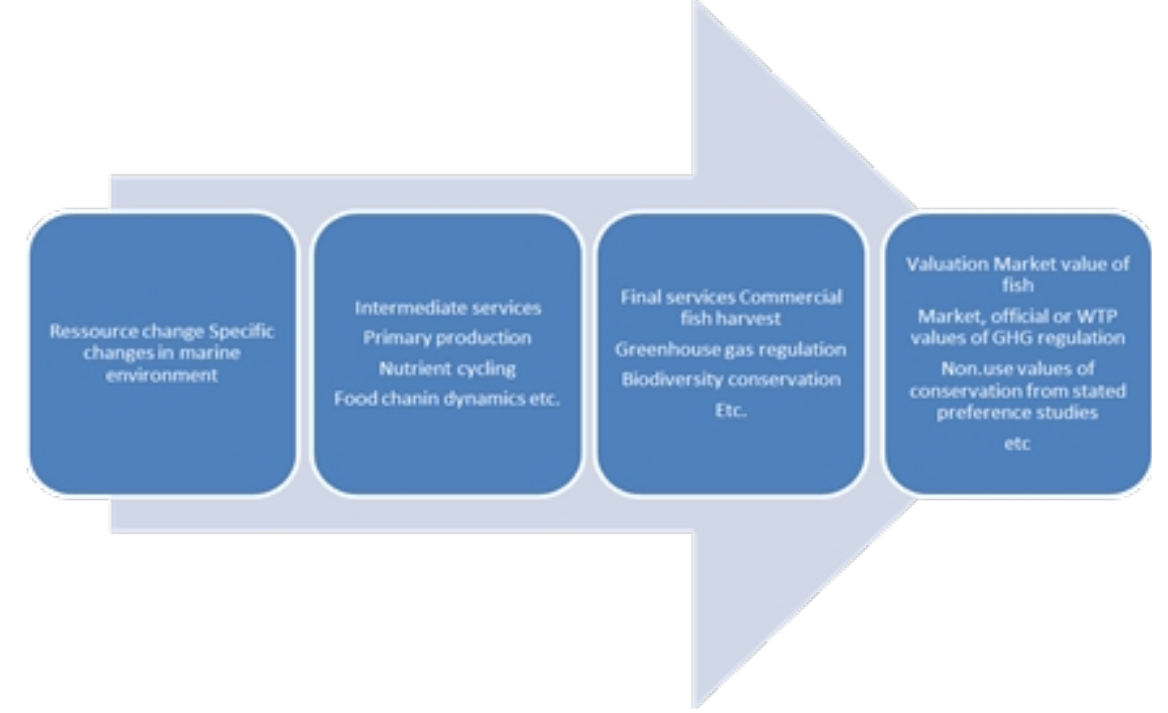

The illustration and the boxes explain the differences between services and goods (what is valued).

Another approach is the before mentioned services provider approach. Cognetti et al. (2010) takes a marine ecologist's perspective, and propose a classification of ES that relies on the biological characteristics and ecosystem functions of the marine ecosystems where they are provided. This is done to create better links between the classification and the ecological analysis and data, linked to the provision of the final goods and benefits - i.e. the focus is still on how ecosystems deliver utility to human beings. To facilitate this classification of marine ecosystem services they identify three main classes of ES provision: in natural, disturbed and human-controlled environments.

Table 4 illustrates how the relations between natural biotopes or ecosystems, the service provider and activity, and the final benefits, can be described and used for classification in natural environments: 
Table 4: Relations between ecosystems, service providers and activity as well as benefits in natural ecosystems

\begin{tabular}{|c|c|c|c|}
\hline Biotope & Service provider & Service provider activity & Benefit \\
\hline Recuitment area & Fry preys & Fish grows & Fisheries improvement \\
\hline Suitable rocky bottom & Coralligenous community & Aesthetic attraction & $\begin{array}{l}\text { Sustenance of Scuba Div- } \\
\text { ing tourism }\end{array}$ \\
\hline $\begin{array}{l}\text { Suitable coastal pelagic } \\
\text { waters }\end{array}$ & Cetacean population & Aesthetic attraction & $\begin{array}{l}\text { Sustenance of whale/ } \\
\text { dolphin watching tourism }\end{array}$ \\
\hline Suitable soft bottom & Bioturbator organisms & Bioturbation & $\begin{array}{l}\text { Water column and sub- } \\
\text { stratum quality }\end{array}$ \\
\hline Suitable sandy bottom & Seagrass Meadow & Barrier to hydrodynamism & $\begin{array}{l}\text { Reduction of coast ero- } \\
\text { sion }\end{array}$ \\
\hline
\end{tabular}

Source: Cognetti et al., 2010, page 1918.

In Table 5 examples are provided on the service provision when the marine environment is disturbed, i.e. is not longer a natural ecosystem. The disturbance type (or pressures in a DPSIR kind of framework) is added to the table:

Table 5: Examples of ecosystem service provision in disturbed environments

\begin{tabular}{lllll}
$\begin{array}{l}\text { Disturbance } \\
\text { type }\end{array}$ & Biotope & Service provider & $\begin{array}{l}\text { Service provider } \\
\text { activity }\end{array}$ & Benefit \\
Oil pollution & Oil polluted areas & $\begin{array}{l}\text { Degrading microor- } \\
\text { ganisms }\end{array}$ & Biodegradation & $\begin{array}{l}\text { Water purification - or } \\
\text { clean water (ed) }\end{array}$ \\
$\begin{array}{l}\text { Organic } \\
\text { pollution }\end{array}$ & $\begin{array}{l}\text { Sewage polluted } \\
\text { areas }\end{array}$ & $\begin{array}{l}\text { Bacteria, phytoplank- } \\
\text { ton etc. }\end{array}$ & $\begin{array}{l}\text { Biodegradation, } \\
\text { antibiotic action }\end{array}$ & $\begin{array}{l}\text { Water purification - } \\
\text { or clean water (ed) }\end{array}$ \\
$\begin{array}{llll}\text { Trawl fishing } \\
\text { Harvested shallow } \\
\text { fishing grounds }\end{array}$ & $\begin{array}{l}\text { Migrants from deep } \\
\text { virgin to fishing } \\
\text { grounds }\end{array}$ & $\begin{array}{l}\text { Community recov- } \\
\text { ery on harvested } \\
\text { fishing grounds }\end{array}$ & $\begin{array}{l}\text { Stock resilience, } \\
\text { fisheries improvement }\end{array}$ \\
\hline
\end{tabular}

Source: Cognetti et al., 2010, page 1919.

The examples in the table illustrate that service providers can deliver biodegradation, antibiotic action and recovery so that the water becomes clean and fisheries improved after disturbance. This service provision by water regulation mechanisms and maintenance of course has a value, just as the service provision of natural ecosystems illustrated above. The value of these services is their ability to for instance degrade organic matter and eliminate pathogenic microorganisms thanks to species of multifunctional importance from different taxa (Cognetti et al., 2010, page 1919). 


\subsubsection{Evaluation of approaches for marine ES classifica- tions}

In Table 6 the strengths and weaknesses of the approaches for marine ecosystem services classifications are outlined.

\begin{tabular}{|c|c|c|}
\hline & Strengths & Weaknesses \\
\hline MEA & $\begin{array}{l}\text { Defined ecosystem services, high policy im- } \\
\text { pact }\end{array}$ & Double-counting, not dealing with changes \\
\hline TEEB & $\begin{array}{l}\text { Avoids risk of double counting by focusing on } \\
\text { final services. Habitat services are included } \\
\text { as separate category. } \\
\text { TEEB are currently developing a TEEB Ocean } \\
\text { concept and assessment. }\end{array}$ & $\begin{array}{l}\text { Not explicitly dealing with scenarios and } \\
\text { changes }\end{array}$ \\
\hline CICES & $\begin{array}{l}\text { Avoids risk of double counting by distinguish- } \\
\text { ing clearly between intermediate and final } \\
\text { services } \\
\text { Complementary tables for abiotic outputs } \\
\text { can be developed }\end{array}$ & $\begin{array}{l}\text { Not explicitly dealing with scenarios and } \\
\text { changes } \\
\text { Very detailed, and can be difficult to have an } \\
\text { overview of the many classes and categories. }\end{array}$ \\
\hline MAES & $\begin{array}{l}\text { MAES applies the concepts of TEEB and } \\
\text { CICES, and focus on the mapping of the eco- } \\
\text { systems. Develop and use consistent links } \\
\text { between ecosystem structures and functions } \\
\text { to the values of the ES. }\end{array}$ & \\
\hline UK NEA & $\begin{array}{l}\text { Concept is inspiring for scenario and policy } \\
\text { assessments, trade-offs between ecosystem } \\
\text { services }\end{array}$ & \\
\hline Cognetti et al. & $\begin{array}{l}\text { The linkages between drivers, pressuresm } \\
\text { ecosystem services and goods. The concept } \\
\text { is fresh and applies other concepts in order } \\
\text { to assess the value of the ecosystems ability } \\
\text { to recover after disturbances. }\end{array}$ & \\
\hline
\end{tabular}

Source: Modified from Brouwer et al., 2013, page 50.

All of the above concepts can be used but for varying purposes. While some are useful for accounting purposes, e.g. CICES, the MAES and UK NEA approaches are more suitable for assessing the value of ecosystem services in a changing environment where focus is on marginal changes.

We have used the concepts to develop a conceptual approach for this project, taking departure from the MAES working group and linking to the UK NEA approach related to policies and drivers for changes affecting the ecosystems. Figure 6 illustrates this concept, and adopts the links between the marine ecosystems and the socio ecosystems as in the MAES 
approach, but also points at the importance of the links to how policies and pressures impacts the ecosystems.

Figure 6: Concept of the linkages between ecosystem structures and functions, ecosystem services, goods, values, pressures and policies (inspired and modified from Haines-Young and Potschin (2010)

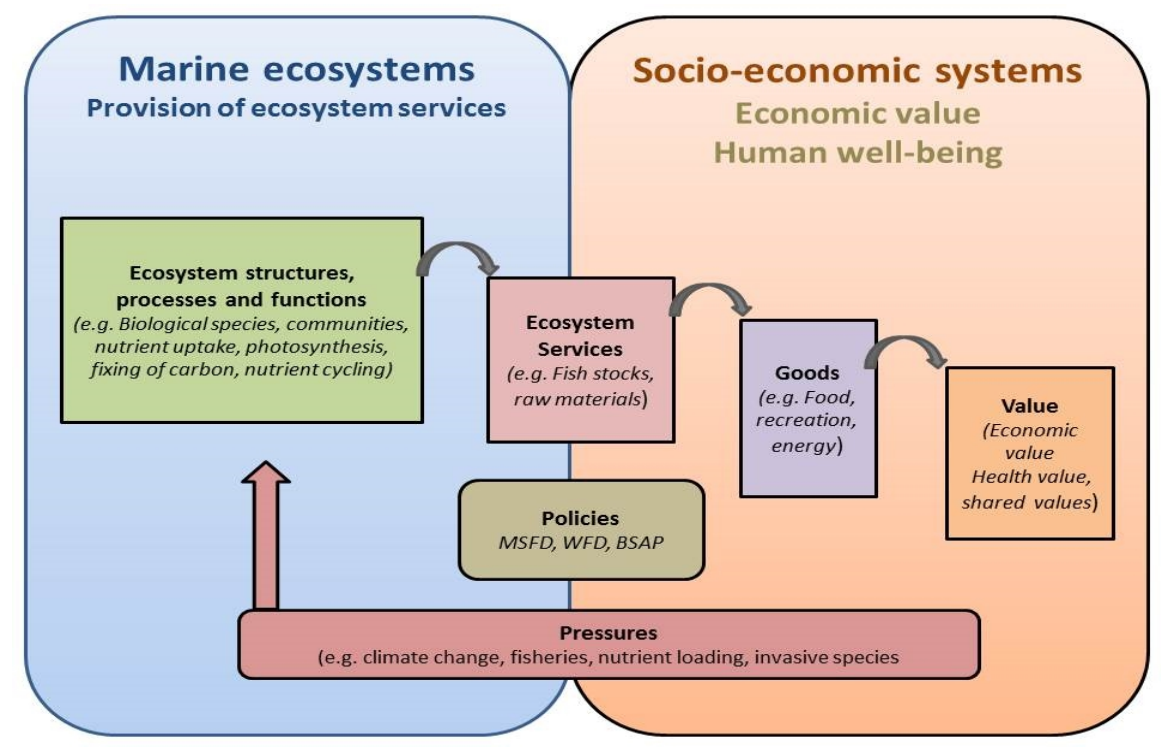

As a conclusion on the presentation and discussion of the different concepts developed for ecosystem services assessments the proposed concept aims at being used for identification of how marine ecosystem structures, processes and functions affects ecosystem services and goods, and the value of these.

In the next chapters we use this concept and focus on assessments of how available data and knowledge can be used for assessting and identifying the intermediate services, ecosystem structures, processes and functions underlying the production of the final ecosystem goods and services, as well as the value of these services from the literature review and the case study. 


\section{Ecosystem Services provided by the Baltic Sea - choice of examples}

The focus of this chapter is the choice of ecosystem services to be used as examples in the rest of the report, i.e. for the assessment of ecosystem condition, for the analysis of links between ecosystem services assessments, descriptors and indicators for good ecological status, as well as for the literature review.

The following ecosystem services are used as examples:

- wild fish for food (provisioning service)

- eutrophication mitigation and sediment regulation (regulation and maintenance service)

- recreation (cultural service).

\subsection{Choice of ecosystem services for the analyses in the report}

As mentioned we have chosen three ecosystem services as a point of departure for the report and our descriptions of how to utilize existing knowledge. The classifications of services, which are presented in Chapter 2, divide services into:

- provisioning services

- regulating and maintenance services

- cultural services.

We have chosen one example of services within each of these categories to exemplify and discuss: 
- how existing data and knowledge regarding ecosystem condition can be used

- how descriptors and indicators used for the ecosystem assessment can be used

- the knowledge we have on the values of these ecosystem services from the literature.

The examples we have chosen are considered important for the Nordic Countries:

- wild fish for food (a provisioning service)

- eutrophication mitigation and sediment retention (in CICES this belongs under regulating and maintenance service section, within division: mediation of waste, toxic, and other nuisances)

- recreation (cultural service, belonging to CICES division physical and intellectual interactions).

For recreation, Chapter 7 presents a case study conducted in Sweden and Denmark to illustrate how this service can be valued and linked to information about water quality and ecosystem condition.

The three ecosystem services are used as examples on how information from habitat and ecosystem condition assessments and links between ecosystem services and the biotic part of the ecosystems can be used for ecosystem services mapping and valuation.

\subsection{Commercial fisheries}

The second largest marine economic activity in the Baltic Sea Region is commercial fisheries (COM, 2014). The three main species (cod, Baltic herring and sprat) constitute about $95 \%$ of the landings, but in addition about 20 other species are caught more locally. Values that include both provisioning (food) and cultural (recreational fishing) ecosystem services have been estimated for the cod stock (Eggert \& Olsson, 2009; Carlsson et al., 2010), Baltic salmon (Kulmala et al., 2012), and fisheries and fish stocks in general (Lewis et al., 2013, Kosenius \& Ollikainen, 2015).

UK NEAFO also focuses on fish as a provisioning service, and Figure 7 illustrates the links between fish provisioning and fisheries with the ecosystem structures, processes and habitats: 
Figure 7: Links between food provision from fish to habitats and ecosystem structure-information (Turner et al., 2014, page 77)

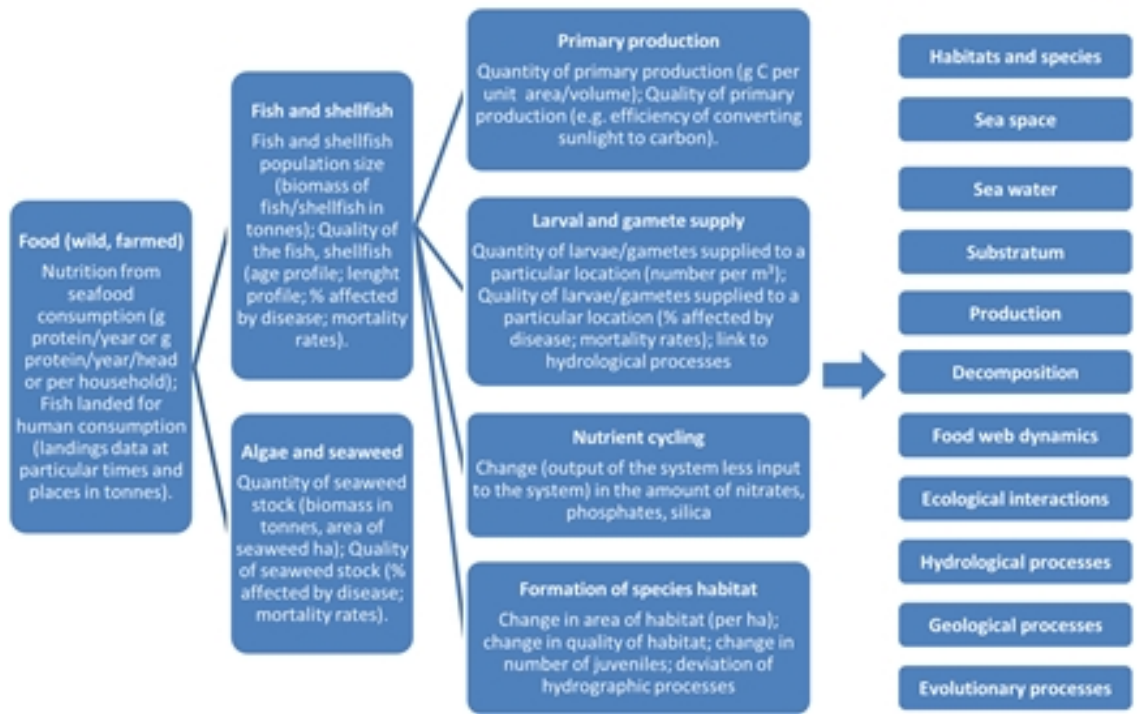

\subsection{Mitigation of eutrophication and sediment retention}

There is a number of regulating and maintenance services that are intermediate ecosystem services, including climate mitigation by carbon sequestration, contamination mitigation linked to dilution, sediment retention and bacterial mineralization of hazardous and toxic substances. Healthy ecosystems providing mitigation of contamination support the production of fish that are safe to eat and support biodiversity with sustainable populations of charismatic species such as sea eagles, seals, and other sea birds and large mammals that are valued by human societies.

Sediment retention is the ability of the ecosystem to stabilize sediment and prevent erosion, both at sea beds in the open sea and along the coast. Erosion prevention in the coastal area is important in order to avoid acute damage from storms, but also in order to avoid slow erosion due to waves, wind and currents, which may affect the ecosystem and also manmade constructions along the coast. Sediment retention is favored by structures on the seafloor and along the beaches, such as those created by vegetation. The restoration of sea grass meadows has been pointed out as one potential tool for preventing deterioration of the service (Garpe, 2008). 
Another important maintenance and regulation service is nutrient removal and water purification mediated by biota and ecosystems, including the sediments. This service mitigates eutrophication, caused by nutrient loading pressures impacting basically all the Baltic Sea biotopes and biotope complexes (HELCOM, 2010). Most of the Baltic Sea is considered to be impacted by eutrophication and failing to achieve good environmental status (GES) by 2020, as expected by the MSFD, nor by 2021, as decided by the BSAP (HELCOM, 2014). Eutrophication is caused by excessive nutrient loads from waterborne sources (rivers and urban waste water outflows) and from atmospheric deposition (HELCOM 2013, PLC5). Most of the transitional and coastal waters reported in the WFD River Basin Management Plans (in 2010) are in less than good status, and coastal areas are mainly affected by point-source and non-point riverine pollution as well as atmospheric nitrogen deposition.

Eutrophication mitigation mediated by biota and ecosystems reduces this threat and contributes to the improvement of other services, such as cultural services and provisioning services. A number of studies have studied nutrient assimilation in the coastal zone as a recognized ecosystem function and service (e.g. Teal, 1962; Odum \& de la Cruz, 1967; Teal $\&$ Teal, 1969). Finally the value of the eutrophication mitigation service could be measured by the value of the final services, or by estimating the replacement or opportunity costs of achieving an equal level of water quality. E.g. Gren (2012) uses the replacement cost method to elicit a value for eutrophication mitigation; i.e. the value is the opportunity cost of other actions that can be taken to reduce eutrophication in the same magnitude. Following Gren "the basic principle for estimating the value of ecosystems' mediation and removal of nutrients, when using the replacement cost method is to calculate total minimum costs for achieving predetermined targets with and without the ecosystem contribution" (Gren, 2012, page 696.) This is further elaborated in Chapter 6.

\subsection{Marine and coastal tourism and recreation}

Marine recreation includes the following types of activities (SwAM, 2012):

- Swimming.

- Diving.

- Windsurfing, water skiing.

- Boating. 
- Fishing.

- Being at the beach or seashore for walking, picnicking, sunbathing, visiting touristic or cultural sites, etc.

- Using water-based transportation.

A good environmental status, provides good opportunities for recreation and supports the tourism industry, such as cruises, holiday housing, leisure boating sectors and commercial accommodation.

Coastal tourism and recreation are currently the largest marine economic activity, and it is growing in the Baltic Sea region (EC, 2014). ${ }^{6}$ Moreover, coastal tourism is the most significant maritime employment sector in almost all EU Member States that have a coastline (ECOTEC, 2006). The choice of marine recreation therefore serves as a good example of an economic important service.

Nature is a significant factor determining the choice of a travel destination; In Denmark $82 \%$ of the visitors named "nature" as the main motivation for the choice of their recreational trip destination (Bjørner et al., 2014). The importance of the marine environment for tourists is also supported by the results of several surveys. For instance in Germany (cf. UNEP, 2009) the most valued features of coastal holiday destinations are clean beaches (no litter) and clean water, no urbanisation of rural areas, no noise pollution from traffic or discothèques, and good nature protection in the holiday destination.

Other studies also indicate that recreation in coastal and marine areas is one of the most important uses of the Baltic Sea environment. In the "BalticSurvey" study around 1000 citizens in each of the nine littoral Baltic countries were interviewed in order to examine how the general public in these countries uses the sea (Söderqvist et al., 2010; Ahtiainen et al., 2013). The survey showed that the majority (approx 80\%) of the citizens around the Baltic Sea have spent leisure time at the sea, which indicates that the cultural services provided by the marine environment are important for the local people. Furthermore, the most common activities in all countries were swimming and being at the beach or seashore for walking, sunbathing or the like. Boating and going on a cruise were also relatively common in some countries.

Many activities carried out in coastal areas, as well as the experience of these activities, depend on the ecosystem condition, including water quality and sometimes also the biodiversity of the marine ecosystems,

${ }^{6}$ Commission's staff working document «A Sustainable Blue Growth Agenda for the Baltic Sea Region» SWD(2014) 167 final. 
such as bathing, angling, bird watching, hunting, and snorkling and scuba diving. Those activities are also affected by eutrophication and its consequences (see Figure 4 in Chapter 4 ) as it serves to reduce the enjoyment of recreational activities or completely put a stop to them, e.g. in case of toxic algal blooms which render swimming and snorkling impossible. However, there are also activities that are not strictly dependent on the condition of the marine ecosystem such as enjoying the sceneries (seascapes), sailing, wind surfing or wreck diving, although knowledge of ecosystem status may increase the enjoyment of these activities.

The BalticSUN study that followed the BalticSurvey showed that the major part of the citizens around the Baltic Sea are concerned about the consequences of eutrophication and that they are willing to make considerable economic sacrifices for a healthier sea (Ahtiainen et al., 2014). These findings are supported by Hasselström et al. (2008) who concluded that blue green algae blooms caused by eutrophication were considered to be the most important nuisance reducing aesthetic and recreational values in beach and coastal areas across the Baltic Sea area. However, Hasselström et al. (2008) found that the presence of the algal blooms did not appear to have any significant impact on bookings or profits in the tourist industries presently. 


\section{Ecosystem Services, ecosys- tem structures and processes in the Baltic Sea}

This chapter describes the linkages between ecosystem function and processes on the one hand, and ecosystem services on the other hand. It is illustrated how eutrophication mitigation, nutrient cycling and water purification might be classified as both services and functions, and that these services affect the two other services assessed. Therefore the class of regulation services differ from the provisioning and cultural services and care should be taken not to double count the value of both service categories. On the other hand it is important to address how the regulating services are affected by scenario changes, as these services have the described effect on other services.

Using information of the spatial mapping of biotopes, habitats and ecosystem components used in the HELCOM HOLAS (2010) an example is presented illustrating how the capacity of ecosystem services provision in the Baltic Sea could be qualitatively assessed and mapped.

\subsection{Introduction}

In this chapter the links between ecosystem structures, processes and functions and the ecosystem services - the pink and green boxes in figure 1 - are described for the three selected ecosystem services. While fish provision and recreation are final goods, eutrophication mitigation is an intermediate service, which influences the two other services.

The intermediate services that are related to recreation and tourism are environmental assets such as clean and transparent water, aesthetic and clean beaches and beautiful sceneries, biodiversity assets, such as the appearance of charismatic species like sea eagles and other sea birds, seals and porpoises, valuable game fish for leisure fishing, and clean seafood (fish). These all are impacted by (primary and secondary) symptoms of eutrophication and by toxic impacts of hazardous substances on biota, and also by other pressures like commercial fishing, habitat destruction 
(by dumping, dredging, and trawling), littering and by underwater noise. Accordingly processes that mitigate eutrophication and retain/remove hazardous substances also increase assets of nature which people associate with clean environments and healthy ecosystems, and therefore they also increase the value of the ecosystem services for recreation. "Eutrophication mitigation" can therefore be considered a function (or intermediate service) provided by the ecosystem processes.

\subsection{Marine ecosystem components providing eutrophication mitigation service}

Primary production by phytoplankton and submerged vegetation (macroalgae and macrophytes) is based on nutrients available in the water column. Primary production is the basic source of energy for the whole ecosystem. Only photosynthetic organisms, in marine environment phytoplankton, macroalgae and macrophytes, are capable in primary production where solar energy and inorganic carbon are used to produce organic carbon compounds. A number of elements that are required to keep the process going are ample in water. Still a few of them may limit photosynthesis, i.e. normally one of them is exhausted, and photosynthesis ceases due to the lack of this element. Nitrogen and phosphorus are the main elements required for active growth of photosynthetic organisms, though in some ocean areas iron, and for some specific organisms silicate or calcium, may be important.

The level of organic matter production varies from very low (Bothnian Bay) to very high (upwelling areas). The natural food webs are balanced to utilize available production. However, in the process of eutrophication the level of production is increased. This increase is normally due to the main nutrient (nitrogen and phosphorus) inputs to water by human actions. These nutrient inputs promote additional primary production, which above a site specific threshold has detrimental effects to ecosystems.

As primary production is a process, it is difficult to quantify. The concentrations of main nutrients are used as indicators of the primary production level. A possible indicator is the available amount of the limiting nutrient. In the Baltic Sea, the concentrations of nutrients in the winter are used as the eutrophication indicator (HELCOM 2014), as during winter all available nutrients are accumulated in the water column before the growth season starts in the spring. One eutrophication pressure indicator is the amount of nutrient loading from all anthropogenic sources. 
In the Baltic Sea both nitrogen and phosphorus are limiting primary production (HELCOM, 2009). However, in the Baltic Sea, when the nitrogen available in the water column is used, but some phosphorus remains, nitrogen fixing cyanobacteria can utilize the extra phosphorus for their growth. Baltic Sea nutrient status is severely hampered by the internal loading of phosphorus from the bottom sediment. This process has been intensified by poor oxygen conditions at Baltic deep water, which is again a consequence of general eutrophication. The situation process is referred to as the "vicious circle of the Baltic Sea', as it intensifies cyanobacteria blooms (Vahtera et al., 2007). Figure 8 below shows effects of nutrient loads in the Baltic Sea (from HELCOM, 2009). Primary and secondary symptoms of eutrophication have been demonstrated to influence the flow of cultural ecosystem services, such as the recreational use of coastal areas (Ahtiainen et al., 2014, Hyytiäinen et al., 2013).

Figure 8: A simple conceptual model of eutrophication symptoms in the Baltic Sea. Based on Cloern (2001). Nutrient loads are channelled into dissolved and particulate organic material that causes the primary and secondary symptoms of eutrophication

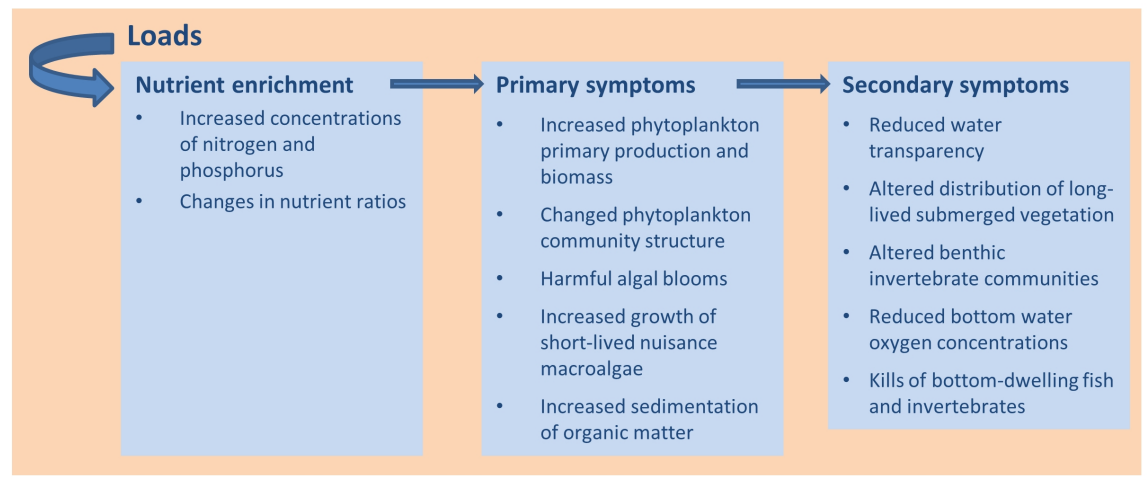

There are a number of processes in the marine ecosystem that counteract the symptoms of eutrophication and provide the service of storage and removal of nutrients (i.e. in CICES those are included in the regulation and maintenance service, more specifically mediation of waste by biota and ecosystems). Such processes are e.g. dilution of nutrient loads by currents and advection, filtration and ingestion by zooplankton and mussels, deposition and accumulation of nutrients in sediments (particularly phosphorus), denitrification of inorganic nitrogen into gaseus dinitrogen and return into atmosphere (Figure 9). These processes elaborate the balance between functions of productive ecosystem that produce fish and other provisioning services, and excessive production of organic material that result into secondary symptoms of eutrophication. In other words, when 
the assimilation capacity of an ecosystem has been exceeded for nutrient loading, secondary (and some primary) symptoms start to appear and gradually become dominant.

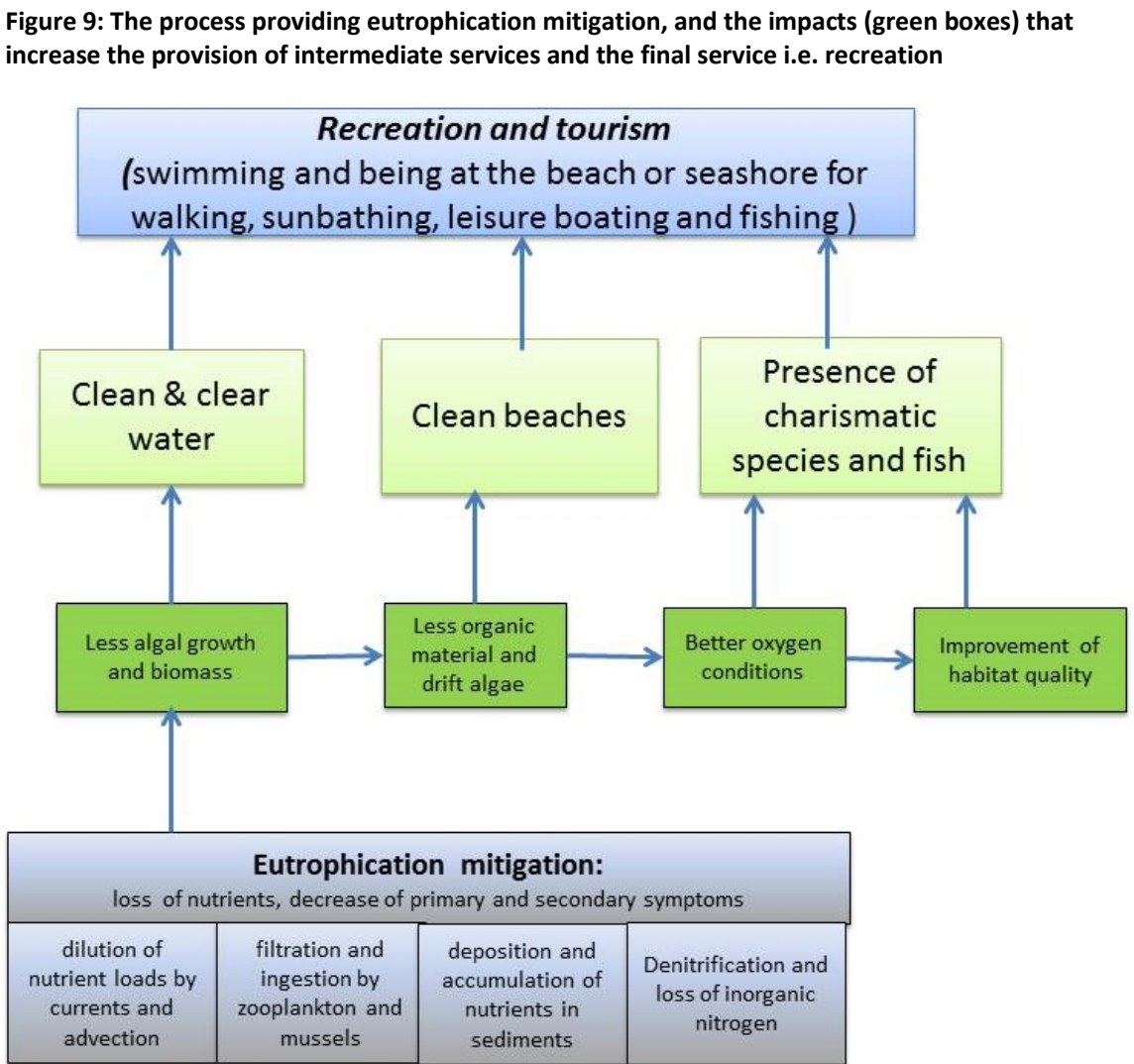

The processes listed above ensure the flow of the intermediate service "clean and clear water" for recreation, and they are fundamental in mitigation of eutrophication (cf. later in this chapter). These processes (or regulation and maintenance services in CICES) are linked with several biotopes or biotope complexes. The maintenance and regulation services (in CICES) are processes that mitigate symptoms of eutrophication in marine ecosystems, and in which biotopes or biotope complexes maintain processes that provide these functions (intermediate services or sub-services).

The linkages between processes that mitigate eutrophication and biotope complexes are described in Table 7. 


\begin{tabular}{|c|c|}
\hline Maintenance and regulation service & Biotope of biotope complex \\
\hline Dilution of nutrient loads by currents and advection & Pelagic \\
\hline Filtration by zooplankton & Pelagic \\
\hline Filtration by mussels & photic and non-photic sediments \\
\hline $\begin{array}{l}\text { Deposition and accumulation of nutrients in sediments (par- } \\
\text { ticularly phosphorus) }\end{array}$ & photic and non-photic sediments \\
\hline Denitrification of inorganic nitrogen into gaseous dinitrogen & $\begin{array}{l}\text { sediments photic and non-photic, non-photic } \\
\text { pelagic }\end{array}$ \\
\hline
\end{tabular}

When the maintenance and regulation services in Table 7 are functioning normally the primary symptoms of eutrophication are occurring at normal level and secondary symptoms are also minimal (or only irregularly occurring due to natural processes). Therefore the indicators that can be used to assess the status of the intermediate service: eutrophication mitigation (that include the ecosystem services in Table 7), are those that are used to assess primary and secondary symptoms of eutrophication, such as concentrations of winter nutrients, chlorophyll, transparency, and oxygen conditions below permanent halocline (HELCOM, 2014).

Impacts of eutrophication are aggravated by the natural characteristics of the Baltic Sea that is a semi-enclosed brackish water area with persistent salinity stratification and long residence time (30 years) and slow exchange of water through narrow and shallow straits between Denmark and Sweden. These characteristics make it a very sensitive area with low self-purification capacity (HELCOM, 2010). As about 85 million people inhabit its catchment presently, anthropogenic impacts have long been observed in the Baltic Sea. The eutrophication has led to massive algal blooms and, consequently, high organic matter sedimentation which has resulted in almost permanent oxygen deficiency in deep basins of the Baltic Sea (HELCOM, 2010, 2013). 


\subsection{Marine ecosystem components providing the flow of ecosystem service "wild fish for food"}

The provisioning ecosystem service "wild fish for food" includes all biomass extracted for the purpose of human consumption by commercial fisheries. Thus marine fish and shellfish harvested from wild populations are all included in this service. The focus is on the wild stocks, i.e. those stocks which are targeted in capture fisheries. However, recreational fishing is not included here, but considered as part of the cultural service recreation and tourism.

Marine ecosystems are composed of biotic communities with a large number of different organisms including bacteria, phytoplankton, zooplankton, fish, mammals and birds. These are all connected into a complex web of interactions ('food webs') and are affected by abiotic environmental factors including substrate type, water depth, nutrients, temperature, salinity and currents. The biotic communities are the basis for production and accumulation of organic (carbon) compounds using energy, matter and space provided by abiotic community. All production in marine ecosystems is ultimately dependent on the carbon fixation of photosynthetic primary producers and the subsequent channelling of the carbon produced through the food web to higher trophic levels.

Fish are an integral part of the marine food webs and have a central role in the energy transfer from plankton to higher trophic levels (marine mammals, seabirds and humans). This transfer of energy follows, in its simple form, the chain: phytoplankton - zooplankton - planktivorous fish (e.g. sardine and herring) - predatory species (e.g. cod and tuna) - marine mammals, seabirds and humans. In practice, the interactions in marine ecosystems are much more complex: even the largest predatory species are part of the plankton community at early stages of their life cycle and, thus, subject to predation from planktivorous species, which they later prey on. A known example of this kind of interaction is the link between cod and herring populations. Cod is a predator of herring, but it is also its prey during larval stage, as adult herrings feed on cod larvae.

Besides the controlling forces that act between trophic levels, i.e. environment and nutrient driven "bottom-up" control, which is based on the production, and "top-down" control based on consumption, other interactions, including competition, mutualism and cannibalism, define and control the state of the ecosystem. All these forces create a complex web of interactions, where every organism has a role in sustaining the function of the whole ecosystem. Thus, both economically and non-economically 
important fish species and populations play an active role in the maintenance of ecosystems and in the provisioning of a wide range of services, of which the production of seafood is an especially important one for human populations.

Predatory species are the most valued target species in fisheries, and thus, subject to overfishing world-wide. These species have high maturation age and excessive fishing pressure with gears that catch unselectively poses a threat in relation to the ability of the population to maintain itself as fishes are caught as juveniles, i.e. before they get change to reproduce.

The current status for the fish provisioning service in the Baltic is that overexploitation of fish stocks is the biggest single threat for the sustainable governance of marine resources. Overexploitation takes place when the harvesting rate exceeds the growth rate of the stock, i.e. present exploitation is endangering the future catches. As a result, the stock will diminish and may eventually collapse. In contrast to overexploitation, fishing is sustainable when both the stock size and exploitation rate (fishing mortality) are within limits that safely can produce high long-term yields, year after year.

Excessive exploitation and selective fishing have already led to severe changes in marine ecosystems as the long-lived piscivorous species are being replaced by invertebrates of lower trophic levels and small planktivorous species (Pauly et al., 1998). Besides these effects, high fishing effort with bottom trawls have been shown to cause severe damage to seafloor integrity (Puig et al., 2012). Implementing sustainability in EU fisheries would lead to overall lower fishing intensity and less harm to non-targeted organisms like marine mammals. Also fuel consumption would decrease significantly as it takes less fishing time to catch a tonne of fish from an abundant stock than from a depleted one. This would reduce carbon emissions as well as the fuel expenditure of vessel owners. Also damages caused on habitats by fishing would decrease.

\subsection{Possibilities and proposals for mapping the ecosystem services}

Mapping of the ecosystem functions, processes, habitats and ecosystem services is important to enable spatial assessments of the marine ecosystem services in the marine areas of the Baltic Sea and the other Nordic marine areas. Examples of such mapping exercises are that of the European North Atlantic benthic ecosystem services, that are mapped by Gal- 
parsoro et al. (2014). In their approach the ES provision capacity by different benthic habitats was estimated based an expert judgment. Their mapping approach was based on the EU SeaMap database of large scale benthic habitats. They based the expert assessment on the identification of the importance and capacity of different ES in each of the large scale habitats (following the expert analysis in Salomidi et al., 2012). An average ES capacity value for each of the habitats was calculated based on the contribution of the given habitat for all ES categories. This information was then transposed into a map that shows the average ES capacity over the studied area. The map is shown in Figure 10.

Figure 10: Spatial distribution of the mean value of aggregated ecosystem service provision capacity in the coastal and self areas of the North East Atlantic Ocean

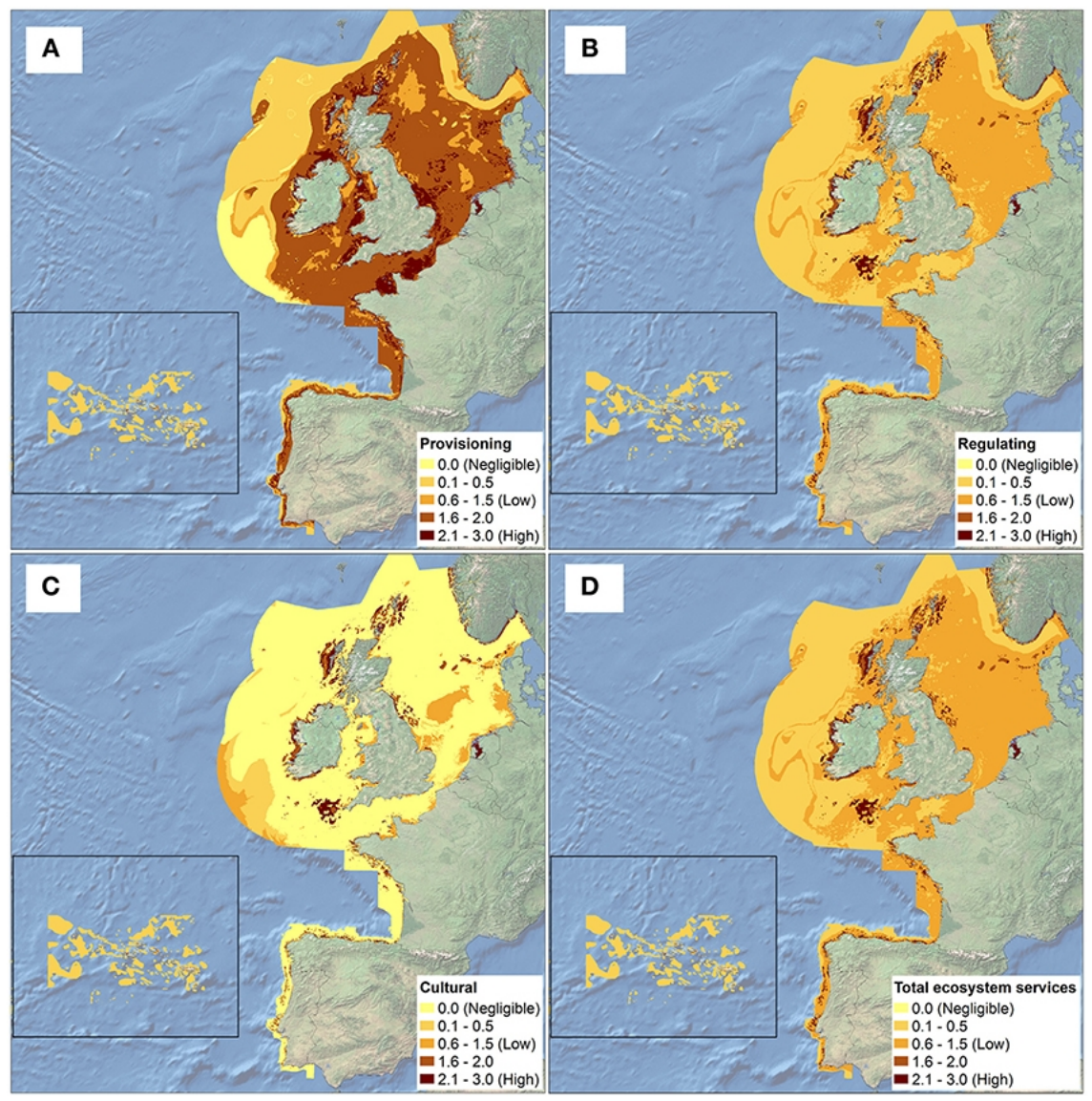

Note: Provisioning services; (B) Regulating services; (C) Cultural services; and (D) Total ecosystem services.

Source: From Galbarsoro et al., July 2014, Volume1, Article23, page 11 
A similar approach to the mapping of ecosystem service capacities in the Northern Atlantic, illustrated in Figure 10, could be tested in the Baltic Sea. With this approach the ES capacity could be assessed using expert knowledge and mapped by using e.g. the large scale habitat database from the EU BALANCE project. Such assessments of ecosystem services capacities could be used together with values retrieved from the literature (cf. Chapter 6) and/or new valuation studies (for the ES we do not have values for) to create maps for the potential value of the ecosystem services. Such qualitative data and maps could be used for assessing changes in the value of the provision of ES, when the level of provision changes due to scenario alterations.

HELCOM HOLAS (HELCOM, 2010) ${ }^{7}$ includes a list of the biotope complexes, habitats, and ecosystem components (e.g. seals, birds, etc.) used for the pressures and impacts assessment. This information could be used for an assessment similar to the assessment in Galbarsoso et al. (2014). The biotope complexes and ecosystem components provide structures, processes and functions that sustain capacities for the provision of the three ecosystem services analysed - wild fish for food, eutrophication mitigation, and recreation and tourism, and following the MESMA project (Salomidi et al., 2012), an assessment of the ecosystem services provided by these biotope complexes could be carried out. A generic example is presented in Table 8.

${ }^{7}$ HELCOM, 2010. Towards a tool for quantifying anthropogenic pressures and potential impacts on the Baltic Sea marine environment: A background document on the method, data and testing of the Baltic Sea Pressure and Impact Indices. Balt. Sea Environ. Proc. 125 (this reference should replace Korpinen et al. 2010). 
Table 8: Preliminary ad hoc evaluation of the potential ecosystem services capacity provided by the biotope complexes (as in HELCOM, 2010) of the Baltic Sea for the three ecosystem services in focus wild fish for food, eutrophication mitigation, and recreation (xx=contributing considerably, $x=$ contributing partially, $n=$ negligible contribution to the capacity for providing the basis to the service)

\begin{tabular}{|c|c|c|c|}
\hline Biotope/ Ecosystem component & $\begin{array}{l}\text { Provisioning } \\
\text { Wild fish } \\
\text { for food }\end{array}$ & $\begin{array}{l}\text { Regulating } \\
\text { Eutrophication } \\
\text { mitigation }\end{array}$ & $\begin{array}{l}\text { Cultural } \\
\text { Recreation and } \\
\text { tourism }\end{array}$ \\
\hline 1. Photic waters & $X x$ & $\mathrm{n}$ & $\mathrm{Xx}$ \\
\hline 2. Non-photic waters & $x$ & $\mathrm{x}$ & $\mathrm{N}$ \\
\hline 3. Photic sand & $x$ & $x$ & $x x$ \\
\hline 4. Non photic sand & $x$ & $\mathrm{x}$ & $\mathrm{N}$ \\
\hline 5. Photic soft bottoms & $\mathrm{Xx}$ & $x$ & $\mathrm{x}$ \\
\hline 6. Non-photic soft bottoms (mud and clay) & $\mathrm{Xx}$ & $x x$ & $\mathrm{~N}$ \\
\hline 7. Photic hard-bottom & $\mathrm{Xx}$ & $\mathrm{n}$ & $x$ \\
\hline 8. Non photic hard-bottom & $\mathrm{Xx}$ & $\mathrm{n}$ & $\mathrm{N}$ \\
\hline 9. Mussel beds & $\mathrm{N}$ & $x x$ & $x$ \\
\hline 10. Zostera meadows & $\mathrm{Xx}$ & $\mathrm{x}$ & $x$ \\
\hline 11. Harbour porpoise distribution in the Baltic Sea & $\mathrm{N}$ & $\mathrm{n}$ & $\mathrm{Xx}$ \\
\hline 12. Grey seals, ringed seals and harbour seals & $\mathrm{N}$ & $\mathrm{n}$ & $\mathrm{Xx}$ \\
\hline 13. Seabird wintering grounds & $\mathrm{N}$ & $\mathrm{n}$ & $\mathrm{Xx}$ \\
\hline 14. Spawning and nursery areas of cod & $\mathrm{Xx}$ & $\mathrm{n}$ & $x$ \\
\hline
\end{tabular}

*Based on HELCOM (2010); BSEP 125).

Such an exercise can be further elaborated and presented as a map grid as done by Galparsoro et al. (2014). A prerequisite for conducting such an analysis is that the spatial locations of the biotope complexes and habitats is known and mapped. 
Figure 11: The presence of the biological ecosystem components (i.e. data sets of species, biotopes and biotope complexes). The number of data layers in a cell is shown by the color gradient from blue (one) to red (13). Note: there was no cell in the area with all the 14 components/ layers present (from HELCOM, 2010)

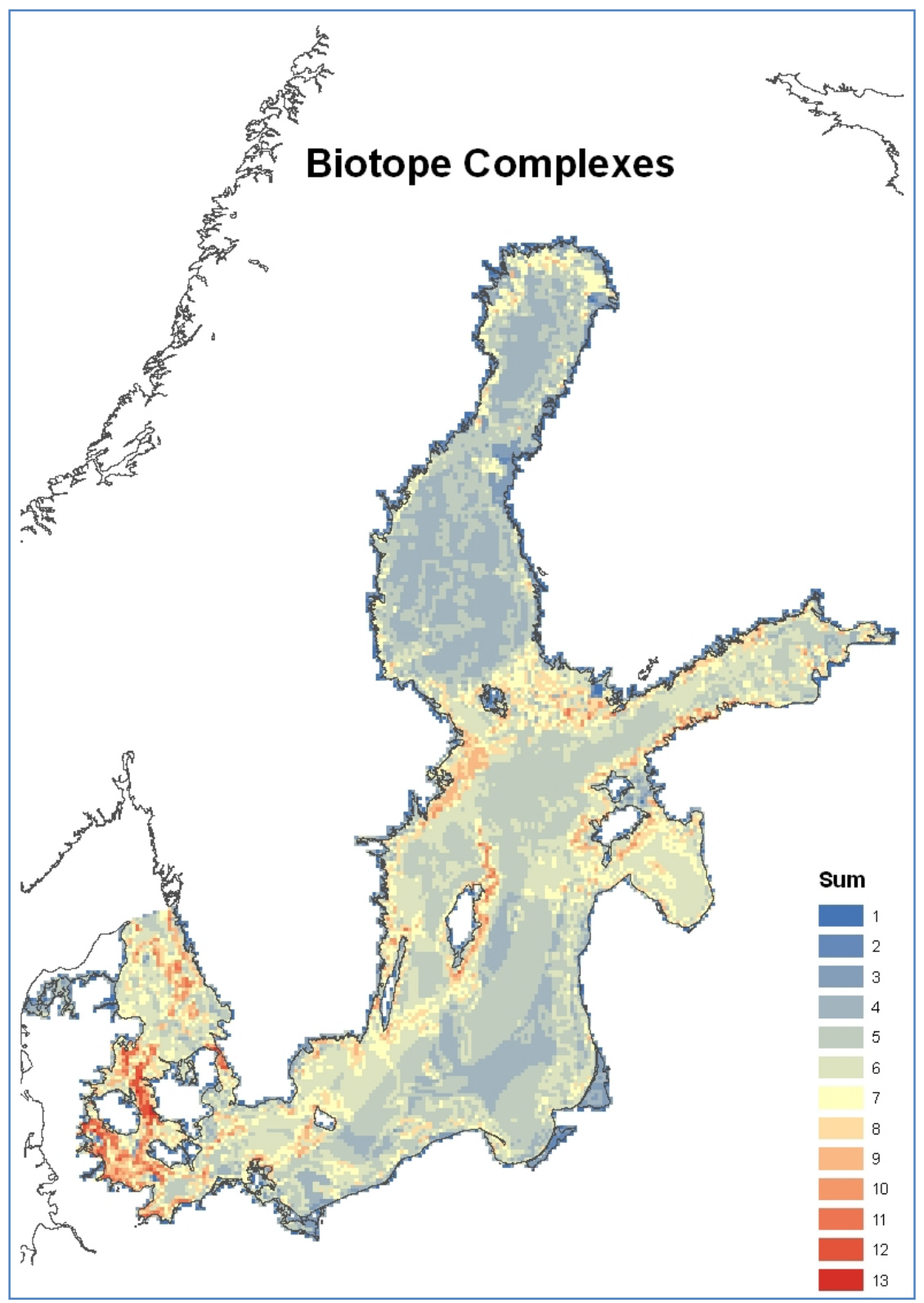

An example of the mapping of the spatial locations of the 13 biotope complexes in the Baltic Sea is illustrated in Figure 11. These biotope complexes and ecosystem structures should be completed and compared with 
the revised structure of the HELCOM Underwater Biotope and habitat classification (HELCOM HUB). ${ }^{8}$

This information has the potential to be used for an assessment, quantifying the information in Table 8 and carrying out a mapping of ecosystem services capacities in the Baltic in line with the Northern Atlantic assessment (Galparsoso et al., Figure 8), could be tested in the Baltic Sea. With this approach the ES capacity could be assessed using expert knowledge and mapped by using e.g. the large scale habitat database from the EU BALANCE project. Such assessments of ecosystem services capacities could be used together with values retrieved from the literature (cf. Chapter 6) and/or new valuation studies (for the ES we do not have values for) to create maps for the potential value of the ecosystem services. Such qualitative data and maps could be used for assessing changes in the value of the provision of ES, when the level of provision changes due to scenario alterations.

Such an analysis and assessment is however beyond the scope of the present project and would require a separate project with dedicated expert workshops in order to provide an assessment of the services provided by the Baltic Sea biotopes and habitats. The example in Table 8 shows a preliminary ad hoc qualitative assessment, based on the expert opinions of the project partners, indicating whether the biotope complexes and ecosystem structures are expected to contribute considerably, partially or negligible to the capacity for providing the ecosystem services. Table 8 is only an example, more detailed assessment should be done in a separate project to assess the ecosystem service capacities of the Baltic Sea biotopes, habitats and ecosystem components.

${ }^{8}$ HELCOM HUB is a common system for biotope and habitat classification in the Baltic Sea. This comprehensive system is designed to be EUNIS compatible and defines 328 underwater biotopes including both common and rare Baltic biotopes. 


\section{Linking selected ecosystem goods and services to de- scriptors and indicators of good environmental status}

The focus of this chapter is to provide possible ways forward in describing the relationship between ecosystem services and descriptors and indicators used for assessing the environmental status connected to the Marine Strategy Framework Directive (MSFD).

The development of these linkages is needed in order to e.g. make economic assessments in relation to Programmes of Measures to achieve Good Environmental Status (GES). If it is possible to link development in descriptors and their associated indicators to ES it means that measured information that is already required according to the directives can be utilized. This provides possibilities of estimating economic benefits from measures by conceptualizing a flow of events from costs of taking measures to the resulting benefits. An example is provided how the HELCOM CORESET indicators could be used to assess the condition of the ecosystem services.

\subsection{Introduction}

State indicators can potentially be used as measures of the magnitude of an ecosystem service (e.g. fish stock size). By analysing the three examples of services chosen as foci for this report: recreation, food (fish) and eutrophication mitigation, we broadly explore possibilities to link the service provision to MSFD descriptors and indicators, and the associated challenges. Some previous analyzes have been conducted on the topic and this chapter will present the findings from these in order to discuss opportunities, challenges and future information needs. 


\subsubsection{Connecting ecology and economics}

Figure 12 illustrates the linkages between the qualitative and quantitative assessments of ecosystem services, and the valuation of the goods and services.

Figure 12: Identification, quantification and valuation. From COWI (2014, p.8)

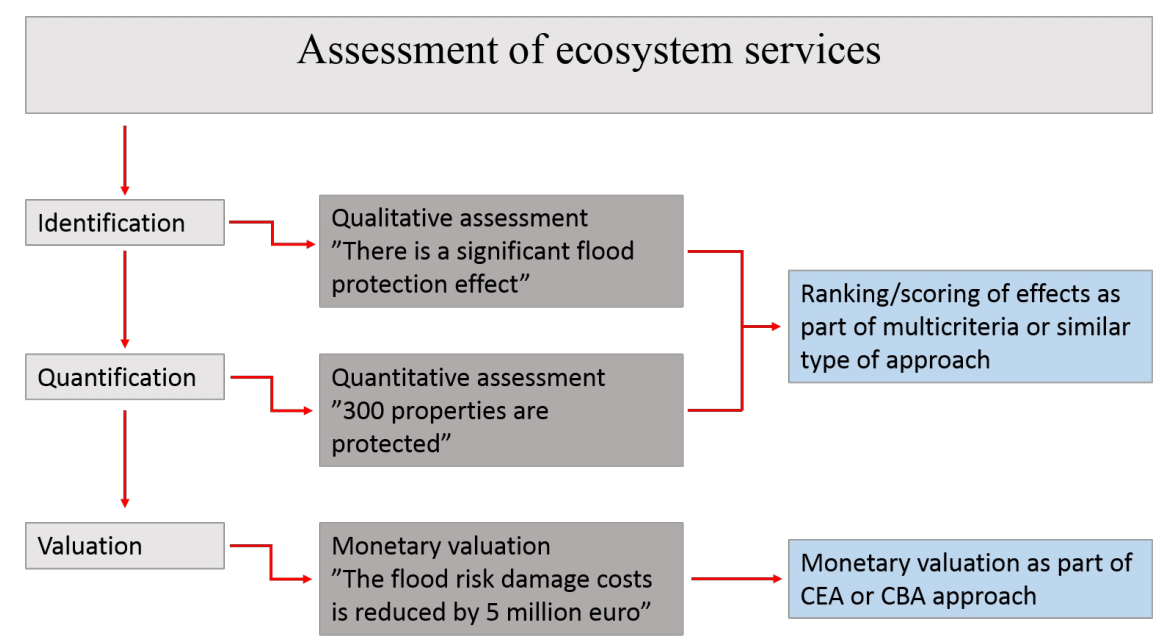

A prerequisite for conducting an analysis of the social and economic impacts from changes in the state of the marine and coastal environment is that it is possible to translate the environmental changes into consequences for human well-being. The ecosystem service approach provides an instrument for such a translation, and a crucial question is how the ecosystem service approach should be further developed for being operational in an evaluation context.

In relation to the MSFD, the Ecosystem service approach has been exemplified as follows (COM, 2010, p.17):

- Identify ecosystem services of the marine areas in cooperation with the analysis of status and the analysis of pressures and impacts.

- Identify and if possible quantify and value the welfare derived from the ecosystem services using different methods to estimate the use and non-use values of these services.

- Identify the drivers and pressures affecting the ecosystem services.

In summary, this can be understood as a need to create a gross list of marine ecosystem services, identify human-induced pressures (and 
driving forces affecting pressures) to these services, and then try to estimate the resulting potential effects on benefits given various scenarios for how the different threats develop. There are several reasons as to why it is relevant to conduct this type of analysis. One reason is communication - by illustrating the benefits that may be lost as a consequence of ecosystem degradation, the importance of a healthy ecosystem can be further highlighted. Another reason is decision support - having information about welfare effects derived from changes in the ecosystem, could help determine economically "optimal" levels of ambition, and it would provide valuable input to discussions concerning reasonable environmental objectives and prioritizations between different environmental objectives. For example, the cost of measures could be compared to the expected benefits, and relative benefits of various environmental policy options could be ranked in terms of economic importance.

For future analyses related to concrete measures to reach GES, the method for assessing impacts to ecosystem services needs to be further refined. Several elements of the analysis framework need elaboration one of them being the links between measurable "environmental" variables and the provision of ecosystem services.

In order to more deeply assess the effects on ecosystem services from changes in the state of the marine ecosystem, the linkages between GES descriptors, and their related indicators, and ecosystem services have to be further developed. The overall framework for this kind of study should be based on the concept of ecological endpoints (e.g. Boyd, 2007; USEPA, 2009). An ecological endpoint is a measurable "environmental" variable with importance for the supply of one or several ecosystem services, thus it can serve as a link between ecology and economy. An example that has been used in several studies in Swedish waters is water clarity, measured as secchi depth. Water clarity is a function of the status of the eutrophied Baltic ecosystem, and it also affects ecosystem services such as recreation. Further, the water clarity is correlated with other ecological variables affecting recreation, such as the amount and frequency of phytoplankton blooms and abundance of filamentous algae.

The continuous measurement of the status of the marine ecosystem related to the MSFD represents a potential source of information for valuation economists, usually lacking the scientific information needed to perform valuation studies and ecosystem services assessments with precision. Continuous measurement of ecological status, pressures and impacts opens opportunities for improving economic and social analyses. 
A change in the flow of ecosystem services can be expected to follow indirectly from changes in the state of the marine ecosystem. For example, the services "lifecycle maintenance" and "resilience', providing an insurance for the future flow of ecosystem services, is likely to be highly dependent on measurable indicators such as indicators describing biodiversity. While it may be difficult to make quantitative assessments of resilience, a connection can be made between the service and biophysical indicators on a conceptual level. Further, to give additional examples, eutrophication mitigation is an indirect function of various processes in water and sediment habitats, recreation opportunities is an indirect function of water clarity, concentrations of hazardous substances, frequency of cyanobacterial blooms, etc.

\subsection{Cultural service: Recreation}

\subsubsection{Links to descriptors and indicators}

SwAM (2012) conducted a study on marine recreation - and this chapter is partly based on their findings related to linkages between the service and descriptors and indicators.

Recreation is dependent on many factors - one of them being water quality. In order to make linkages between the service and water quality descriptors, SwAM identified which other, intermediate services, are affecting recreation. As a basis for their analysis, they divided recreation into different recreational activities: swimming, diving, wind surfing/water skiing, boating, fishing, being at the beach or seashore, skating/skiing, and using water based transportation. These activities all depend on intermediate services but to different extents, where swimming is most dependent on these and water based transportation is the least dependent on intermediate services.

At an overall level, three intermediate services were found to be particularly important for recreation: Eutrophication mitigation, regulation of hazardous substances and scenery. The next step in the analysis is to connect these intermediate services to descriptors and indicators that best associate with the services (Table 9. For additional details, see SwAM, 2012). 


\begin{tabular}{|c|c|c|}
\hline Ecosystem service & Descriptors & Indicators \\
\hline $\begin{array}{l}\text { Eutrophication } \\
\text { mitigation }\end{array}$ & D5. (Nutrients) & $\begin{array}{l}\text { 5.1.1. Nutrient concentration in the water column } \\
\text { 5.2.1 Chlorophyll concentration in the water column } \\
\text { 5.2.2 Water transparency } \\
\text { 5.3.1. Abundance of perennial seaweeds and seagrasses } \\
\text { 5.3.2 Dissolved oxygen }\end{array}$ \\
\hline \multirow[t]{2}{*}{$\begin{array}{l}\text { Regulation of haz- } \\
\text { ardous substances }\end{array}$} & $\begin{array}{l}\text { D8. (Concentration of } \\
\text { contaminants) }\end{array}$ & $\begin{array}{l}\text { 8.1.1. Concentration of the contaminants mentioned above, } \\
\text { measured in the relevant matrix (such as biota, sediment and } \\
\text { water) in a way that ensures comparability with assessments } \\
\text { under Directive } 2000 / 60 / E C\end{array}$ \\
\hline & $\begin{array}{l}\text { D9. (Contaminants in } \\
\text { seafood) }\end{array}$ & $\begin{array}{l}\text { 9.1.1. Actual levels of contaminants that have been detected } \\
\text { and number of contaminants which have exceeded maxi- } \\
\text { mum regulatory levels }\end{array}$ \\
\hline Scenery & D10. (Litter) & $\begin{array}{l}\text { 10.1.1. Trends in the amount of litter washed ashore and/or } \\
\text { deposited on coastlines, including analysis of its composition, } \\
\text { spatial distribution and, where possible, source }\end{array}$ \\
\hline
\end{tabular}

The logic is that if the relevant GES indicators are impaired and below GES, recreation activities will be affected through the intermediate services listed. When Eutrophication mitigation, Regulation of hazardous substances, or Scenery are adversely affected, the quality of recreation will be reduced.

Below, an example is provided of how the HELCOM CORESET indicators can be used to assess the condition of the first intermediate service "Eutrophication mitigation" which links to D5 descriptor (in Table 9). Table 10 provides an overview of connections between the eutrophication mitigation service, MSFD indicators, and HELCOM indicators (HELCOM, 2014), potential impacts and affected recreation activities. When nutrient levels rise, it affects recreation in a negative way due to direct effects such as increased phytoplankton biomass in surface waters (measured as chlorophyll a concentration in waters) or due to secondary impacts caused by increased nutrient levels like increased growth of filamentous algae in littoral zone. 
Table 10: Relevant MSFD indicators for Descriptor D5 Eutrophication and the corresponding HELCOM CORESET indicators (which follow the MSFD D5), that can be used to assess the condition of the intermediate service "Eutrophication mitigation" and recreation activities that are adversely impacted if the eutrophication D5/ HELCOM indicators are impaired and below good environmental (GES) status targets

\begin{tabular}{|c|c|c|c|}
\hline MSFD D5 indicators & HELCOM D5 indicators & Impact & $\begin{array}{l}\text { Activity that is adversely } \\
\text { affected }\end{array}$ \\
\hline $\begin{array}{l}\text { 5.1.1. Nutrient con- } \\
\text { centration in the wa- } \\
\text { ter column }\end{array}$ & $\begin{array}{l}\text { Nutrient levels: winter } \\
\text { (December-February) } \\
\text { dissolved inorganic nitro- } \\
\text { gen (DIN) and dissolved } \\
\text { inorganic phosphorus } \\
\text { (DIP) concentrations in } \\
\text { the surface layer } \\
\text { (0-10 m depth) (CORE) }\end{array}$ & $\begin{array}{l}\text { Causing direct impacts like } \\
\text { phytoplankton and fila- } \\
\text { mentous algal growth } \\
\text { (based on high nutrient } \\
\text { levels), decreased trans- } \\
\text { parency of water and po- } \\
\text { tential increase in fre- } \\
\text { quency of nuisance/ toxic } \\
\text { blooms }\end{array}$ & $\begin{array}{l}\text { No direct effects: } \\
\text { High nutrient concentra- } \\
\text { tions are not problem as } \\
\text { such, if the regulatory ser- } \\
\text { vice of Dilution is function- } \\
\text { ing. } \\
\text { Secondary impacts affect } \\
\text { following activities: } \\
\text { Swimming } \\
\text { Diving } \\
\text { Fishing }\end{array}$ \\
\hline $\begin{array}{l}\text { 5.2.1 Chlorophyll con- } \\
\text { centration in the wa- } \\
\text { ter column }\end{array}$ & $\begin{array}{l}\text { Direct effects: Summer } \\
\text { (June-September) chlo- } \\
\text { rophyll a concentration in } \\
\text { the surface layer (0-10 m } \\
\text { depth) (CORE) }\end{array}$ & $\begin{array}{l}\text { Direct effects: Increased } \\
\text { phytoplankton growth, de- } \\
\text { creased transparency of } \\
\text { water, potential increase } \\
\text { in frequency of nuisance/ } \\
\text { toxic blooms and floating } \\
\text { cyanobacteria stranded on } \\
\text { beaches }\end{array}$ & $\begin{array}{l}\text { Swimming } \\
\text { Diving } \\
\text { Fishing } \\
\text { Impaired scenic experience } \\
\text { in beach walking, picnick- } \\
\text { ing }\end{array}$ \\
\hline $\begin{array}{l}\text { 5.2.2 Water transpar- } \\
\text { ency }\end{array}$ & $\begin{array}{l}\text { Direct effects: Summer } \\
\text { (June-September) Secchi } \\
\text { depth (in meters) (CORE) }\end{array}$ & $\begin{array}{l}\text { Secondary impacts: de- } \\
\text { creased depth of macro- } \\
\text { phytes }\end{array}$ & $\begin{array}{l}\text { Swimming } \\
\text { Diving } \\
\text { Fishing }\end{array}$ \\
\hline $\begin{array}{l}\text { 5.3.1. Abundance of } \\
\text { perennial seaweeds } \\
\text { and seagrasses (e.g. } \\
\text { Fucoids, eelgrass and } \\
\text { neptune grass) ad- } \\
\text { versely impacted by } \\
\text { decrease in water } \\
\text { transparency }\end{array}$ & $\begin{array}{l}\text { Indirect effects: Lower } \\
\text { depth distribution limit of } \\
\text { macrophyte species (m) } \\
\text { (PRECORE) }\end{array}$ & $\begin{array}{l}\text { Less habitats for nursery } \\
\text { function } \\
\text { Impaired scenic experi- } \\
\text { ence when diving }\end{array}$ & $\begin{array}{l}\text { Diving } \\
\text { Fishing }\end{array}$ \\
\hline $\begin{array}{l}\text { 5.3.2 Dissolved } \\
\text { oxygen }\end{array}$ & $\begin{array}{l}\text { Indirect effects: Annual } \\
\text { Oxygen debt below the } \\
\text { halocline (or in specific } \\
\text { cases concentration) } \\
\text { (CORE): }\end{array}$ & $\begin{array}{l}\text { Less habitats for fish feed- } \\
\text { ing; decline of biodiversity } \\
\text { and ecological functioning } \\
\text { of biota; } \\
\text { Declined regulatory ser- } \\
\text { vice: Nutrient dilution, i.e. } \\
\text { nutrient retention by sedi- } \\
\text { ments }\end{array}$ & Fishing \\
\hline
\end{tabular}


Concluding on this, there is no descriptor that is directly linked to the recreational service provision. Hence, the analysis has been based on finding the most relevant intermediate services, and then in turn, identifying the descriptors and indicators most suitable to describe the status of these intermediate services. The indicators found to be most relevant are to some extent predicting the perceived benefits of recreational activities. These indicators might to some extent be usable also for other cultural services, not the least aesthetic values.

This type of exercise can be made given various set-ups of indicators. In Table 10, we exemplified with the HELCOM CORESET indicators (HELCOM, 2013). The CORESET indicators that are following the MSFD system are considered particularly suitable for Baltic-wide assessments.

A final remark is that the analysis above is based on a high level of delimitation. Recreation is likely to be affected also by the condition and changes of other descriptors, such as D3 on commercial fish species, which links particularly to recreational fishing, D1 on biodiversity, which links to experiences of nature and aesthetic values, which in turn affects the experience of diving, etc. Hence, the analysis above is limited to the descriptors and indicators that have a rather direct effect on particularly important intermediate ecosystem services, and also to the indicators that are rather directly functioning as an ecological endpoint for these services. It should be noted that altogether, changes in many descriptors and indicators are likely to lead to an aggregated impact.

\subsection{Provisioning service: Wild fish for Food}

The provisioning of fish and shellfish for consumption is the result of harvesting or farming. Here, the focus is on the wild fish stocks, i.e. those stocks which are targeted in commercial fisheries excluding recreational fisheries. In the Baltic Sea, the three main species for commercial fishing are cod, herring and sprat, but many other species are important as well.

\subsubsection{Links to descriptors and indicators}

The ability of the Baltic's ecosystem to produce fish is related to many factors and many intermediate ecosystem services. However, there is an obvious connection between the ecosystem service and the fish populations, which means that estimations of fish populations are good measures of the service. 
If the aim is to assess the potential capacity (supply) of the ecosystem service, i.e. production of fish, indicators that reflect the production of fish stocks should be used, when possible.

If the demand driven approach is used, aiming to assess the actual flow of the ecosystem service (sensu Liquite et al., 2013), the amount of the harvested fish would be the service, for which the landings (or the proportion of landings consumed by humans) would be suitable indicator.

The MSFD descriptor 3 calls for assessment of the sustainability of the commercially exploited fish stock. Indicators selected for the assessment of the descriptor focus on the fishing pressure, the reproductive capacity of the stocks, and the population age and size distribution. Table 11 summarizes the descriptor and its indicators.

In theory, the status of the provisioning service "wild fish for food" could be assessed directly if there were complete information on population dynamics and fisheries of all the fish stocks that are harvested. However, as only part of the fish stocks are assessed, the indicator values are based on the stock assessment data available (Table C).

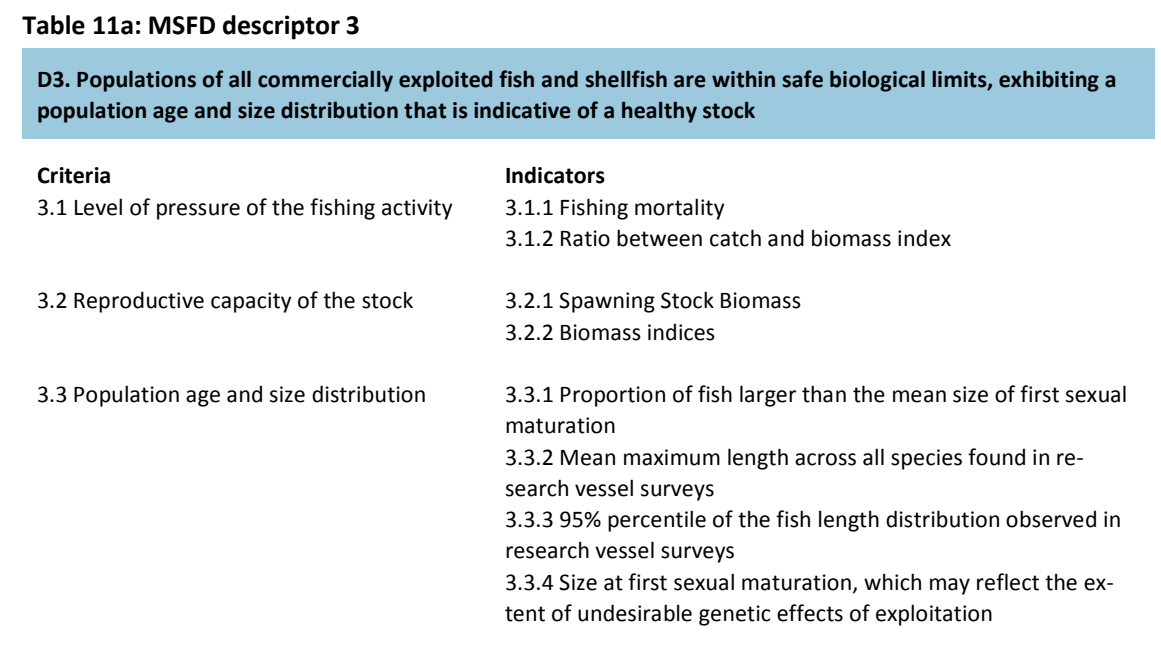

Most of the economically important fish species in European marine regions are included in the Data Collection framework (DCF), an EU community framework for the collection, management and use of data in the fisheries sector and supporting development of the scientific advice regarding the Common Fisheries Policy (CFP). The stock assessments of commercial fish stocks are undertaken in the working groups (WGs) of the ICES (International Council for the Exploration of the Sea) and GFCM 
(the General Fisheries Commission for the Mediterranean). These are reviewed by STECF (Scientific, Technical and Economic Committee for Fisheries) which also assess e.g. fleet effort data and perform economic analyses of the European fisheries.

ICES (2014) have produced an assessment of the Baltic Sea commercial fish stocks according to Criteria in D3 (Table below). However, obtaining an indicator and a reference point for an age structure (criteria 3.3) was found to be challenging. ICES are not assessing the status of stocks based on size or age structure of the populations (acc. criteria 3.3). For this criterion, the biomass of large fish relative to the spawning stock biomass was suggested as an indicator, but there has not been an agreement among the experts how to carry out this assessment (ICES, 2014).

\begin{tabular}{|c|c|c|c|c|c|c|}
\hline & 3.1.1 & 3.2.2 & 3.2.1 & 3.2 .2 & 3.3 & Unknown \\
\hline Number of stocks & 7 & 2 & 7 & 7 & 0 & $0 / 5 / 0 / 1$ \\
\hline Number of stocks achieving green status & 4 & 1 & 6 & 5 & NA & \\
\hline Percentage of stocks achieving green status & 57 & 50 & 86 & 71 & NA & \\
\hline
\end{tabular}

There were about 70 different species or species-groups landed and reported (ICES catch statistics for 1983-2009). Out of the 17 stocks assessed by ICES in the Baltic Sea, it is possible to make the MFSD assessment for 14 stock that are assessed using F and SSB metrics that are required for the criteria 3.1. and 3.2.

Furthermore, Descriptor 9 (Contaminants in seafood) has a direct connection to food provisioning. This descriptor provides information on quality of the seafood and thus supports the assessment of the provisioning service. It gives a general indication of trends but cannot be used in the evaluation of the actual flow of the service. Table 11 shows the relevant indicators.

Table 12: MSFD Descriptor 9

D9. Contaminants in fish and other seafood for human consumption do not exceed levels established by EU legislation or other relevant standards

\begin{tabular}{ll} 
Criterion & Indicators \\
$\begin{array}{l}\text { 9.1 Levels, number and fre- } \\
\text { quency of contaminants }\end{array}$ & $\begin{array}{l}\text { 9.1.1 Actual levels of contaminants that have been detected and number of } \\
\text { contaminants which have exceeded maximum regulatory levels } \\
\text { 9.1.2 Frequency of regulatory levels being exceeded }\end{array}$ \\
\hline
\end{tabular}


HELCOM experts have recommended a list of hazardous substances as core indicators for Descriptors 8 (contaminants in the environment) and Descriptor 9 (example Table below; HELCOM, 2013). The indicators for biological effects of hazardous substances proposed for the MSFD Criterion 8.1. and 8.2. also support the assessment of the capacity of the provisioning service wild fish for food. There are indicators such as Tributyltin (TBT) and imposex, and fish diseases as fish stress indicator.

Table 13: Proposed core indicators for the biological effects of hazardous substances (HELCOM, 2013)

\begin{tabular}{|c|c|c|c|c|c|c|c|c|c|c|}
\hline Proposed core indicator & $\begin{array}{l}\text { Viable } \\
\text { popula- } \\
\text { tions of } \\
\text { species }\end{array}$ & $\begin{array}{l}\text { Concenra- } \\
\text { tions of } \\
\text { hazarous } \\
\text { sub- } \\
\text { stances } \\
\text { close to } \\
\text { natural } \\
\text { levels }\end{array}$ & $\begin{array}{l}\text { Healthy } \\
\text { wildlife }\end{array}$ & $\begin{array}{l}\text { Radioac- } \\
\text { tivity at } \\
\text { pre Cher- } \\
\text { nobyl } \\
\text { level }\end{array}$ & $\begin{array}{l}\text { Fish safe } \\
\text { to eat }\end{array}$ & $\begin{array}{l}\text { MSFD cri- } \\
\text { terion } \\
1.3 .^{*}\end{array}$ & $\begin{array}{l}\text { MSFD Cri- } \\
\text { terion } \\
\text { 4.1.** }\end{array}$ & $\begin{array}{l}\text { MSFD Cri- } \\
\text { terion } \\
\text { 8.1.*** }\end{array}$ & $\begin{array}{l}\text { MSFD Cri- } \\
\text { terion } \\
\text { 8.2.**** }\end{array}$ & $\begin{array}{l}\text { MSFD Cri- } \\
\text { terion } \\
9.1 . * * * * *\end{array}$ \\
\hline PAH metabolites & & $x$ & $x$ & & & $x$ & & $x$ & $x$ & \\
\hline $\begin{array}{l}\text { Tributyltin (TBT9 and im- } \\
\text { posex }\end{array}$ & $x$ & $x$ & $x$ & & & $x$ & & $x$ & $x$ & $x$ \\
\hline $\begin{array}{l}\text { Eelpout and amphipod } \\
\text { embryo malformations }\end{array}$ & $x$ & & $x$ & & & $x$ & $x$ & & $x$ & \\
\hline $\begin{array}{l}\text { Fish diseases - a fish } \\
\text { stress indicator }\end{array}$ & & & $x$ & & & $x$ & & & $x$ & \\
\hline $\begin{array}{l}\text { Micronuclei test - a } \\
\text { genotoxity indicator }\end{array}$ & & & $x$ & & & $x$ & & & $x$ & \\
\hline $\begin{array}{l}9 \mathrm{HS} \text { concentration } \\
\text { indicators }\end{array}$ & & $x$ & & $x$ & $x$ & & & $x$ & & $x$ \\
\hline
\end{tabular}

*MSFD Criterion 1.3.: Population condition (species).

**MSFD Criterion 4.1.: Productivity (production per unit biomass) of key species or trophic groups.

***MSFD Criterion 8.1.: Concentration of contaminants.

**** MSFD Criterion 8.2. Effects of contaminants.

***** MSFD Criterion 9.1. Levels, number and frequency of contaminants.

The indicators of descriptor D3 are suitable for measuring the status of food provisioning when this is interpreted in terms of fish for commercial use. However, this descriptor is less suitable for other types of provisioning services such as biotic materials, biomass for energy, ornamental resources, and so on. Also, descriptor D9 about contaminants in seafood is highly relevant. 


\subsection{Maintenance/regulating services: Sediment retention}

Sediment retention is the ability of the ecosystem to stabilize sediment and prevent erosion, both at sea beds in the open sea and along the coast. Erosion prevention in coastal areas is important in order to avoid acute damage from storms, but also in order to avoid slow erosion due to waves, wind and currents, which may affect the ecosystem and also man-made constructions along the coast.

Sediment retention is favored by structures on the seafloor and along the beaches, such as those created by vegetation. The restoration of sea grass meadows has been pointed out as one potential tool for preventing deterioration of the service (Garpe, 2008).

Sediment retention is, in terms of its intermediate services, closely related to habitat. It is affected by pressures such as dredging, sea traffic that create waves, the physical removal of vegetation in coastal areas for exploitation, bottom trawling, and the overall state of the ecosystem in terms of its effect on erosion-preventing vegetation. Sediment retention can also be understood as being an intermediate service in itself, to several other services such as recreation (by preventing coastal erosion that might lead to negative consequences for recreation) and food provision (by preventing erosion that is harmful to habitats and food webs).

The service is thus an interesting example, being an intermediate service to other services and goods while also being dependent on other intermediate services.

In terms of GES descriptors, D6 (Sea floor integrity) is the descriptor that is most closely linked to the service. The most relevant indicators are 6.1.2 and 6.2.3, see Table 14 .

\begin{tabular}{l} 
Table 14: MSFD indicator D6 that is most closely linked to sediment retention \\
$\begin{array}{l}\text { D6. Sea-floor integrity is at a level that ensures that the structure and functions of the ecosystems are safe- } \\
\text { guarded and benthic ecosystems, in particular, are not adversely affected }\end{array}$ \\
$\begin{array}{ll}\text { Criteria } & \begin{array}{l}\text { Indicators } \\
6.1 \text { Physical damage, having regard to substrate } \\
\text { characteristics }\end{array} \\
\begin{array}{l}\text { 6.1.2 Extent of the seabed significantly affected by human } \\
\text { activities for the different substrate types }\end{array} \\
\begin{array}{l}\text { 6.2.3 Proportion of biomass or numbers of individuals in } \\
\text { the macrobenthos above some specified length/size }\end{array}\end{array}$ \\
\hline
\end{tabular}




\subsection{Concluding remarks and discussion}

In general, none of the descriptors are fully capturing the service sediment retention. The development of Descriptor 6 (Sea-floor integrity) is likely to have direct impacts for sediment retention. However, it is likely to be dependent indirectly on many other descriptors, such as D1 (Biodiversity).

In this chapter, we have provided an overview of potential analytical linkages between a selection of ecosystem goods/services and the state of the marine environment in terms of MSFD descriptors and their associated indicators. This type of linkage may be useful for economic and social assessments during the coming years. While the chapter has not been aimed at providing an exhaustive list of "final" or "recommended" links, the examples given may indicate potential starting points for further analysis.

A particularly interesting issue to further investigate is the usage of the HELCOM CORESET indicators. The usage of these indicators implies possibilities for coordination between countries and conducting analyses on a Baltic wide scale.

The ecosystem service approach is a suitable tool for connecting the "environmental" dimension of marine policy with the economic dimension. By starting in the environmental dimension, and using indicators that are already in place, or will be in place in the near future, the economic dimension can be added to existing analytical frameworks. This may increase analytical efficiency and also create possibilities for holistic assessments and broader sustainability assessments, where the state of the environment represents the logical central node to which the economic impacts of changes can be related.

The implicit assumption behind the framework used in this chapter is that measures taken in order to affect the environmental status, affects the flow of ecosystem services, which in turn entails economic consequences. However, this analytical framework may oversimplify the analysis of the economic consequences following implementation of measures, since the measures themselves, regardless of their effect on the environmental status, have economic consequences. For example, restrictive fishery policies may lead to increasing fish stocks, which affects the ecosystem service Food and is likely to generate long-term economic benefits. However, the measure will also have a direct, short-term economic consequence to fisheries, regardless of whether the measure leads to long-term effects or not. Thus, when analyzing effects of measures, both consequences that follow directly from the measure as well as consequences that follow indirectly from the environmental effects of the measure need to be considered. The framework provided in this chapter is aimed at supporting analysis concerning b). 


\section{Literature study on the value of marine ecosystem services}

The focus of this chapter is to describe the current knowledge of valuing marine ecosystem services. This is done by linking recent valuation studies and the results to environmental indicators, namely the descriptors of good environmental status (GES) in the Marine Strategy Framework Directive (MSFD) described in Chapter 5. The results are also linked to the HELCOM CORESET indicators. The valuation studies are assessed and described with reference to spatial explicitness, marginality, double-counting, and nonlinearities and threshold effects, as these factors are important determinants of the validity of the studies in an ES setting. The possibilities for benefit transfer and aggregation of values across larger geographic scales are also assessed.

\subsection{Introduction}

Valuation of marine and coastal ecosystem services is an important part of understanding the significance of marine ecosystems to human wellbeing. Ecosystem services are valued to assess the socio-economic benefits (or losses) resulting from changes in the state of ecosystems and biodiversity. This view is essentially anthropocentric and focuses on human welfare. Valuation of ecosystem services is interdisciplinary, combining the approaches of natural and social sciences to characterize the relationships between ecosystems, the provision of ecosystem services, goods, and human well-being.

The concept of goods is useful in linking the ecological processes and services to human well-being (UK NEA, 2011). Goods are objects that people value and that are produced by final ecosystem services. Examples of goods provided by marine ecosystem services include food, recreation and energy. In addition, there are also non-use benefits that are not related to the use of ecosystem services, such as existence values. Goods can be valued to estimate the effects on human well-being resulting from changes in the provision of ecosystem services. The values of welfare improvements are typically called benefits. 
Previous reviews have identified several studies on the economic value of marine and coastal ecosystem services in the Baltic Sea area. These reviews have linked the value estimates to specific ecosystem services (Söderqvist \& Hasselström 2008; Turner et al., 2010a; Ahtiainen \& Öhman, 2014), and also assessed the relevance of the value estimates to the Marine Strategy Framework Directive (COWI, 2010). Although these previous reports are useful in assessing the existing knowledge, it is possible to provide new insights by examining additional features of the studies.

The aim of the present literature review is to advance our knowledge of valuing marine ecosystem services by linking recent valuation studies to environmental indicators, namely the descriptors of good environmental status (GES) in the Marine Strategy Framework Directive (MSFD) (European Commission 2010) and the CORESET indicators of the HELCOM Baltic Sea Action Plan (BSAP) (HELCOM, 2013). In addition, we assess the studies based on the critical issues that should be taken into account in valuing ecosystem services: spatial explicitness, marginality, doublecounting, and nonlinearities and threshold effects (Turner et al., 2010b). We also discuss the possibilities for benefit transfer and aggregation of values across larger geographic scales. The review is limited to recent studies, as these are more likely to consider ecosystem services and current policy targets explicitly, providing more relevant information for decision-making.

This chapter is structured as follows. In the next section, we briefly introduce the previous literature reviews on the value of marine ecosystem services. Section 6.3 discusses the valuation of ecosystem services and the special features therein, and section 6.4 illustrates the valuation of three ecosystem goods and services: recreation, food and eutrophication mitigation. The literature is reviewed and assessed in section 6.5. The last section presents discussion and conclusions.

\subsection{Previous reviews of the value of marine ecosystem services}

There are several reviews of studies that value marine ecosystem services, both in the Baltic Sea region and elsewhere. Söderqvist \& Hasselström (2008), together with specialists and researchers from all littoral countries around the Baltic, investigated the existing information (1990s-2007) on the economic value of ecosystem services provided by the Baltic Sea and Skagerrak and identified gaps of knowledge. The report presented a summary table of how the different ecosystem services were 
covered by valuation studies and the details of each study. The ecosystem service classification used was based on Garpe (2008), where services were classified into supporting, regulating, provisioning and cultural following the Millennium Ecosystem Assessment (MA) (2005). The review noted that previous research had focused on habitats, diversity, food, recreation and aesthetic value, which were also seen as important areas for future research. In addition, the report suggested further studies of the benefits of reduced eutrophication, improving the state of the cod stock, recreational fishing and decreased risk of oil spills.

In the context of introducing socio-economic assessments in the MSFD, Turner et al. (2010a) reviewed previous valuation studies (1980s2008 ) in the North-East Atlantic Ocean and the Baltic Sea. In addition to providing the basic details of the studies, they also identified the associated ecosystem services and benefits. Turner et al. (2010a) used a similar classification of ecosystem services as Söderqvist \& Hasselström (2008), but separated between ecosystem services and benefits. The report indicated that there were challenges in linking the valuation studies to specific ecosystem services, and noted the lack of a common framework for valuation.

In a report on the economic assessments in the MSFD, COWI (2010) conducted a non-exhaustive review of the valuation literature that could provide relevant information for the economic requirements of the MSFD (2002-2009). The review was not limited to a specific area, but the majority of the studies included were from the Baltic Sea area. COWI (2010) did not use a specific ecosystem services classification, as the main focus was in assessing the relevance to the MSFD. The report noted a lack of monetary valuation studies due to the limited knowledge on the relationship between marine ecosystems, biodiversity and ecosystem services.

The most recent review on the value of marine and coastal ecosystem services can be found in Ahtiainen \& Öhman (2014). The report focused on the Baltic Sea, including general information on the valuation of ecosystem services and updating the Söderqvist \& Hasselström (2008) review by shortly describing the results of some recent studies conducted in the Baltic Sea area (2009-2013). The report divided ecosystem services into supporting, regulating, provisioning and cultural, and separated between intermediate and final ecosystem services following Fisher et al. (2009). The report emphasized the discussions and results of a workshop on the valuation of marine and coastal ecosystem services, and also identified main challenges in assessing marine ecosystem services and integrating them into decision-making. 


\subsection{Valuation of ecosystem services}

Valuation of ecosystem services includes multiple types of values and valuation methods. Firstly, ecosystem service values can be classified into monetary, socio-cultural and ecological values (Gómez-Baggethun et al., 2014). Monetary (or economic) valuation entails assessing the values resulting from changes in ecosystem services in monetary terms. In this framework, values are typically divided into use (e.g. recreation) and nonuse (e.g. existence) values. Socio-cultural values are those that cannot readily be measured with monetary metrics, such as moral, spiritual and therapeutical values. Ecological values relate to ecological importance, meaning, for example, biophysical, instrumental or intrinsic values associated with ecosystems.

Secondly, valuation can be carried out on a qualitative, quantitative or monetary level. Qualitative valuation means describing the possible goods and benefits provided by ecosystem services. This is the simplest approach, and can typically be included in any ecosystem service assessment. Quantitative valuation entails expressing the goods and benefits in measurable units, for example, number of visitors. Information about the quantities is a further step in characterizing the importance of ecosystem services, and makes it possible to assess the change in the quantifiable outputs if the provision of ecosystem services changes. Monetary valuation includes assessing the values resulting from changes in ecosystem services in monetary terms.

Third, it is possible to classify the ways of measuring values into categories: either to monetary and non-monetary valuation (Gómez-Baggethun et al., 2014), or to economic valuation, health benefits and shared (social values) (UK NEA, 2011). Economic valuation is, in many respects, synonymous to monetary valuation, as the purpose is to express the monetary value of goods provided by ecosystem services. These values represent individual values, and can be based on a number of valuation methods. Non-monetary valuation refers to heterogeneous valuation approaches which do not rely on monetary measures. This methodology has not yet been formalized.

Health values incorporate different aspects of health, including physical, mental and social health. It is possible to express health benefits using qualitative assessments, quantitative units or monetary estimates. Shared values are estimated using participatory and deliberative approaches that place emphasis on the social process of valuation. Shared values can be expressed in monetary terms, and they may be especially 
useful for understanding the values linked to some cultural ecosystem services and goods (UK NEA, 2011).

This review focuses on the economic valuation of ecosystem services. Estimating monetary values of environmental goods and services can be time-consuming and typically requires the use of environmental valuation methods (see e.g. Champ et al., 2003; Bateman et al., 2011 or Barton et al., 2012 for a review of valuation methods). These methods are based either on actual behaviour (revealed preferences: travel cost method, hedonic pricing), or survey responses revealing people's willingness to pay for environmental improvements (stated preferences: contingent valuation, choice experiment). If the goods are traded in the markets, value estimates can be based on market prices, although adjustments for market distortions may be needed. Another option is to base the value estimates on costs, e.g. costs of replacing goods provided by ecosystem services, or costs avoided due to ecosystem services (e.g. storm damages avoided due to coastal wetlands). The advantage of using economic valuation is that when values are expressed in monetary terms, their comparison to other economic actions, such as the costs of improving the state of the ecosystem, is straightforward.

\subsubsection{Critical issues in the economic valuation of ecosys- tem services}

Previous research has identified specific issues that should be accounted for in the valuation of ecosystem services. These include double-counting, marginality, spatial explicitness, nonlinearities and threshold effects (Turner et al., 2010b). We introduce these concepts shortly, as they are used in the literature review to assess if and how the studies can be used for valuation of ecosystem services.

Double-counting occurs when underlying ecosystem services that contribute to final service benefits are valued both separately and via the final services, and the values are aggregated to obtain estimates of ecosystem value (Turner et al., 2010b). For example, valuing nutrient cycling and recreation in marine areas separately and adding the values up leads to double-counting, as nutrient cycling contributes to making the water suitable for recreation. Thus, the value of nutrient cycling is already embodied in the recreation benefits. Although double-counting can be a problem, it can be avoided by having a clear understanding of the interactions of ecosystem services and the goods and benefits they produce. One option is to value only goods and benefits provided by final ecosystem services (Fisher et al., 2009). In principle, the value of a good captures the 
value of all intermediate and final ecosystem services related to that good. It is important to note, however, that one ecosystem services may contribute to the production of several other goods. Another possibility is to value the intermediate processes directly, without adding these up with the value of final services and goods. If a study separately estimates the values of both intermediate and final services, or final services and goods, and adds these values up to produce the "total" value, this raises concerns about possible double-counting. Therefore, care should be taken before considering the summation of values of connected intermediate and final ecosystem services. If the aim is to analyze trade-offs between ecosystem services e.g. from policy changes, double counting is not critical, and then it can be useful to assess the implications of how changes in the intermediate services changes the value of the final good. This is how intermediate services, such as some regulating services, can be accounted for.

Marginal valuation entails that marginal changes in value are estimated instead of total values. Estimating the total economic value of ecosystem services as such, without relating the value to any specific environmental change is typically neither useful nor advisable (Brouwer et al., 2013). First, marginal value reflects the value of an additional unit of ecosystem services, and it changes with the level of provision of ecosystem services. This means, for example, that when the level of ecosystem services provision is low, marginal values are likely to be high, while they are expected to decrease when the provision of ecosystem services reaches a higher level. Therefore, multiplying marginal values with large quantities may lead to biased estimates of total value. Second, the total value of ecosystem services that are fundamental to human well-being is argued to be infinite. Third, policy decisions rarely consider or imply total losses of ecosystem services, and thus valuing marginal changes is more useful for supporting decision-making.

Spatial explicitness means that it is important to account for the spatial heterogeneity of ecosystem services both in terms of provision and benefits (Turner et al., 2010b). Provision of ecosystem services is affected by, for example, the extent of the ecosystem providing the services, quality and the scale of delivery, and the benefits depend on the number of affected people, distance to the ecosystem and availability of substitutes, among others (Brouwer et al., 2013). It is important to put emphasis on determining the number of beneficiaries as it typically has a large impact on the magnitude of the estimated aggregate value of ecosystem services.

Nonlinearities are often present in ecosystem service deliveries, meaning that there are certain thresholds after which the system changes dramatically into another steady state. Possible thresholds should also be 
considered in valuation to produce appropriate benefit estimates. Thresholds are difficult to account for in valuation, as there may be significant ecological uncertainty related to their occurrence.

\subsection{From goods to values and benefits}

According to the ecosystem service classification used in UK NEA (2011), final ecosystem services produce goods that can be valued. The term good is understood broadly to encompass all use and non-use outputs that have value for people. Examples of goods produced by marine ecosystem services include food, recreation and energy. In addition to such use-related goods, there are non-use benefits which stem from the knowledge that marine ecosystems are healthy and that other people may enjoy their use and existence.

The following discusses the valuation of two goods or final ecosystem services: recreation, and food, and valuation of eutrophication mitigation as a regulating and maintenance service.

\subsubsection{Recreation}

Marine and coastal recreation activities include, for example, walking along the coast, swimming, sunbathing, boating, diving, fishing and nature watching. The value of recreation is most commonly estimated using the travel cost method, which utilizes information on the travel costs and number of trips to estimate the demand for and value of recreation. If information is available on several locations that differ in environmental or ecosystem service quality, it is possible to estimate how the quality affects the recreational value. Stated preference methods are also often used to estimate recreational values and how these change if the provision of ecosystem services changes. It is also possible to use the contingent behaviour method, which combines the travel cost method with stated preferences.

Valuation of recreation is complicated in the sense that recreation in natural areas also is associated with the joint consumption of conventional goods and services and ecosystem services. Ecosystems provide the surroundings and aesthetic landscape for recreation, but often conventional goods and services, such as park facilities, accommodation and equipment, are also needed for the recreation experience. Consequently, the entire value of recreation should not be assigned to ecosystem services, but the contribution of ecosystem services to the economic value of recreational use of environment should be identified (UK NEA, 2011). 
Tourism is closely related to recreation. The economic impacts of nature tourism can be evaluated based on the consumption expenditure of tourists, tourism revenues and the employment impact of tourism. As with other types of recreation, economic valuation methods may also be used in estimating recreation values of tourists.

Marine and coastal recreation is a popular activity in the Baltic Sea area. The value of recreation has been estimated in several recent studies, mainly together with non-use benefits (see Table 15). Some earlier studies conducted in Sweden have focused solely on recreational values (Soutukorva, 2001; Sandström, 1996), and the value of recreational fishing has been studied in Paulrud (2004), Söderqvist \& Soutukorva (2005), and Toivonen et al. (2000, 2004). Some recent publications (Söderqvist et al., 2010; Ahtiainen et al., 2013) characterize and quantify marine and coastal recreation in the Baltic Sea area, but as they do not present estimates of marine recreation values, comparable information of values across countries is missing.

\subsubsection{Food}

Most provisioning services, such as food, can be associated with consumptive direct use values, referring to the actual use of resources extracted from the ecosystem. The value of food can be inferred from market behaviour and prices. For example, the volume and value of the provision of fish and shellfish for consumption can be based on catch landings and market prices. Thus, it is rather straightforward to estimate the value of changes in the provision of food. In addition, stated preference methods may be used to reveal the general public's valuation of improved fish stocks. However, these values may also be related to the non-use and existence benefits of fish stocks and not only to direct use values.

Kulmala et al. (2012) used market prices to assess the commercial value of Baltic salmon. The estimated annual value of total landings was 0.9-3.6 million $€$ in Denmark, Finland, Poland and Sweden. Depellegrin and Blažauskas (2013) also based their estimate of fishery values on annual landings and market prices. Tegeback and Hasselström (2012) assessed the losses in the turnover of fisheries from oil spills. In addition to these studies relying on market information, stated preference methods have been used recently to estimate the benefits from increases in cod stocks (Eggert and Olsson, 2009) and fish stocks in general (Carlsson et al., 2010, Kosenius and Ollikainen, 2015). 


\subsubsection{Eutrophication mitigation}

Several habitats in the coastal waters perform vital services such as nutrient filtration and sedimentation, which contribute to eutrophication mitigation and thus affects marine and coastal water quality. Gren (2013) calculated the economic value of coastal zones as nutrient filters by using the replacement cost method, assuming a nutrient retention between 0 and $22 \%$ in the coastal zone of the Baltic Sea. The conclusion of the study was that in addition to the retention rate, the estimated value of the service is dependent of the costs of the other abatement measures included in the assessment, as well of the spatial scale of the assessment. The model results indicated that the filtration effect of the coastal zone serves to reduce the costs of reaching nutrient reduction targets by 35\% (in total 66 billion EUR over 70 years), which corresponds to $1.9 \%$ of the Baltic Sea region's total gross domestic product.

If the benefits from regulating and maintenance services, such as nutrient filtration in sediment habitats, are already considered in the values of final services or goods, one should be careful about double-counting. In that case, maintenance and regulating services can be intermediate services whose value is already included in the value of the final services or goods. If the valuation assessment aims at calculating the benefits from changes in ecosystem services, double-counting is possible. But, if the aim of the assessment is to analyze the trade-offs between policies, all services and how they are affected should be included so differences in the provision of regulatory and other intermediate services are also analysed. Double-counting only occurs when the values of intermediate services and final service are summed up.

\subsection{Evaluation of literature}

The identified studies are listed in Table 15. The literature review was restricted to the last 5 years, as there are several existing reviews that include older studies (see Section 6.2). All identified studies were conducted in the Baltic Sea area, including either the whole sea or some subbasin of the sea.

The ecosystem service classification used in Table 15 is based on the MA (2005), differentiating between supporting, regulating, provisioning and cultural services. It is good to note that supporting services are always intermediate (i.e. they do not contribute to human welfare directly), and thus they are not included in the table. In addition, we separated goods/benefits from ecosystem services following UK NEA (2011), as this 
approach is appropriate for the purposes of valuation and facilitates linking the studies to the ecosystem service framework. All reviewed studies valued cultural and/or provisioning services. Both categories are classified as final services in the UK NEA (2011). In most cases, the studies estimated the value of recreation, food and/or non-use benefits. One study also included aesthetic benefits and one tourism benefits.

This section focuses on two issues: 1) Is it possible to connect the study to the descriptors of environmental status, in particular certain MSFD and BSAP indicators? and 2) Have the critical issues (spatial explicitness, marginality, double-counting, nonlinearities and thresholds) been taken into account in the study? The aim is to assess the suitability of the studies for estimating the benefits of reaching the current environmental targets set for marine ecosystems.

\subsubsection{Descriptors of environmental status}

The EU Marine Strategy Framework Directive includes 11 descriptors of good environmental status (European Commission 2010). Most of the valuation studies could be connected to the descriptors D1 Biodiversity is maintained, D3 The population of commercial fish species is healthy, and D5 Eutrophication is minimized.

The most common primary descriptors, i.e. those that best correspond to the environmental changes considered in the valuation studies, were D3 Fish species and D5 Eutrophication. Several studies could be linked to D3 Fish species. Values were estimated for the cod stock (Eggert \& Olsson, 2009; Carlsson et al., 2010), Baltic salmon (Kulmala et al., 2012), and fisheries and fish stocks in general (Lewis et al., 2013; Kosenius \& Ollikainen, 2015), and they included both provisioning (food) and cultural (recreational fishing) ecosystem services.

Another common descriptor that could be identified was D5 Eutrophication. Ahtiainen et al. (2014) described reduced eutrophication in terms of water clarity, blue-green algal blooms, fish species composition, the state of underwater meadows and oxygen conditions in sea bottoms. In addition to these, Kosenius (2010) used the state of bladder wrack to describe eutrophication status, and some studies employed more general descriptions of water quality (Eggert \& Olsson, 2009; Östberg et al., 2013). Gren (2013) used the replacement cost method to estimate the value of coastal zone filtering of nutrients, thereby obtaining an estimate of the value of eutrophication mitigation. The value estimates from this study are not comparable to using e.g. stated preference methods, as they are 
based on costs and estimate the total (not marginal) values of coastal waters' filtering capacity.

The largest number of studies could be related to D1 Biodiversity. This is the case despite the fact that none of the studies had biodiversity as their primary focus. However, the change in the environmental status was typically described also using biodiversity-related features. For example, Carlsson et al. (2010) estimated the value of endangered species, while also studying fish stocks and surveillance of oil and chemical discharges, and Eggert \& Olsson (2009) included biodiversity as one of the attributes in their choice experiment. Kosenius \& Ollikainen (2015) valued healthy vegetation. Also some studies that valued reduced eutrophication could be linked to biodiversity (Ahtiainen et al., 2014; Kosenius, 2010).

In addition to the three most common descriptors, two studies focused on oil spills (Tegebäck \& Hasselström, 2012; Depellegrin \& Blažauskas, 2013), which could be linked to D8 Concentrations of contaminants give no effects. These studies were not primary valuation studies, but used the results of other studies to examine the value of losses in ecosystem services caused by oil spills. We could also identify one study that valued littering and marine noise (Östberg et al., 2013). These values could be linked to D10 Marine litter does not cause harm and perhaps D11 Introduction of energy (including underwater noise) does not adversely affect the marine environment. Thus, value estimates were available only for 6 descriptors of the 11 listed in the MSFD.

The HELCOM Baltic Sea Action Plan CORESET indicators (HELCOM 2013) are linked to three strategic goals: 1) Favourable conservation status of Baltic Sea biodiversity, 2) The Baltic Sea undisturbed by hazardous substances, and 3) The Baltic Sea unaffected by eutrophication, each of which is characterized further with ecological objectives. The HELCOM strategic goals and ecological objectives are to a certain extent comparable with the descriptors and criteria of the EU MSFD. The MSFD descriptors cover more issues than the BSAP, but the BSAP goals are broader and can include several MSFD descriptors. In addition, HELCOM has developed 20 core indicators for biodiversity, 13 for hazardous substances and 5 for eutrophication, which measure the distance of the state of the sea to the GES and HELCOM objectives.

In Table 6.1, the studies were linked to the BSAP strategic goals in as these goals correspond best to the precision level of the MSFD descriptors. For the BSAP goals, most studies were related to the biodiversity goal (six studies), followed by eutrophication (5) and hazardous substances (4). It is relevant to note that as there is no separate goal for fish species in the BSAP, these studies were classified to the biodiversity and 
the hazardous substances goals. For the biodiversity goal, studies could be linked to all ecological objectives, i.e. landscapes, communities of plants and animals and populations of species. Studies linked to hazardous substances were mainly related to oil, and there was one study on tributyltin (TBT). In many cases studies of reduced eutrophication used similar indicators to describe the eutrophication status as the BSAP ecological objectives, namely nutrient concentrations, water clarity, level of algal blooms, distribution and occurrence of plants and animal and oxygen levels. Thus, it is fairly straightforward to link the results to these eutrophication objectives.

\subsubsection{Critical issues in valuation}

Double-counting: Although the structure of ecosystem services is not always explicit in the valuation studies, there is, in most cases, no reason to suspect double-counting. The value estimates typically came from one study which valued either intermediate or final ecosystem services, but not both. The only study where double-counting might be a problem is Depellegrin \& Blažauskas (2013), in which the aggregate value estimates included both intermediate and final ecosystem services and goods (e.g. nutrient cycling and recreation). Therefore, double-counting of values is likely, and aggregate values may have been overestimated. Double-counting would also be a problem if the values estimated in different studies were summed together.

Marginal values: Most studies estimated marginal values, i.e. the values of changes in the marine environment and ecosystem services. Especially the choice experiment method is suitable for estimating marginal values for different-sized changes, as it describes the environmental characteristics using several levels. This allows assessing the possible nonlinearity of benefits, e.g. that marginal benefits decrease when the state of the environment improves.

Spatial explicitness: In the identified studies, there was typically a uniform improvement in the environmental quality in the study area, e.g. the reduction in eutrophication was expected to occur in the same degree everywhere. Exception of this are Ahtiainen et al. (2014), who defined the environmental conditions separately for each basin of the Baltic Sea, and Gren (2013) who separated between seven sea regions. Although it is simplifying to assume that the ecosystem will change identically throughout the study area, it might be too difficult to specify a very detailed spatial distribution for the change, especially if the study area is large. Despite 
the fact that spatial aspects have been uncommon in defining the environmental change, some studies took into account the spatial distribution of the benefits by including substitutes or distance to the marine area in modelling. Substitutes are especially relevant for use values such as recreation. When studies cover the entire Baltic Sea, relevant substitutes for marine recreation could be, for example, lakes and rivers, other sea areas or even forests.

Thresholds: Thresholds or sudden dramatic changes in the environmental system were not addressed in the valuation studies. This may stem from the difficulty of communicating these kinds of changes to the general public in an understandable manner. Also, there may be considerable uncertainty about possible environmental thresholds in the scientific community, hindering their inclusion in valuation studies. In one sense, nonlinearities were present in some valuation studies as there were several levels of environmental change that were specified nonlinearly. This enables estimation of potential nonlinearities in the value of benefits, but it does not provide information on the losses related to abrupt changes in the ecosystem. 
Table 15: Valuation studies, ecosystem services, indicators and critical issues

\begin{tabular}{|c|c|c|c|c|c|c|c|c|c|}
\hline Author(s) & Focus & Area & $\begin{array}{l}\text { Ecosystem services } \\
\text { (goods) }\end{array}$ & Double counting & $\begin{array}{l}\text { Marginal } \\
\text { values }\end{array}$ & Spatial issues & Thresholds & $\begin{array}{l}\text { GES descriptors in MSFD, pri- } \\
\text { mary descriptor(s) in bold }\end{array}$ & $\begin{array}{l}\text { BSAP goals (indica- } \\
\text { tors), primary goal(s) } \\
\text { in bold }\end{array}$ \\
\hline $\begin{array}{l}\text { Ahtiainen et al. } \\
\text { (2014) }\end{array}$ & $\begin{array}{l}\text { benefits of reduced eu- } \\
\text { trophication }\end{array}$ & $\begin{array}{l}\text { the Baltic Sea (interna- } \\
\text { tional, } 9 \text { countries) }\end{array}$ & $\begin{array}{l}\text { cultural (recreation, } \\
\text { non-use benefits) }\end{array}$ & no & yes & $\begin{array}{l}\text { improvement differs } \\
\text { between sub-basins, } \\
\text { subjective perception } \\
\text { of substitutes in- } \\
\text { cluded }\end{array}$ & not included & $\begin{array}{l}\text { D5. Eutrophication is mini- } \\
\text { mized, } \\
\text { D1. Biodiversity is maintained }\end{array}$ & $\begin{array}{l}\text { Eutrophication, } \\
\text { Biodiversity }\end{array}$ \\
\hline $\begin{array}{l}\text { Depellegrin and } \\
\text { Blažauskas (2013) }\end{array}$ & $\begin{array}{l}\text { value of biological and } \\
\text { socio-economic re- } \\
\text { sources and losses due to } \\
\text { oil spills }\end{array}$ & $\begin{array}{l}\text { Lithuanian coast, the } \\
\text { Baltic Sea (regional, } \\
\text { Lithuania) }\end{array}$ & $\begin{array}{l}\text { provisioning (food), } \\
\text { cultural (recreation, } \\
\text { non-use benefits) }\end{array}$ & $\begin{array}{l}\text { yes (value of in- } \\
\text { termediate and } \\
\text { final ES and } \\
\text { goods) }\end{array}$ & no & $\begin{array}{l}\text { spatially explicit, val- } \\
\text { ues for each grid cell }\end{array}$ & not included & $\begin{array}{l}\text { D8. Concentrations of contami- } \\
\text { nants give no effects }\end{array}$ & Hazardous substances \\
\hline $\begin{array}{l}\text { Carlsson, Kataria } \\
\text { and Lampi (2010) }\end{array}$ & $\begin{array}{l}\text { benefits from improved } \\
\text { marine environment (en- } \\
\text { dangered species, oil sur- } \\
\text { veillance, fishing jobs, } \\
\text { fish stocks) }\end{array}$ & $\begin{array}{l}\text { the Baltic Sea (national, } \\
\text { Sweden) }\end{array}$ & $\begin{array}{l}\text { provisioning and cul- } \\
\text { tural services (food, } \\
\text { recreation, non-use } \\
\text { benefits) }\end{array}$ & no & yes & $\begin{array}{l}\text { uniform improve- } \\
\text { ment in the study } \\
\text { area }\end{array}$ & not included & $\begin{array}{l}\text { D1. Biodiversity is maintained, } \\
\text { D3. The population of commer- } \\
\text { cial fish species is healthy }\end{array}$ & $\begin{array}{l}\text { Biodiversity, } \\
\text { Hazardous substances }\end{array}$ \\
\hline $\begin{array}{l}\text { Eggert and Ols- } \\
\text { son (2009) }\end{array}$ & $\begin{array}{l}\text { benefits of improved wa- } \\
\text { ter quality }\end{array}$ & $\begin{array}{l}\text { coastal waters of Skag- } \\
\text { errak and Kattegat (re- } \\
\text { gional, Sweden) }\end{array}$ & $\begin{array}{l}\text { provisioning and cul- } \\
\text { tural services (food, } \\
\text { recreation, non-use } \\
\text { benefits) }\end{array}$ & no & yes & $\begin{array}{l}\text { uniform improve- } \\
\text { ment in the study } \\
\text { area }\end{array}$ & not included & $\begin{array}{l}\text { D1. Biodiversity is maintained, } \\
\text { D3. The population of commer- } \\
\text { cial fish species is healthy }\end{array}$ & Biodiversity \\
\hline Gren (2013) & $\begin{array}{l}\text { Value of filtering of nutri- } \\
\text { ents in the coastal zone } \\
\text { in the Baltic }\end{array}$ & $\begin{array}{l}\text { The Baltic Sea, divided } \\
\text { into } 7 \text { sea regions (in- } \\
\text { ternational, } 9 \text { countries) }\end{array}$ & $\begin{array}{l}\text { regulating services } \\
\text { (eutrophication miti- } \\
\text { gation) }\end{array}$ & $\begin{array}{l}\text { no, but adding } \\
\text { this value to rec- } \\
\text { reation and ex- } \\
\text { istence values } \\
\text { would lead to } \\
\text { double counting }\end{array}$ & no & $\begin{array}{l}\text { coastal waters across } \\
\text { the Baltic Sea }\end{array}$ & not included & D5. Eutrophication is minimized & Eutrophication \\
\hline Kosenius (2010) & $\begin{array}{l}\text { benefits of reduced eu- } \\
\text { trophication }\end{array}$ & $\begin{array}{l}\text { the Gulf of Finland (na- } \\
\text { tional, Finland) }\end{array}$ & $\begin{array}{l}\text { cultural services (rec- } \\
\text { reation, non-use ben- } \\
\text { efits) }\end{array}$ & no & yes & $\begin{array}{l}\text { uniform improve- } \\
\text { ment in the study } \\
\text { area }\end{array}$ & not included & $\begin{array}{l}\text { D5. Eutrophication is mini- } \\
\text { mized, } \\
\text { D1. Biodiversity is maintained }\end{array}$ & $\begin{array}{l}\text { Eutrophication, } \\
\text { Biodiversity }\end{array}$ \\
\hline $\begin{array}{l}\text { Kosenius and Ol- } \\
\text { likainen (2015) }\end{array}$ & $\begin{array}{l}\text { benefits of changes in } \\
\text { coastal habitats (healthy } \\
\text { vegetation, pristine ar- } \\
\text { eas, fish stocks) }\end{array}$ & $\begin{array}{l}\text { Finnish-Swedish archi- } \\
\text { pelago and Lithuanian } \\
\text { coast (international, } 3 \\
\text { countries) }\end{array}$ & $\begin{array}{l}\text { provisioning and cul- } \\
\text { tural services (food, } \\
\text { recreation, non-use } \\
\text { benefits) }\end{array}$ & no & yes & $\begin{array}{l}\text { uniform improve- } \\
\text { ment in the study } \\
\text { area }\end{array}$ & not included & $\begin{array}{l}\text { D1. Biodiversity is maintained, } \\
\text { D3. The population of commer- } \\
\text { cial fish species is healthy, } \\
\text { D5. Eutrophication is minimized }\end{array}$ & $\begin{array}{l}\text { Eutrophication, } \\
\text { Biodiversity }\end{array}$ \\
\hline $\begin{array}{l}\text { Kulmala et al. } \\
\text { (2012) }\end{array}$ & $\begin{array}{l}\text { benefits of ecosystem } \\
\text { services provided by Bal- } \\
\text { tic salmon }\end{array}$ & $\begin{array}{l}\text { the Baltic Sea (interna- } \\
\text { tional, } 4 \text { countries) }\end{array}$ & $\begin{array}{l}\text { provisioning and cul- } \\
\text { tural services (food, } \\
\text { recreation) }\end{array}$ & no & no & $\begin{array}{l}\text { spatial issues not ad- } \\
\text { dressed }\end{array}$ & not included & $\begin{array}{l}\text { D1. Biodiversity is maintained, } \\
\text { D3. The population of commer- } \\
\text { cial fish species is healthy }\end{array}$ & Biodiversity \\
\hline
\end{tabular}




\begin{tabular}{|c|c|c|c|c|c|c|c|c|c|}
\hline Author(s) & Focus & Area & $\begin{array}{l}\text { Ecosystem services } \\
\text { (goods) }\end{array}$ & Double counting & $\begin{array}{l}\text { Marginal } \\
\text { values }\end{array}$ & Spatial issues & Thresholds & $\begin{array}{l}\text { GES descriptors in MSFD, pri- } \\
\text { mary descriptor(s) in bold }\end{array}$ & $\begin{array}{l}\text { BSAP goals (indica- } \\
\text { tors), primary goal(s) } \\
\text { in bold }\end{array}$ \\
\hline $\begin{array}{l}\text { Lewis et al. } \\
\text { (2013) }\end{array}$ & $\begin{array}{l}\text { values of marine cultural } \\
\text { ecosystem services (algal } \\
\text { blooms, species visibility } \\
\text { and population, fisheries } \\
\text { catch and profitability) }\end{array}$ & $\begin{array}{l}\text { Gdynia (regional, Po- } \\
\text { land) }\end{array}$ & $\begin{array}{l}\text { cultural services (rec- } \\
\text { reation, aesthetic } \\
\text { benefits, non-use } \\
\text { benefits) }\end{array}$ & no & yes & $\begin{array}{l}\text { no information on } \\
\text { spatial aspects }\end{array}$ & not included & $\begin{array}{l}\text { D1. Biodiversity is maintained, } \\
\text { D3. The population of commer- } \\
\text { cial fish species is healthy, } \\
\text { D5. Eutrophication is minimized }\end{array}$ & $\begin{array}{l}\text { Biodiversity, } \\
\text { Eutrophication }\end{array}$ \\
\hline Noring (2014) & $\begin{array}{l}\text { benefits from reducing } \\
\text { tributyltin (TBT) on the } \\
\text { ecosystem and species }\end{array}$ & $\begin{array}{l}\text { Swedish coast of the } \\
\text { Baltic Sea (regional, } \\
\text { Sweden) }\end{array}$ & $\begin{array}{l}\text { cultural services } \\
\text { (non-use benefits) }\end{array}$ & no & yes & $\begin{array}{l}\text { change presented on } \\
\text { maps }\end{array}$ & not included & $\begin{array}{l}\text { D1. Biodiversity is maintained } \\
\text { D8. Concentrations of contami- } \\
\text { nants give no effects }\end{array}$ & Biodiversity \\
\hline $\begin{array}{l}\text { Tegeback and } \\
\text { Hasselström } \\
\text { (2012) }\end{array}$ & $\begin{array}{l}\text { market and non-market } \\
\text { costs of oil spills (clean- } \\
\text { up, tourism, fisheries, en- } \\
\text { vironmental) }\end{array}$ & $\begin{array}{l}\text { three study areas on } \\
\text { the Swedish and Polish } \\
\text { coast (international } 2 \\
\text { countries) }\end{array}$ & $\begin{array}{l}\text { provisioning and cul- } \\
\text { tural services (food, } \\
\text { recreation, tourism) }\end{array}$ & no & no & $\begin{array}{l}\text { three oil spill scenar- } \\
\text { ios in different loca- } \\
\text { tions }\end{array}$ & not included & $\begin{array}{l}\text { D8. Concentrations of contami- } \\
\text { nants give no effects }\end{array}$ & Hazardous substances \\
\hline $\begin{array}{l}\text { Östberg et al. } \\
\text { (2013) }\end{array}$ & $\begin{array}{l}\text { benefits from improved } \\
\text { coastal environment (wa- } \\
\text { ter quality, cyanobacte- } \\
\text { rial blooms, noise, litter- } \\
\text { ing) }\end{array}$ & $\begin{array}{l}\text { the Eight Fjords area, } \\
\text { Skagerrak and Him- } \\
\text { merfjärden, the Baltic } \\
\text { Proper ( } 2 \text { regions in } \\
\text { Sweden) }\end{array}$ & $\begin{array}{l}\text { cultural services (rec- } \\
\text { reation, non-use ben- } \\
\text { efits) }\end{array}$ & no & Yes & $\begin{array}{l}\text { two study areas, uni- } \\
\text { form improvement }\end{array}$ & not included & $\begin{array}{l}\text { D5. Eutrophication is mini- } \\
\text { mized, } \\
\text { D10. Marine litter does not } \\
\text { cause harm, } \\
\text { D 11. Introduction of energy } \\
\text { (including underwater noise) } \\
\text { does not adversely affect the } \\
\text { marine environment }\end{array}$ & Eutrophication \\
\hline
\end{tabular}




\subsection{Concluding remarks and discussion}

Although there are several studies on the monetary benefits of changes in the Baltic Sea marine environment, the knowledge is somewhat fragmented. In most cases, it is straightforward to link existing valuation studies to the GES descriptors of the Marine Strategy Framework Directive and to the Baltic Sea Action Plan strategic goals. However, when these goals are defined further with ecological objectives and core indicators, the links are not that obvious. Thus the value estimates cannot typically be used to estimate e.g. the benefits of improving one of the BSAP core indicators.

The valuation studies are clearly concentrated on some descriptors of GES, namely D1 Biodiversity is maintained, D3. The population of commercial fish species is healthy and D5 Eutrophication is minimized. Some studies can also be linked to D8 Concentrations of contaminants give no effects, D10 Marine litter does not cause harm, and D11 Introduction of energy (including underwater noise) does not adversely affect the marine environment. Thus, value estimates are available only for six descriptors.

Especially descriptors D2 Non-indigenous species do not adversely alter the ecosystem and D9 Contaminants in seafood are below safe levels would require studies, as non-indigenous species and contaminants can have a direct effect on human welfare and identified economic valuation studies are very few. Descriptors D4 Elements of food webs ensure longterm abundance and reproduction, D6 The sea floor integrity ensures functioning of the ecosystem and D7 Permanent alteration of hydrographical conditions does not adversely affect the ecosystem are more likely to affect human well-being indirectly, and may thus be captured by studies focusing on other descriptors.

Related to D2 Non-indigenous species, Kataria (2007) estimated the costs and benefits of introducing signal crayfish in Sweden based on market prices, i.e. the benefits only included direct use values related to the species, and Gren et al. (2009) calculated the costs of 13 invasive species in Sweden. Thus, valuation studies of non-consumable invasive species outside Sweden are missing. For D9 Contaminants in seafood, in particular dioxins, the sources, effects, risks and cost-effective measures have been identified, but there seem to be no monetary estimates of the associated effects on human health. However, there are some risk assessments that use the benefit/risk ratio, which compares the benefits and health risks of consuming Baltic dioxin-rich fish (Assmuth \& Jalonen, 2005). 
It is not clear if the values can be used to estimate the benefits of reaching the MSFD or BSAP targets of good environmental status. If the environmental changes required by the MSFD or the BSAP differ substantially from those evaluated in the studies, it may be difficult to extrapolate the results to match the changes in the ecosystem required by the MSFD or the BSAP. Another challenge in using the results of valuation studies in assessing the benefits of the MSFD or the BSAP is that most studies are tied to a specific geographical location and context. This makes it challenging to estimate the aggregate benefits of reaching a good status with regard to a certain descriptor.

The situation is most promising for eutrophication and the benefits of its reduction. The benefits of reducing eutrophication have been studied at regional, national and international levels throughout the Baltic Sea, and the valued changes in the level of eutrophication correspond reasonably well with the target of reaching good environmental status with regard to eutrophication. For example, Ahtiainen et al. (2014) estimated the benefits of reducing eutrophication in the whole Baltic Sea area and all nine coastal countries, i.e. country-specific estimates of the value of reducing eutrophication are available. The environmental change corresponds rather well with the BSAP targets of reducing eutrophication, and could also be connected with the MSFD targets. Thus, there should be enough evidence for assessing the benefits of reaching the MSFD or BSAP targets in all coastal countries, and providing policy support with regard to eutrophication.

The studies do not consider the spatial distribution of ecosystem services and benefits. Based on existing knowledge, the construction of spatially explicit maps of ecosystem goods or benefits is impossible. Most studies reviewed do not present the spatial distribution of the benefits either in the marine environment or in the land area. Therefore, it is difficult to illustrate the valuation results using maps. An exception is the study by Depellegrin \& Blažauskas (2013), which divides the study area into 87 grid cells and presents values separately for each cell. However, as the study estimates total instead of marginal values and is likely to suffer from double-counting problems, the usability of the value estimates for policy support is questionable.

Thus, more emphasis needs to be given to the spatial aspects in valuation studies, both in terms of where the ecosystem services are located and where the benefits accrue. The existing ecological knowledge on the spatial distribution of ecosystem services should be used in valuation studies. It would also be interesting to identify so called marine and coastal "hotpots", which are locations that are very important to human 
well-being, for example, due to their extensive use. Despite some restrictions regarding spatially explicit benefit estimates, existing valuation results and benefit transfer could be used to point out some hotspots of values in the Baltic Sea area, e.g. for recreation or fisheries. This would be especially useful for marine spatial planning.

There are no value estimates of ecological thresholds, i.e. abrupt and dramatic changes in the ecosystem. Incorporating ecological threshold effects into valuation studies requires careful consideration of how to describe these effects, especially if there is ecological uncertainty about their occurrence. 


\section{Case study on seaside recrea- tion in Denmark and Sweden}

The Marecos case study is a pilot study for a larger valuation study, to be conducted in Sweden and Denmark. The main survey will assess the value of coastal recreation as an ecosystem service, and investigate how the value of this ES is affected by changes in water quality, litter, congestion and substitute recreational sites.

The method choice experiment is chosen for the pilot and subsequently also for the main survey, to allow for an analysis of how several attributes of the ecosystem service "recreation" influence the value of recreation. This method also allows for the assessment of marginal changes. By linking the stated preference method choice experiment and the travel costs as payment vehicle the choice situation is as close to reality as we can come, taking into consideration that the scenarios represent hypothetical changes of the ecosystem service provided.

In the case study focus is on highlighting the potentials and difficulties associated with the valuation of coastal recreation as an ecosystem service. Furthermore the focus is on presenting results regarding the preferences of Swedish and Danish populations for use of coastal areas for recreation, i.e. quantitative knowledge about this ecosystem service.

The chapter presents and discusses the pilot test results in terms of the descriptive statistics of attitudes to water quality and recreational habits among the sampled Swedish and Danish respondents. The willingness to pay estimates resulting from the pilot study are not presented here however because the survey design will be changed in the main survey.

The results from the pilot study indicate that Danes and Swedes generally seem to have a very positive perception of the water quality in coastal areas, and that they perceive coastal areas as important for their recreational choices. The results indicate similarities regarding the views on water quality, while the sample results indicate different habits in terms of how long the respondents travel for recreation. 


\subsection{Introduction}

The objective of the case study is to illustrate the potentials and difficulties of economic valuation of marine/coastal ecosystem services, and we have chosen coastal recreation as the case. Coastal recreation represents an ecosystem service which is believed to be of great importance in the marine and coastal areas of the Nordic countries, but yet studies focusing on assessment of this value are sparse.

As a means to fulfil the above mentioned objective the case study, focusing on assessment of the economic importance of the cultural ecosystem service "coastal recreation", has been carried out in Denmark and Sweden. Preparations have also started for carrying out a study in Finland. The design and the resulting experiences from these case studies are described and discussed in the present chapter, including descriptive statistics of respondents' recreational habits, perceptions and attitudes.

The value and choice of coastal recreation is site specific in the sense that it is expected to vary across sites, depending on a number of site characteristics such as for example access to the area (including parking lots), the environmental quality, the spatial location of the site, the travel distance to the site for potential visitors, the availability of substitute recreational sites in the area, services of different kind (restaurants, toilets, cafés etc.) and also the actual number of visitors. The natural and environmental characteristics include e.g. the physical appearance of the shore: beach, stonecoast, meadow or wetland, and the water quality, i.e. whether it is clear or turbid. While it is practically impossible to take all the potentially relevant factors into account in case studies as the ones conducted here, it is important to ensure that the most important factors are included.

Starting from our own hypotheses, partly built on literature, theory and own experiences, about what influences the recreational value of coastal areas and other water bodies, we used focus groups to determine which factors should be included in the valuation and ended up with five factors: water quality, crowding (many/few people visiting the site), litter, the availability of substitute recreational sites and the distance from where people live to the site. Based on the case studies it will be possible to test the hypothesis that the included factors are indeed important determinants of the recreational value of coastal areas, and it will also be possible to asses any potential differences in how much these factors influence the value of this ecosystem service. Since the study is conducted in both Sweden and Denmark it is also possible to assess the similarities and differences between the countries. 
There are good reasons for choosing coastal recreation as the ecosystem service to investigate further in this case study. In Denmark no valuation studies focusing on marine and coastal recreation have been conducted, and while studies have been conducted in Sweden there are still aspects believed to be important which have not been investigated, e.g. the interplay between recreational value and presence of litter at the coasts.

Some of the critical issues of economic valuation mentioned in the introduction to this report are addressed in practice in the case study, more specifically spatial explicitness and marginality. The questions of double counting problems, non-linearities of benefits and threshold effects are not addressed directly, but should be when linking the results to scenarios of changes in water quality. The critical issues mentioned are further explored in Chapter 6 "Literature study on the value of marine ecosystem services".

Due to limited project resources the original intention of the Marecos case study was primarily to set up a design for valuation of ecosystem services, and subsequently test this in focus groups. Since the pilot has been submitted and the data are analysed it is possible to report the part of the pilot that cover the respondents' use of different recreational sites and their preferences regarding where to go for recreation etc. Based on the pilot results the design of the main study has changed, in order to better address the complex issues of this valuation problem. This implies that it is not yet possible to present results in terms of willingness to pay estimates for good water quality, reduced littering and crowding.

This chapter presents how a valuation study to elicit a value of the ecosystem service coastal recreation may be designed. Also, descriptive statistics are presented in terms of i) how respondents in the two countries use the coastal areas for recreation, and ii) how important these coastal areas are compared to potential substitutes.

\subsection{About the survey}

The survey is described presenting the structure and main questions, the sampling procedure and the choice experiment used to elicit the willingness to pay for the different ecosystem service characteristics. 


\subsubsection{The structure of the survey and the main questions in the questionnaire}

The questionnaire is included in Appendix 1 of this report (in English, but the respondents received the questionnaire in Danish and Swedish). The questionnaire is structured by the following sections with a number of questions in each section:

- Socio-economic facts about the respondents (age, sex, family size, education level, income, address etc.)

- The respondents' visits to different types of nature areas:
a. sea/coast,
b. forest,
c. nature areas

- Information about respondents' last trip to a coast, forest or nature area
a. Type of area (coast, forest, nature area)
b. Where did the trip start?
c. Location of recreation site?
d. Distance to site?
e. Time spent to get to the site?
f. Activities on site?

i. Go for a walk

ii. Walk the dog,

iii. Sunbathing,

iv. Swimming,

v. Bicycling,

vi. Boating,

vii. Fishing etc.

g. Characteristics of the site

viii.Water quality/clarity

ix. Crowded or not

$\mathrm{x}$. Litter or not

h. Mode of transportation to get to the site?

- Presentation of choice situations (the choice experiment, which include eight choice situations in total). Each choice situation contains three trip alternatives and a no-trip alternative, in order 
not to force respondents to choose a trip, they would never consider making in reality. Each trip alternative was described by four attributes including a cost attribute.

- Questions about respondents' perceptions of the CE, i.e. the weight attached to the different attributes when making the choices, and how the respondents perceived the eight choice situations (easy difficult)

- Question about if the respondents believe it is possible to attain good environmental quality in Danish/Swedish waters.

\subsubsection{Sampling procedure and region}

The pilot survey was carried out in August 2014 for Denmark and in December 2014 for Sweden. The survey institute Userneeds was responsible for administering the survey which was conducted as an online survey among members of Userneeds web panel.

When sampling a survey it is important to select the target population, i.e. who (individuals, households, visitors of the areas), the territory (whole country or part of country) and also decide on a suitable sample size.

It was decided that travel choice is an individual choice and that individuals should be asked instead of households.

The sampling territory is Zealand in Denmark and the region of SouthWestern Sweden. In South-Western Sweden the sampling area is the counties: Hallands län, Skåne län and Västra Götalands län, with a distribution between these of 9:40:51, which corresponds to the distribution of the population in these regions.

In Denmark the whole island of Zealand constitutes the sampling area, and a representative sampling between Copenhagen (the capital) and the areas outside the capital area has been assured. The blue area on the map is the catchment area in Sweden loading to Kattegat and Skagerrak.

The region is chosen because of the respondents' vicinity to the common marine area Kattegat and Øresund.

The sample size in each country was set to 300 respondents for budgetary reasons. In the main survey 1000 responses will be collected for each country. 300-500 responses can be regarded as a medium sized sample, while 1,000 responses constitute a large sample that will be well suited to meet the statistical requirements. 


\subsubsection{The design of the choice experiment}

The non-market valuation method choice experiments (CE) belong to the group of stated preferences methods (see e.g. Freeman et al, 2003; Bateman et al 2002; Hanley et al. 2006). Using CE, value estimates are obtained from analysis of data pertaining to respondents' repeated choices between alternatives. The alternatives differ with respect to the levels of attributes characterizing the good/service as well as a cost attribute. The alternatives and choice sets are designed in a way that ensures that the willingness to pay (WTP) for the different attributes can be derived from the choices made by the respondents.

The most important advantage of CE, compared e.g. to the contingent valuation (CV) method, is that a $\mathrm{CV}$-study estimates the total value of a scenario change for a good or service, while the CE can be used to value both the total value and the marginal value of each of the attributes. Therefore the use of CE meets the described challenge of valuing marginal changes by making it possible to assess WTP for the individual attributes and thereby gaining insights not only into peoples' preferences for the collective good but also into the relative importance of the different attributes. Furthermore, the method provides much more information from each respondent, because the respondents are asked to answer a number of choice situations providing data from each of these choices. Disadvantages of the method are that it is sometimes demanding for the respondents in terms of the amount of information that needs to be processed, and it is also relatively more costly to implement than ordinary $\mathrm{CVs}$ as greater samples are usually required.

In the case of valuing marine and costal recreation in Denmark and Sweden the choice of using CE is motivated by the fact that the choice of recreational site is expected to be affected by several factors referred to as "attributes" in CE. Hence, solely focusing on one aspect would only provide a partial picture of how people make their recreational choices, and the results would only provide results pertaining to "all else equal" scenarios. By using the CE method it is possible to investigate the effect of simultaneously varying several attributes, implying that the results can be used to predict the value of a whole range of different scenarios. In the present study the following attributes are investigated in terms of their impact on respondents' WTP for recreation:

- What is the importance of good water quality for the choices respondents make when they engage in coastal recreation?

- What does the amount of litter at recreational sites mean for the recreational choices made by respondents? 
- What does the number of visitors to a recreational site mean for the choices made by respondents?

- What is the value of a substitute trip to the respondents, i.e. "forest trip" as a substitute to "coastal trip"?

Determining the optimal number of attributes, attribute levels, alternatives and choice sets is a trade-off between statistical considerations and considerations of respondents' cognitive capabilities. Likewise, determining how attributes and their levels are to be defined, also contains inherent trade-offs between providing sufficient, and sufficiently unambiguous, information about the good being valued and respondents cognitive capacity. There are a number of studies testing the effects of few contra many choice sets to define the "optimal design size" and amount of information, but no precise guidance can be given as this also depend on the problem assessed.

\subsubsection{Attributes in the choice experiment}

Four attributes were defined for the choice experiment; water quality, litter, visitors and transport distance. The attributes and their levels are described in Table 16, which is identical to the table included in the questionnaire to inform respondents' about the attributes. As already mentioned, each choice set consisted of three trip alternatives and a no-trip option, in order to avoid the risk of respondents feeling forced to choose a trip they might not want to make. In Table 17 an example of a choice set is presented. 
Table 16: Description of the trip characteristics

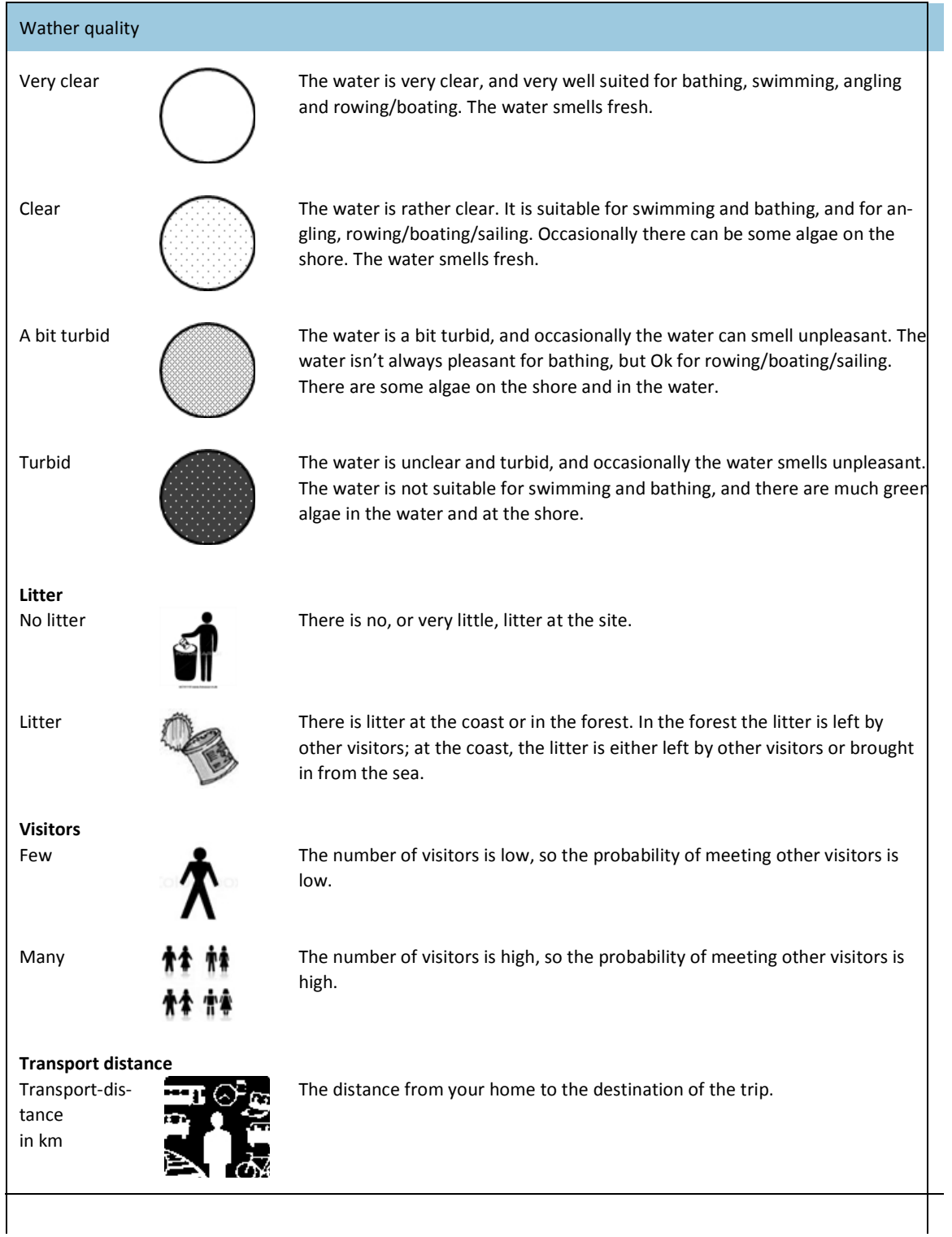




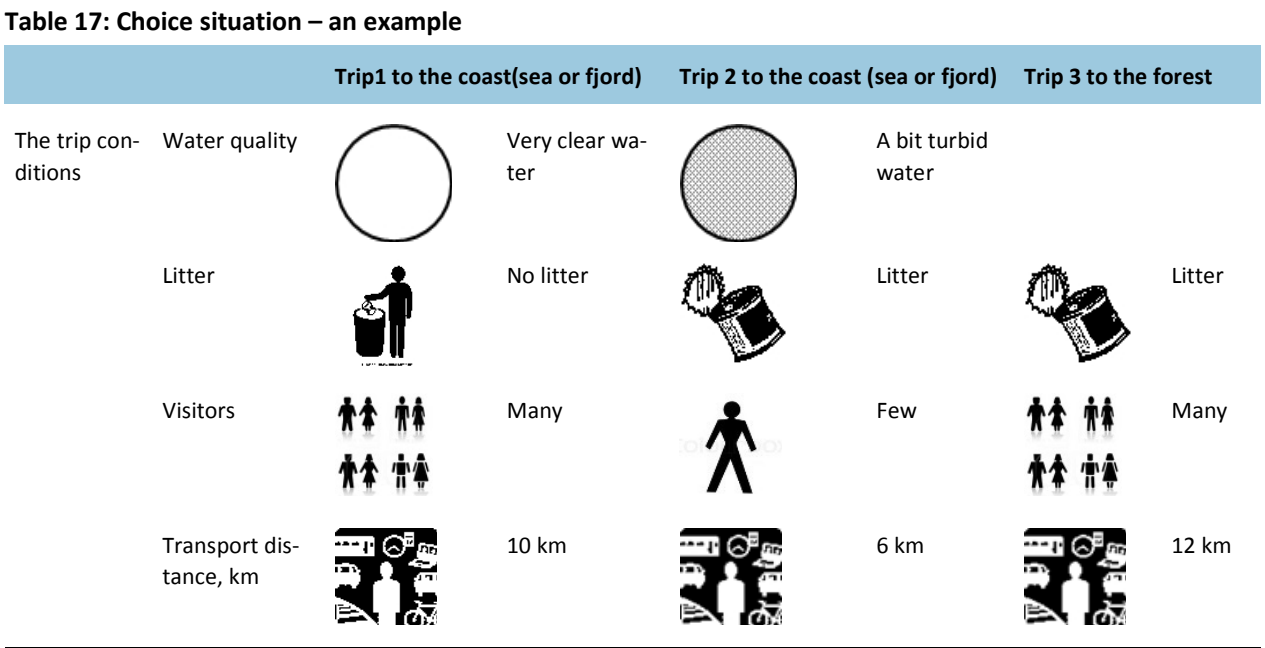

The choice of which attributes to include in the CE was made with the purpose that choice situations should reflect the conditions respondents immediately perceive when visiting a forest or a coastal area, and that they should represent some of the factors believed to be most important in relation to respondents' choice of recreational site. The attributes used in the study are therefore not directly related to non-use values, such as wildlife in the sea, which are often considered important when dealing with the value of coastal ecosystems. Instead, focus is on readily observable characteristics that are expected to influence respondents' recreational habits. As high water quality may often be correlated with good conditions for biodiversity, it may however be noted, that a management strategy based on increasing recreational use values based on peoples preferences for improved water quality indirectly may serve to also increase the non-use values provided by coastal areas.

\section{Water quality}

The water quality attribute is included to enable assessment of the effect of improved water quality on the recreational value of coastal areas. The attribute is characterized by four discrete levels of water clarity. Water quality can be defined in many ways and can be described by a number of different indicators. In relation to a CE, however, it is important to keep it as simple as possible, and therefore it was decided to use water clarity as the prime indicator of water quality. Hence, water clarity is expected to be the most immediate and readily observable indicator of water quality in relation to recreational use. In the attribute descriptions included in the questionnaire prior to the choice sets (see Table 17) the properties of the 
four different water clarity classes are described in terms of the associated suitability of the water for different water based activities, smell and presence of algae.

\section{Substitute - trip to forest}

Adding a substitute to the valuation is recommendable to adequately represent a realistic supply of recreational possibilities for the respondent (see e.g. Hanley et al. 2000). How such a substitute should be defined may vary depending on what the specific substitutes are in an area as well as on the purpose of the study. The prime focus here is on investigating how the people choose between coastal recreational sites with different characteristics. It is important to acknowledge that the availability of substitutes may affect the decision process in different ways/at different levels. Hence it may not be sufficient to look at substitution between sites within the same nature type.

The decision process related to recreational choices may thus involve consideration of substitutes at several levels:

- choice between nature based recreational activities or non-nature based recreational activities,

- choice between different nature types, and

- choice between different destinations within the same category of nature types.

How the consideration of substitutes affects the choice of an individual will depend on his/her preferences - as an example, some individuals may know from the outset that they will only consider going to forests, while others are open to other destination types.

The design of the CE used in the present survey allows for all three types of substitution listed above by including the no-trip alternative in each choice set respondents are allowed to substitute between naturebased recreational activities and non-nature based recreational activities. Substitution between different types of nature areas are incorporated in the design by the inclusion of a forest alternative.

It can be argued that other types of nature areas should also be included, and that including different kinds of substitutes may be necessary in a study that includes more than one country.

The reason for choosing forest as the substitute option is that a number of Danish surveys have shown that the nature area most often visited by Danish people are forests (Bjørner et al., 2014; Jensen, 2012). Hence, 
forests are considered to be the most relevant substitute in terms of nature type in Denmark.

Finally, the substitution between different sites within the same nature type is accommodated for by the inclusion of two alternatives representing trips to the coast.

In terms of how to define the nature type substitute, i.e. the forest alternative, results from focus group testing indicated that the forest alternative should be as similar as possible compared to the two coast trip alternatives. Thus water quality is the only attribute which is specific for coastal recreation; the other two qualitative attributes are common for all three trip alternatives. By the inclusion of the forest substitute it was expected that it would be possible to get a more realistic picture of the willingness to pay for coastal recreation, since it implied that a respondents' choice was not a choice between going to the coast or staying at home, which may have induced some respondents to choose a trip that was in fact not very attractive to them, because that was the only option to staying at home.

\section{Litter}

The litter attribute is common for all three trip alternatives. For the coast alternatives it was discussed if a distinction should be made between litter left by beach visitors and marine litter and oil spill. In order to keep the CE as simple as possible, however, it was hypothesized that people are probably more concerned about the amount of litter than the source of the litter. Also, not making a distinction between the sources of the litter for the coast alternatives implied that it was unnecessary to operate with separate definitions of the litter attribute for the coast and forest alternatives. It is though mentioned in the attribute description that there may be different sources of the litter. The attribute is described by two discrete levels; no litter (or very little litter) and litter.

\section{Number of visitors}

Congestion is widely accepted as having an important impact on the value associated with nature based recreation. Hence, even though it is not directly related to the environmental quality of the forest or the coast it may play an important role in relation to the recreational decisions made by respondents. The number of visitor attribute can take two discrete levels - few and many. Again these definitions are not purely objective in the sense that "many visitors" is perceived identically by all respondents. 


\section{Cost attribute}

The cost associated with the trip alternatives was not specified in monetary terms but in terms of the distance from the respondents' home to the trip destination. In order to calculate WTP's for the attributes water clarity, litter and congestion, a cost attribute should be used. The distances are used in this CE, converting the distances into monetary amounts based on the costs of the time spent travelling and other associated costs of transportation. The time spent is calculated as the opportunity cost of time.9 The reason for choosing this approach rather than the standard approach of a monetary cost was this method made the scenarios similar to the situations respondents' face in reality when deciding where to go on recreational trips. Hence, respondents were expected to be more familiar with making tradeoffs between transport distances and site characteristics, than between specific monetary amounts and site characteristics.

Nunes et al. (2015) used a similar cost attribute in a stated-choice questionnaire to estimate the amount of time respondents would be willing to add to their journey in order to reduce the risk of encountering jellyfish blooms in the Catalan coast. The time was calculated as the reported extra travel time, and the cost was estimated using the opportunity cost of time.

The cost attribute used in the survey was constructed using eight different levels representing increases in the distance between the home of the respondents and the nearest coast (for the two coast alternatives) and nearest forest (for the forest alternative). The levels included were 25\%, $50 \%, 75 \%, 100 \%, 125 \%, 150 \%, 150 \%$ and $200 \%$.

The choice sets used for the pilot were designed using the software Ngene, and consisted of a total of 32 choice sets divided into four blocks. This means that each respondent answered eight choice sets, and that there were in total four different combinations of choice sets, randomly distributed among the respondent sample.

${ }^{9}$ The costs are estimated using the prices from DTU Transport (2013), used for transport-economic assessments in Denmark. 


\subsection{Implementation of the Danish case study}

\subsubsection{Focus group testing in Denmark}

After designing the questionnaire, it was tested in three focus group meetings in the Copenhagen area. The participants of the meetings were recruited from the general public (19-75 years) of Denmark, and 3-5 people participated in each focus group. One of the main purposes of the Danish focus groups was to learn about respondents' habits in relation to coastal recreation, and therefore the discussion was about the kind of activities people engage in when visiting the coast, and what their motives for visiting coastal areas are. Hence, it is important that the choice sets reflect the conditions regarded as important by the respondents (Hanley et al., 2001).

Another purpose was to test participants' understanding of the choice sets as this provides important input for determining if the included attributes, and their levels, are relevant and perceived correctly by respondents. Following the focus group testing, several changes were made to the questionnaire. Some participants found the choice sets a little complicated, and it was therefore decided to include an example of a choice situation, before the respondents were asked to answer the eight choice situations (see Table 17 above). Another thing added to the questionnaire after focus group testing was the table including trip characteristics (see Table 16 above).

The focus group test supported the choice of using distance as a proxy for costs. The participants found it both easier and more realistic to relate to how far they were willing to travel compared to how much money they were willing to pay in order to get to a given nature area.

\subsubsection{Pilot testing in Denmark}

Following the revisions made based on the focus group testing the questionnaire was ready for the pilot testing, which forms the basis for the results presented in this report. This pilot survey was distributed by the survey institute Userneeds in August 2014 as an online survey using their web panels. There were in total 300 respondents (19-75 years of age), of which 75 responded to each of four different blocks of the choice sets. Geographically, the questionnaire was sent to respondents in Zealand (Sjælland), including the capital area Copenhagen. The sampling approach was designed to ensure a representative distribution of respondents between 
the capital area and the rest of Zealand. The main survey is scheduled to be launched late 2015 .

\subsection{Results from the Danish case study}

As mentioned above, 300 respondents, evenly distributed across the four blocks, completed the questionnaire. Inspection of the data revealed that 10 respondents had provided invalid answers to the questions regarding distance from their home to the nearest forest and/or coast. ${ }^{10}$ These 10 respondents were excluded from the data set, since valid answers to these distance-questions are necessary for subsequently being able to calculate respondent specific levels of the distance attributes in the choice sets. Failure to provide valid answers to these questions disqualifies respondents from entering the analysis. In addition to this, two more respondents were excluded from the sample; one because he was found to live outside the sampling area, and one due to how he answered the debriefing questions following the choice exercise. The excluded respondent was one of the six respondents who in all choice sets had chosen the no-trip alternative, and the reason he was excluded was that his stated reason for doing so was that he found the exercise boring, thus indicating that his choices did not reflect his preferences for the trips but rather his opinion about the survey. In total 12 respondents were excluded resulting in an effective sample of 288 respondents.

\subsubsection{Descriptive statistics}

It is investigated if the effective sample is representative of the population in the sampling area in terms of gender, age, education and income. It is found that the sample is representative of the population in terms of gender and age, but not in terms of education and income. Hence, there is found to be an over-representation of people with a high level of education in the sample and a corresponding under-representation of people with a low level of education. The same goes for income, as people with high incomes are overrepresented in the sample, while people with low incomes are underrepresented.

In the first part of the questionnaire respondents were asked a range of question regarding their most recent visits to nature areas in general,

10 The invalid responses were that they were not numerical. 
and forests and coasts in particular. ${ }^{11}$ Questions were included for example regarding which activities respondents engaged in during their visit, how they got to the sites, how far they travelled to get to the site, if there were many other visitors, if there was litter and if they went alone or together with others. Below the distribution of respondents' answers to some of the questions about their last visit to forests and coastal areas is presented, thereby providing a context for interpretation of the findings from the case study.

One of the first questions included in the questionnaire related to the type of nature area that the respondents visited during their most recent visit to a nature area. The answers to the question are depicted in Table 16 , which shows that $49 \%$ of the respondents visited coastal areas, and $40 \%$ visited forests. Other studies of the recreational habits of Danes have found forest to be the most frequently visited nature type. This difference can possibly be explained by the fact that the survey was conducted in August, after a hot summer. It is reasonable to expect a high share of coastal visits if the weather conditions during the summer are good. Had the survey been conducted in winter time the distribution between forests and coastal areas would possibly have been different.

Table 18: Type of nature area visited most recently ( $N=288)$

\begin{tabular}{lrr} 
& No of respondents & Percent of respondents \\
Forest & 115 & 39.9 \\
Lake or river/stream & 53 & 18.4 \\
Beach/Coast & 142 & 49.3 \\
Park & 63 & 21.9 \\
Other area & 17 & 5.9 \\
Total & & 135.4 \\
\hline
\end{tabular}

Note: Sums to more than 100 percent since respondents were allowed to mark more than one type of area.

In terms of activities, walking is the most frequently mentioned activity for both forest and coastal visits - the most common activity in $75 \%$ of the most recent forest visits, and in $47 \%$ of the most recent visits to coastal areas.

\footnotetext{
${ }^{11}$ In relation to the results pertaining to the questions regarding most recent visit to forests and coastal areas it should be noted that some of these have only been answered by a share of the respondents. Hence, some of the questions related to most recent forest visits have only been answered by the 173 respondents who did not visit a forest during their last visit to a nature area; the specifics regarding these respondents' most recent visit to a forest are instead recorded under the answers to the questions pertaining to their most recent visit to a nature area. The same goes for some of the questions regarding respondents' most recent visit to a coastal area; here the number of respondents having answered the questions specifically related to most recent visit to a coastal area is 14 .
} 
For coastal areas, the second and third most popular activities mentioned are "Swimming/bathing/sunbathing" (40\%) and "Relaxing" (36\%). For forests, the second most popular activity is "Relaxing" (30\%), and "Walking the dog" and "bike-riding" share the third place by each being mentioned by $9 \%$ of respondents answering the question. ${ }^{12}$ For visits to nature areas in general, the three most common activities on the respondents' most recent recreational trip were: 1) walking (55\%), 2) experiencing nature (39\%) and 3) relaxing (38\%).

In Table 19 below the results regarding the means of transport used on the most recent visit to nature areas, forests and coastal areas are presented. For forests and coastal areas several means of transport could be marked, implying that the total can exceed $100 \%$. The table shows that car and walking are the most commonly used means of transport in relation to the respondents' last visit to a nature area "in general". Car is the most popular means of transport for the data pertaining to most recent visits to forests and coastal areas. Assuming that the most recently visited area also represents the most frequently visited nature area, it makes sense that the share of respondents going by foot is relatively high, since it suggests that the most frequently visited areas are close to respondents homes. This observation of a link between distance and frequency of use may be important to keep in mind. It is important to find out if improvements of the recreational characteristics of a given site will result in increased number of visits or increased level of utility experienced by current visitors.

Table 19: Means of transport for the most recent visits to nature areas (percent)

\begin{tabular}{l|rrr} 
Means of transport & Nature areas $(\mathbf{N}=\mathbf{2 8 8})$ & Forests $(\mathbf{N}=\mathbf{1 7 3})$ & Coastal areas $(\mathbf{N}=\mathbf{1 4 6})$ \\
Train/bus/S-train & 3 & 13 & 11 \\
Car & 37 & 49 & 53 \\
Bike & 20 & 16 & 21 \\
By foot & 38 & 26 & 20 \\
Other & 1 & - & - \\
\hline
\end{tabular}

Respondents were also asked, if they went alone or together with others on their most recent trip to a nature area. $32 \%$ stated that they went alone and the remaining $68 \%$ stated to have been together with others.

As mentioned, a hypothesis of the valuation study is that the choice of recreation sites is affected not only by the water quality and the distance

12 Note that respondents could mark more than one activity, and that the percentages therefore can add to more than 100 . 
to the site, but also from the amount of litter and congestion at nature sites. Given this, it was considered relevant to know if respondents have experienced congestion and/or the presence of litter at the coasts and forests they most recently visited. Table 20 presents the results from the question regarding litter. Results from the question about number of other visitors are presented in Table 21 . Altogether, the results indicate that litter and, in particular, congestion might constitute a bigger problem in coastal areas than in forests.

Table 20: The presence of litter during respondents' most recent visit to forest and coastal areas

\begin{tabular}{lrr} 
& $\begin{array}{r}\text { Forest } \\
\text { (Percent; N=288) }\end{array}$ & $\begin{array}{r}\text { Coastal area } \\
\text { (Percent; N=288) }\end{array}$ \\
There was no litter in the forest/at the coast & 55.9 & 41.7 \\
There was some litter in the forest/at the coast & 28.8 & 47.9 \\
There was a lot of litter in the forest/at the coast & 2.4 & 4.2 \\
Don't know & 12.8 & 6.3 \\
Total & 100.0 & 100.0 \\
\hline
\end{tabular}

Table 21: Respondents' perceptions of congestion on the most recent visit to forest and coastal areas

\begin{tabular}{lrr} 
& Forests (Percent; N=288) & Coastal areas (Percent; N=288) \\
\hline There were no other visitors & & 2.8 \\
There were some other visitors & 14.6 & 50.0 \\
There were many other visitors & 64.2 & 45.5 \\
Don't know & 17.0 & 1.7 \\
Total & 4.2 & 100.0 \\
\hline
\end{tabular}

Respondents were asked two different questions regarding their perception of the water on their most recent visit to the coast. First, they were asked to judge the state of the water in terms of the four quality classes that are subsequently to be used in the CE. Second, they were asked to specify if they believed the water to be of good or poor quality, or somewhere in between. The distribution of answers to the two water quality related questions are presented in Tables 22 and 23 below. The tables show that respondents generally seem to have a very positive perception of the water, i.e. more than $90 \%$ of the respondents describe the water as being either clear or very clear, and $70 \%$ believe that the water quality is good. 
Table 22: Respondents' perceptions of the water during their most recent visit to a coastal area

Q 43 - How would you describe the water at your last visit to the coast?
The water is very clear, and very well suited for bathing, swim-
ming, angling and rowing/boating. The water smells fresh.
The water is rather clear. It is suitable for swimming and bathing,
and for angling, rowing/boating/sailing. Occasionally there can be
some algae on the shore. The water smells fresh.
The water is a bit turbid, and occasionally the water can smell un-
pleasant. The water isn't always pleasant for bathing, but Ok for
rowing/boating/sailing. There are some algae on the shore and in
the water.
The water is unclear and turbid, and occasionally the water smells
unpleasant. The water is not suitable for swimming and bathing,
and there are much green algae in the water and at the shore.
Total

Table 23: Respondents' perceptions of the water quality during their most recent visit to a coastal area

\begin{tabular}{|c|c|c|}
\hline \multicolumn{3}{|c|}{ Q 44 - How would you describe the water quality? } \\
\hline & No. Of respondents & Percent $(\mathrm{N}=\mathbf{2 8 8})$ \\
\hline Good quality & 203 & 70.5 \\
\hline Neither good nor bad quality & 75 & 26.0 \\
\hline Poor quality & 10 & 3.5 \\
\hline Total & 288 & 100.0 \\
\hline
\end{tabular}

Respondents were also asked to state the distance between: 1) their home and the nearest forest and coast, and 2) their home and the most frequently visited forest and coast. The answers are presented in Table 24 below. It may be noted, that the maximum distances to both the forest and coastal areas visited most frequently are quite high. It can be expected that part of the explanation may be that the respondents stating these long distances might primarily visit forests/coastal areas when on vacation in e.g. their summer cottages. 
Table 24: Distances between respondents' homes and forests and coastal areas visited

\begin{tabular}{lrr} 
& Mean distance (km) & Max. distance (km) \\
Nearest coast $(\mathrm{N}=288)$ & 7.9 & 80 \\
Coast visited most frequently ${ }^{*}(\mathrm{~N}=145)$ & 15.2 & 116 \\
Nearest forest $(\mathrm{N}=288)$ & 5.3 & 33 \\
Forest visited most frequently** $(\mathrm{N}=164)$ & 14.1 & 171 \\
\hline
\end{tabular}

* 1 respondent reporting a distance above $250 \mathrm{~km}$ has been deleted.

** 3 respondents providing non-numerical answers, and 6 respondents reporting distances above $250 \mathrm{~km}$, have been deleted.

To get information about the level of participation in forest and coastal recreation respondents were asked to state how many trips they make per year to forest and coastal areas. For forests, the mean number of annual visits is 24 , and the minimum and maximum number of trips is 0 and 400 , respectively. For coastal visits, the corresponding numbers are 28,0 and 365. Hence, the number of annual trips to the two different types of areas varies significantly across respondents. Also, it is interesting to see that the mean number of trips is quite similar for the two types of recreational areas.

\subsection{Implementation of the Swedish case study}

\subsubsection{Focus group testing in Sweden}

The Swedish focus group testing was carried out a few months after the Danish, i.e. one focus group meeting was undertaken in Gothenburg in September 2014. Five people participated in a two-hour long meeting focusing primarily on the choice set part of the questionnaire. Since three focus groups had already been held in Denmark the need for further testing was limited, but still needed. In general the participants had a good understanding of the questionnaire but still some comments and suggestions. One example of this is the question whether there were any litter and visitors on site. Some members of the focus group suggested that the question was rephrased like "did you see any litter/other visitors" since there might have been litter/other visitors on site, but the respondents did not see this. 


\subsubsection{Pilot testing in Sweden}

After some minor revisions and translation of the questionnaire to Swedish, the pilot test was carried out in December 2014.

\subsection{Results from the Swedish case study}

The data set for Sweden contained responses from 301 respondents. Of these, five respondents did not provide useable answers for the two distance questions (i.e. distance to nearest forest and distance to nearest coast) and therefore these five respondents were excluded from the data set. Inspection of the answers to the debriefing questions, which followed the choice experiment did not reveal any invalid answers, hence no respondents had to be excluded on this account. The effective sample for the Swedish survey after this data cleaning consists of 296 respondents.

\subsubsection{Descriptive statistics}

It is investigated if the sample is representative of the population in the sampling area in terms of gender, age, education and income. It is found that the sample is representative in terms of gender and income, and that there is a slight overrepresentation of older people and very highly educated people ( $>5$ years).

As mentioned the respondents are asked a number of questions about their most frequent recreational destinations, as well as about the most recent trip. The allocation between the types of activities at the most recent trip gives a picture of the preferences for different activities, but the distribution between activities might of course change with season.

Just like the Danish sample, the three most common recreational activities of the Swedish sample during the last recreational trip were:

1) walking (65\%)

2) experiencing nature (46\%)

3) relaxing (33\%).

Other important activities of the Swedish sample were running/exercising $(16 \%)$ and walking the dog $(17 \%)$.

During forest visits the top three activities were: walking (68\%), relaxing (31\%) and running/exercising (11\%). The corresponding top 
three coastal activities were: walking (56\%), relaxing (37\%) and swimming/bathing/sunbathing (33\%).

Since we have sampled in counties with areas very far from the coast, it is necessary to pay attention to how far from the coast/forest the respondents live. The maximum distance from the respondents' home to the nearest forest is $50 \mathrm{~km}$, and the maximum distance to the nearest coast is $310 \mathrm{~km}$ for the Swedish sample. We have restricted the sample to respondents living within a distance of $100 \mathrm{~km}$ from the coast. Our reasoning is that travelling more than $200 \mathrm{~km}$ (both ways) for a daytrip is not realistic. Such trips should more likely be considered as holiday/weekend trips, which are different from the recreational trips we are interested in here. Thirteen respondents live more than $100 \mathrm{~km}$ from the coast and these respondents are therefore removed from the sample. These considerations of distance will be scrutinized before submission of the main survey.

The effective Swedish sample is therefore reduced to 283 respondents.

Table 25: Type of nature area visited most recently $(\mathrm{N}=\mathbf{2 8 3})$

\begin{tabular}{lrr} 
& No of respondents & Percent of respondents (N=283) \\
Forest & 169 & 59.7 \\
Lake or river/stream & 44 & 15.5 \\
Beach/coast & 96 & 33.9 \\
Park & 69 & 24.4 \\
Other area & 4 & 1.4 \\
Total & 382 & 135.0 \\
\hline
\end{tabular}

Note: Sums to more than 100 percent since respondents were allowed to mark more than one type of area.

The Table 26 below shows the results regarding the means of transport for visiting nature areas, forests and coastal areas. As for forests and coastal areas several means of transport could be marked, which implies that the total can exceed $100 \%$. Table 26 shows that car and walking are the most commonly used means of transport in relation to the respondents' last visit to a nature area "in general". Car is the most popular means of transport used for the most recent visits to forests and coastal areas. This pattern is similar to the Danish sample. Further, it may be noted that the share of respondents going by foot is relatively high for forests and nature areas. This can probably be explained by the fact that these areas are often situated closer to the homes of the respondents than the coastal areas. 
Table 26: Means of transport in connection with recent visits to nature areas (percent)

\begin{tabular}{lrrr} 
Means of transport & Nature areas $\mathbf{( N = 2 8 3 )}$ & Forests $(\mathbf{N}=\mathbf{1 1 4})$ & Coastal areas $(\mathbf{N}=\mathbf{1 8 7})$ \\
Train/bus/S-train & 4 & 4 & 10 \\
Car & 45 & 59 & 65 \\
Bike & 6 & 7 & 13 \\
By foot & 44 & 31 & 14 \\
Other & 1 & - & - \\
\hline
\end{tabular}

The Swedish respondents were also asked if they went alone or together with others on their most recent trip to a nature area. $41 \%$ answered that they went alone, and the remaining $59 \%$ answered to have been together with others.

Table 27 shows that around half of the sample (56.5\%) stated that there was some litter on the beach. $58.7 \%$ answered that there was no litter in the forest. $6.4 \%$ answered that there was a lot of litter on the beach, while only $1.8 \%$ found that there was a lot of litter in the forest. Litter therefore seems to be a larger problem in the coastal areas than in forests.

\begin{tabular}{|c|c|c|}
\hline & $\begin{array}{r}\text { Forest (Percent; } \\
\mathrm{N}=\mathbf{2 8 3})\end{array}$ & $\begin{array}{r}\text { Coastal area (Percent } \\
\mathrm{N}=\mathbf{2 8 3}\end{array}$ \\
\hline There was no litter in the forest/at the coast & 58.7 & 32.9 \\
\hline There was some litter in the forest/at the coast & 35.0 & 56.5 \\
\hline There was a lot of litter in the forest/at the coast & 1.8 & 6.4 \\
\hline Don't know & 4.6 & 4.2 \\
\hline Total & 100.0 & 100.0 \\
\hline
\end{tabular}

Similarly, $28 \%$ answered that there were no other visitors in the forests, while $11 \%$ gave this answer for the coastal areas. Moreover, $13.4 \%$ found that there were many visitors in the forests (coastal areas). The answers do not reveal if the respondents find this pattern problematic or not, but simply indicate that congestion is more common on beaches and coastal areas compared to the forests. 
Table 28: Respondents' perceptions of congestion on the most recent visit to forest and coastal areas

\begin{tabular}{lrr} 
& Forests (Percent; $\mathbf{N = 2 8 3 )}$ & Coastal areas (Percent; N=283) \\
\hline & & \\
There were no other visitors & 27.9 & 10.6 \\
There were some other visitors & 56.2 & 56.2 \\
There were many other visitors & 13.4 & 31.4 \\
Don't know & 2.5 & 1.8 \\
Total & 100.0 & 100.0 \\
\hline
\end{tabular}

In Table 29 the distances between the respondents' homes and recreational sites are presented, indicating that the most frequently visited coastal as well as forest areas are located further away than the nearest coastal and forest areas. That is, the respondents in the Swedish sample are not discouraged from travelling longer distances to get to their preferred recreational sites.

Table 29: Distances between the respondents' homes and forests and coastal areas visited

\begin{tabular}{lrr} 
& Mean distance $(\mathbf{k m})$ & Max. distance $(\mathbf{k m})$ \\
Nearest coast $(\mathrm{N}=283)$ & 13.6 & 96 \\
Coast visited most frequently ${ }^{*}(\mathrm{~N}=186)$ & 28.4 & 200 \\
Nearest forest $(\mathrm{N}=283)$ & 4.4 & 50 \\
Forest visited most frequently** $(\mathrm{N}=110)$ & 13.6 & 200 \\
\hline
\end{tabular}

Note: $\quad$ *1 respondent stating distance above 250 has been deleted.

** 2 respondents providing non-numerical answers and 2 respondents stating distances above $250 \mathrm{~km}$ have been deleted.

To get information about the level of participation in forest and coastal recreation the Swedish respondents were asked to state how many trips they make per year to forests and coastal areas. For forests, the mean number of annual visits is 52 , which is twice as much compared to the Danish sample. The minimum and maximum numbers of trips are 0 and 400 , respectively. For coastal visits, the corresponding numbers are 44,0 and 365. The number of annual trips to the two different types of areas thus varies significantly across respondents, but the mean number of trips is quite similar for the two types of recreational areas. Compared to the Danish sample, the mean number of trips is higher in the Swedish sample, for both types of recreational areas. Another difference between the two countries is that coastal trips are more common than forest trips in Denmark. In Sweden, it is the opposite.

Just like the Danish sample, the respondents in the Swedish sample were asked two different questions regarding their perception of the water 
on their most recent visit to the coast. First, they were asked to judge the state of the water in terms of the four quality classes that are subsequently to be used in the CE. Second, they were asked to specify if they believed the water to be of good or poor quality, or somewhere in between. The distribution of answers to the two water quality related questions are presented in Tables 30 and 31 below. The tables show that respondents generally seem to have a very positive perception of the water, i.e. around $93 \%$ of the respondents describe the water as being either clear or very clear, and $73 \%$ believe that the water quality is good.

Table 30: Respondents' perceptions of the water during their most recent visit to a coastal area

Q 43 - How would you describe the water at your last visit to the coast?
$\begin{aligned} & \text { No. of respond- Percent (N=288) } \\ & \text { ents }\end{aligned}$
The water is very clear, and very well suited for bathing, swim-
ming, angling and rowing/boating. The water smells fresh.
The water is rather clear. It is suitable for swimming and bathing,
and for angling, rowing/boating/sailing. Occasionally there can be
some algae on the shore. The water smells fresh.
The water is a bit turbid, and occasionally the water can smell un-
pleasant. The water isn't always pleasant for bathing, but Ok for
rowing/boating/sailing. There are some algae on the shore and in
the water.
The water is unclear and turbid, and occasionally the water smells
unpleasant. The water is not suitable for swimming and bathing,
and there are much green algae in the water and at the shore.
Total

Table 31: Respondents' perceptions of the water quality during their most recent visit to a coastal area

\begin{tabular}{lrr} 
Q 44 - How would you describe the water quality? & & \\
& No. of respondents & Percent (N=288) \\
& & \\
Good quality & 206 & 72.8 \\
Neither good nor bad quality & 72 & 25.4 \\
Poor quality & 5 & 1.8 \\
Total & 283 & 100.0 \\
\hline
\end{tabular}

Finally, it can be noted that of the four attributes water quality, number of visitors, litter and distance $43 \%$ of the Swedish respondents find water quality to be important to a large extent. The corresponding percentages for number of visitors, litter and distance are $33 \%, 36 \%$ and $27 \%$, respectively. That is, of the presented attributes water quality and litter seem to concern the Swedish respondents the most. Only 3\% of the respondents 
state that water quality is not at all important. The corresponding percentages for number of visitors, litter and distance are $4 \%, 2 \%$ and $10 \%$. Again, this indicates that water quality and litter are most important and distance the least important for the Swedish respondents.

\subsection{Conclusions and discussion}

The results from the pilot study, retrieved from the descriptive statistics presented, provide new knowledge about coastal recreation as an ecosystem service. The main findings are that:

- The Danish and Swedish respondents generally seem to have a very positive perception of the water quality in coastal areas. Around $90 \%$ of both the Danish and the Swedish respondents describe the water as being either clear or very clear, and well or very well suited for important recreation activities such as bathing, swimming, angling and rowing/boating.

- Compared to the Danish sample, the mean number of recreational trips to forests and coastal areas is a lot higher in the Swedish sample, and the mean distance to the most frequent visited site is almost twice as long in Sweden compared to Denmark (28 km versus $15 \mathrm{~km}$ ).

- Another difference between the two countries is that coastal trips are more common than forest trips in Denmark. In Sweden, it is the opposite. This can be explained by the time of the survey submissions - in Denmark the survey was submitted during summer, while it was submitted in the autumn/early winter in Sweden. A former study confirms this as forests are found to be the most frequent visited nature area in Denmark (DøRS, 2014). The conclusion is, however, that in both countries coastal areas are important for recreation.

From the focus group interviews that have been conducted in both in Sweden and Denmark the conclusions are that water quality, litter, number of visitors and distance are all important factors for how the recreational area is perceived and the potential value of the sites.

The descriptive statistics give some indications regarding what affect the value of coastal recreation, for example: 
- Of the presented attributes (water quality, number of visitors, litter and distance), water quality and litter seem to concern the Swedish respondents the most and is possibly also what people value the most. The answers from the Danish respondents indicate that congestion might be important as well. The results further indicate that the distance might have different relevance for the respondents in the two countries as the Swedish respondents are willing to travel longer to their most frequently visited site.

- The most frequently visited coastal areas are located further away than the nearest coastal areas. That is, the Danish and Swedish respondents do not seem to be discouraged from travelling longer distances to get to their preferred recreational sites. 


\section{Conclusions and discussions}

Understanding marine ecosystem services requires information and knowledge of both the complex relationships between functions, processes and services in the marine ecosystems and the wellbeing the services serves for human beings. Research and assessments of the values of the services is therefore indispensable, but so is also research and understanding of how the ecosystem services depend on ecosystem structures (such as species and habitats), processes and functions. Knowledge from both of these domains is therefore necessary for mapping and assessment of the condition and distribution of marine ecosystem services, and to pave the way for increased understanding of the potential socioeconomic value of ecosystem services.

This study has not provided an exhaustive list of "final" or "recommended" links but have aimed to present examples, and the examples may indicate potential starting points for further analysis of exploring how the ecosystem service approach can be used to connect the "environmental" dimension of marine policy with the economic dimension. We began in the environmental dimension and demonstrated how indicators that are already in place, or will be in place in the near future, can be linked to valuation results also already available. The examples and analyses presented may serve as inspiration for holistic assessments and broader sustainability assessments, where the state of the environment is the logical central node and the economic impacts of changes are explicitly related to this specific node.

The valuation literature examined is clearly concentrated on some descriptors of GES, namely biodiversity maintenance, healthy fish populations, eutrophication and contaminants and litter. Non-indigenous species are studied to a very modest extent. From these valuation studies examined the conclusion is that only some of the MSFD GES descriptors have been valued, and there is a lack of studies on the descriptors Non-indigenous species (D2) and Contaminants in seafood (D9). To assess the benefits of reaching GES with regard to these descriptors, new studies are needed. The ecological uncertainty regarding these descriptors may complicate valuation.

The conclusion is also that it would be useful to have more valuation studies that use GES as the policy scenario, so that the benefit estimates 
could be directly linked to the goals of the MSFD. Other options would be to tie the benefits to measurable indicators of environmental status to enable assessing the benefits at different levels of environmental change (and also at GES).

To complement existing literature, international studies that provide comparable benefit estimates for several countries would be useful. In addition, future studies of ecosystem service values need to be spatially explicit, so that they provide information on how ecosystem services and their benefits are distributed on the coast and sea area. There are no value estimates of ecological thresholds, i.e. abrupt and dramatic changes in the ecosystem. Incorporating these to valuation studies requires careful consideration of how to describe these threshold effects, especially if there is ecological uncertainty about their occurrence.

The conclusion is therefore that if ecosystem services assessment is considered important to guide policy development more emphasis is needed to the spatial aspects in valuation studies, both in terms of where the ecosystem services are located (the capacity mapping) but also where the benefits accrue. One way ahead could be to identify so called marine and coastal "hotspots", which are locations that are very important to human well-being, for example, due to their extensive use. Despite some restrictions regarding spatially explicit benefit estimates, existing valuation results and benefit transfer could be used to point out some hotspots of values in the Baltic Sea area, e.g. for recreation or fisheries. This would be especially useful for marine spatial planning.

The case study conducted as part of Marecos has not had the ambition to solve all these problems, but on the other hand to illustrate how a valuation study of marine ecosystem services can be conducted and to come up with new results for parts of the marine region studied in Marecos. The survey values coastal recreation as an ecosystem service. The results indicate that coastal areas play an important role as recreational areas and that this type of recreation is an important ecosystem service. The results of the case study also indicate that both improved water quality, no litter on the coast and a low number of other visitors influence the value of this ecosystem service. 


\section{References}

Ahtiainen, H., Artell, J., Czajkowski, M. et al. 2014. Benefits of meeting nutrient reduction targets for the Baltic Sea - a contingent valuation study in the nine coastal states. Journal of Environmental Economics and Policy 3(3):278-305.

Ahtiainen, H. \& Öhman, M. 2014. Ecosystem Services in the Baltic Sea. Valuation of Marine and Coastal Ecosystem Services in the Baltic Sea. Nordic Council of Ministers, TemaNord 2014:563. Copenhagen, Denmark. http://dx.doi.org/10.6027/ TN2014-563

Ahtiainen, H., Artell, J., Czajkowski, M., Hasler, B., Hasselström, L. et al. 2013. Public preferences regarding use and condition of the Baltic Sea - An international comparison informing marine policy. Marine Policy 42: 20-30.

Assmuth, T. \& Jalonen, P. 2005. Risks and management of dioxin-like compounds in Baltic Sea fish: An integrated assessment. TemaNord 2005:568. Nordic Council of Ministers, Copenhagen.

Bateman, I., Mace, G., Fezzi, C., Atkinson, G. \& Turner, K. 2011. Economic Analysis for Ecosystem Service Assessments. Environmental and Resource Economics, 48, 177-218.

Bateman, I.J., Harwood, A.R., Mace, G.M., Watson, R.T., Abson, D.J., Andrews, B., Binner, A., Crowe, A., Day, B.H., Dugdale, S., Fezzi, C., Foden, J., Hadley, D., HainesYoung, R., Hulme, M., Kontoleon, A., Lovett, A.A., Munday, P., Pascual, U., Paterson, J., Perino, G., Sen, A., Siriwardena, G., van Soest, D. \& Termansen, M. 2013. Bringing Ecosystem Services into Economic Decision-Making: Land Use in the United Kingdom. Science, vol 341, nr. 6141, s. 45-50., 10.1126/science.1234379).

Barton, D.N., Lindhjem, H., Magnussen, K., Norge, S. \& Holen, S. 2012. Valuation of Ecosystem services from Nordic Watersheds - from avareness raising to policy support? (VALUESHED). Nordic Council of Ministers, TemaNord 2012:506. Copenhagen, Denmark.

Bjørner, T.B., Jensen, C.U. \& Termansen, M. 2014. Den rekreative værdi af naturområder i Danmark. De Økonomiske Råd, Arbejdspapir 2014:1.

Boyd, J. 2007. The endpoint problem. Resources 165, 26-28. Resources for the Future, Washington, DC.

Boyd, J. \& Banzhaf, S. 2007. What are ecosystem services? The need for standardized environmental accounting units, Ecological Economics, Volume 63, Issues 2-3, 1, Pages 616-626, ISSN 0921-8009, http://dx.doi.org/10.1016/j.ecolecon. 2007.01.002. (http://www.sciencedirect.com/science/article/pii/ S0921800907000341)

Boyd, J. \& Krupnick, A. 2009. The Definition and Choice of Environmental Commodities for Nonmarket Valuation (September 17, 2009). Available at SSRN: http:// ssrn.com/abstract=1479820 or http://dx.doi.org/10.2139/ssrn.1479820

Brouwer, R., Brander, L., Kuik, O., Papyrakis, E. \& Bateman, I. 2013. A synthesis of approaches to assess and value ecosystem services in the EU in the context of TEEB. Final Report. 15 May 2013. VU University Amsterdam, Institute for Environmental Studies. Available at: http://ec.europa.eu/environment/nature/ biodiversity/economics/pdf/EU\%20Valuation.pdf 
Böhnke-Henrichs, A., Baulcomb, C., Koss, R., Hussain, S.S. \& de Groot, R.S. 2013. Typology and indicators of ecosystem services for marine spatial planning and management. J Environ Manage. 2013 Nov 30;130:135-45. doi: 10.1016/j.jenvman. 2013.08.027. Epub 2013 Sep 26.

Carlsson, F., Kataria, M. \& Lampi, E. 2010. Dealing with ignored attributes in choice experiments on valuation of Sweden's environmental quality objectives. Environmental and Resource Economics 47:65-89.

Champ, P.A., Boyle, K.J. \& Brown, T.C. (eds.) 2003. A Primer on Nonmarket Valuation. Kluwer Academic Publishers, Dordrecht.

Cognetti, G. \& Maltagliati, F. 2010. Ecosystem service provision: an operational way for marine biodiversity conservation and management. Mar Pollut Bull. 2010 Nov;60(11):1916-23. doi: 10.1016/j.marpolbul.2010.09.017. Epub 2010 Oct 8.

COM, 2000. Directive 2000/60/EC of the European Parliament and of the Council of 23 October 2000 establishing a framework for Community action in the field of water policy. European Commission.

COM, 2010. Economic and social analysis for the initial assessment for the Marine Strategy Framework Directive: A guidance document. Non-legally binding. European Commission, DG Environment, Working Group on Economic and Social Assessment, 21 December 2010.

COM, 2011. 0244 final: Our life insurance, our natural capital: an EU biodiversity strategy to 2020. EU Commission.

COWI, 2010. Scoping study on the requirements for economic assessment in the Marine Strategy Framework Directive. Final report, June 2010. European Commission DG Environment.

COWI, 2014. Support Policy Development for Integration of Ecosystem Service Assessments into WFD and FD Implementation Resource Document. January 2014.

Depellegrin, D. \& Blažauskas, N. 2013. Integrating Ecosystem Service Values into Oil Spill Impact Assessment. Journal of Coastal Research 29:836-846.

DTU Transport, 2013. Transportøkonomiske enhedspriser (2013). Version 1.4, November 2013.

Eggert, H. \& Olsson, B. 2009. Valuing multi-attribute marine water quality. Marine Policy 33:201-206.

European Commission, 2010. COMMISSION DECISION of 1 September 2010 on criteria and methodological standards on good environmental status of marine waters (2010/477/EU). L 232/14 Official Journal of the European Union 2.9.2010.

European Commission, 2014. A sustainable blue growth agenda for the Baltic Sea Region. SWD 2014, 167 Final. Commission staff document.

EU Commission/JRC 2013. Mapping and Assessment of Ecosystems and their Services. An analytical framework for ecosystem assessments under Action 5 of the EU Biodiversity Strategy to 2020.Technical Report - 2013 - 067.

Fisher, B., Turner, R.K. \& Morling, P. 2009. Defining and classifying ecosystem services for decision making. Ecological Economics 643-653.

Fisher, B., Bateman, I. \& Turner, R.K. 2011. Valuing Ecosystem Services: Benefits, Values, Space and Time Ecosystem Services Economics (ESE) Working Paper Series Environment for Development.

Galparsoro, I., Borja, A. \& Uyarra, M.C. 2014. Mapping ecosystem services provided by benthic habitats in the European North Atlantic Ocean. Front. Mar. Sci. 1:23. doi: 10.3389/fmars.2014.00023.

Garpe, K. 2008. Ecosystem services provided by the Baltic Sea and the Skagerrak. Report 5873, Swedish Environmental Protection Agency, Stockholm. 
Gren, I.M. 2013. The economic value of coastal waters as nutrient filters for the Baltic Sea. Reg Environ Change (2013) 13:695-703 DOI 10.1007/s10113-012-0370-x.

Gren, I.M, Isacs, L. \& Carlsson, M. 2009. Costs of Alien Invasive Species in Sweden. AMBIO 38(3):135-140.

Gómez-Baggethun, E., Martín-López, B., Barton, D., Braat, L., Saarikoski, H., Kelemen, M., García-Llorente, E., van den Bergh, J., Arias, P., Berry, P.L., Potschin, M., Keene, H., Dunford, R., Schröter-Schlaack, C. \& Harrison, P. 2014. State-of-the-art report on integrated valuation of ecosystem services. European Commission FP7, pp. 1-33.

Hasselström, L. (ed) 2008. Tourism and recreation industries in the Baltic Sea area How are they affected by the state of the marine environment? An interview study. Swedish Environmental Protection Agency.

Haines-Young, R. \& Potschin, M. 2010. The links between biodiversity,ecosystem services and human well-being. British Ecological Society.

HELCOM, 2009. Eutrophication in the Baltic Sea - An integrated thematic assessment of the effects of nutrient enrichment and eutrophication in the Baltic Sea region. Balt. Sea Environ. Proc. No. 115B.

HELCOM, 2010. Towards a tool for quantifying anthropogenic pressures and potential impacts on the Baltic Sea marine environment: A background document on the method, data and testing of the Baltic Sea Pressure and Impact Indices. Balt. Sea Environ. Proc. 125

HELCOM, 2010. Ecosystem Health of the Baltic Sea 2003-2007: HELCOM Initial Holistic Assessment. Balt. Sea Environ. Proc. No. 122.

HELCOM, 2013. HELCOM core indicators. Final report of the HELCOM CORESET project. Baltic Sea Environment Proceedings No. 136.

HELCOM, 2013b. HELCOM Copenhagen Ministerial Declaration Taking Further Action to Implement the Baltic Sea Action Plan - Reaching Good Environmental Status for a healthy Baltic Sea 3 October 2013, Copenhagen, Denmark

HELCOM, 2014. Eutrophication status of the Baltic Sea 2007-2011 - A concise thematic assessment. Baltic Sea Environment Proceedings No. 143ICES 2014. Report of the Workshop to draft recommendations for the assessment of Descriptor D3 (WKD3R), 13-17 January 2014, Copenhagen, Denmark. ICES CM 2014/ACOM:50. 153pp.

Hyytiainen, K., Blyh, K., Hasler, B., Ahlvik, L., Ahtiainen, H., Artell, J. \& Ericsdotter, S. Environmental economic research as a tool in the protection of the Baltic Sea costs and benefits of reducing eutrophication. Tema Nord.

Jensen, F.S. (ed.), Tvedt, T.S. (ed.), Gentin, S., Lottrup, L.B.P., Stigsdotter, U.K., EjbyErnst, N. \& Mygind, E. 2012. Friluftslivets samfundsværdi: Oplevelser og aktiviteter $i$ naturen er vigtige goder. Miljøministeriets Forlag.

Jensen, C.L., Nissen, C.J.V., Olsen, S.B., \& Boesen, M.V. 2010. Analyse af tyske lystfiskerturisters valg af ferieland - med fokus på Danmark. København: Fødevareøkonomisk Institut, Københavns Universitet. Rapport Nr. 203.

Jäppinen, J.-P. \& Heliölä, J. (eds.) 2015. Towards a sustainable and genuinely green economy. The value and social significance of ecosystem services in Finland (TEEB for Finland). Synthesis and roadmap. The Finnish Environment 1en/2015. The Finnish Ministry of Environment, Helsinki. 144 p.

Kataria, M. 2007. A cost-benefit analysis of introducing non-native species: the case of signal crayfish in Sweden. Marine Resource Economics 22:15-18.

Kosenius, A-K. 2010. Heterogeneous preferences for water quality attributes: The case of eutrophication in the Gulf of Finland, the Baltic Sea. Ecological Economics 69:528-538. 
Kosenius, A-K. \& Ollikainen, M. 2012. Ecosystem benefits from coastal habitats - a three-country choice experiment. Marine Policy 58:15-27.

Kulmala, S., Haapasaari, P., Karjalainen, T.P., Kuikka, S., Pakarinen, T., Parkkila, K., Romakkaniemi, A. \& Vuorinen, P.J. 2012, Ecosystem services provided by Baltic salmon - a regional perspective to the socio-economic benefits associated with a keystone migratory species. Socio-economic importance of ecosystem services in the Nordic Countries. Synthesis in the context of The Economics of Ecosystems and Biodiversity (TEEB). TemaNord 2012:559, Nordic Council of Ministers.

Lewis, A.R., Baulcomb, C., Fletcher, R., Margońsk, P., Glenk, K., Nadolma, K.A., Luzeńczyk, A.M., Hussain, S. 2013. Identifying and Valuing Marine Cultural Ecosystem Services: Poland and the Baltic Sea. Rural Policy Centre Research Briefing, July 2013.

Lier-Hansen, et al. 2013. Naturens goder - om verdier av økosystemtjenester Norges Offentlige utredninger (NOU) 2013: 10.

Luisetti, T., Turner, K.R, Bateman, I., Morse-Jones, S., Adams, C. \& Fonseca, L. 2011. Coastal and marine ecosystem services valuation for policy and management: Managed realignment case studies in England. Ocean \& Coastal Management 54 (2011) $212 \mathrm{e} 224$.

Luisetti, T., Turner, K.T., Bateman, I.J., Morse-Jones, S., Adams, C. \& Fonseca, L. 2012. Coastal and marine ecosystem services valuation for policy and management: Managed realignment case studies in England. Coastal Management, Volume 54, Issue 3, 2011, 212-224 http://dx.doi.org/10.1016/j.ocecoaman.2010.11.003

Mace, G.M. \& Bateman, I. 2011. Conceptual framework and methodology. In: UK National Ecosystem Assessment: understanding nature's value to society (eds. Watson, R. and S. Albon). London: UK National Ecosystem Assessment (NEA).

Mangi, S.E., Davis, C.D., Payne, L. D., Austen, M., Simmonds, D., Beaumont, N.J. \& Smyth, T. 2011. Valuing the regulatory services provided by marine ecosystems. Environmetrics 22:686-698.

Maes, J. et al. 2013. Mapping and Assessment of Ecosystems and their Services. An analytical framework for ecosystem assessments under action 5 of the EU biodiversity strategy to 2020. Publications office of the European Union, Luxembourg.

Maes, et al. 2014. Indicators for mapping ecosystem services - 2nd MAES Working Paper. European Union, doi: 10.2779/75203.

Millennium Ecosystem Assessment, 2005. Ecosystems and Human Well-Being: Current State and Trends. Island Press, Washington DC.

Miljö- och Engeridepartementet, 2013. Synliggöra värdet av ekosystemtjänster - Åtgärder för välfärd genom biologisk mångfald och ekosystemtjänster. Sveriges Offentliga Utredningar (SOU), SOU:68.

Nordic Council of Ministers, 2013. The Nordic Environmental Action Plan 2013-2018. Norden.

Noring, M. 2014. Valuation of ecotoxicological impacts from tributyltin based on a quantitative environmental assessment framework. In Noring, M. 2014. Valuing ecosystem services - linking ecology and policy. Doctoral thesis in planning and decision analysis. KTH Royal Institute of Technology. Stockholm, Sweden.

Nunes, P, Loureriro, M., Pinol, L., Satre, S., Voltaire, L. \& Canepa, A. 2015. Affiliation: Ecosystem Services Economics Unit, Division of Environmental Policy Implementation, United Nations Environment Programme (UNEP), United Nations Avenue, 00100, Nairobi, Kenya. Affiliation: Institut de Ciencies del Mar - CSIC, 3749 Passeig Marítim de la Barceloneta, 08013, Barcelona, Spain. Analyzing Beach Recreationists' Preferences for the Reduction of Jellyfish Blooms: Economic Results from a Stated-Choice Experiment in Catalonia, Spain. PLOS ONE, DOI: 
10.1371/journal.

pone.0126681

Pauly 1998 AS.

Paulrud, A. 2004. Economic valuation of sport-fishing in Sweden - empirical findings and methodological developments. Doctoral thesis. Swedish University of Agricultural Sciences (SLU). Umeå, Sweden.

Petersen, J.K., Hasler, B., Timmermann, K., Nielsen, P., Bruunshøj Tørring, D., Larsen, M.M. \& Holmer, M. 2014. Mussels as a tool for mitigation of nutrients in the marine environment. Marine Pollution Bulletin 82(1-2):137-143.

Ring, I., Hansjurgens, B., Elmqvist, T., Wittmer, H. \& Sukhdev, P. 2010. Challenges in framing the economics of ecosystems andbiodiversity: The TEEB Initiative. Current Opinion in Environmental Sustainability 2010, 2 15-26.

Salomidi, M., Katsanevakis, S., Borja, A., Braeckman, U., Damalas, D., Galparsoro, I., et al. 2012. Assessment of goods and services, vulnerability, and conservation status of European seabed biotopes: a stepping stone towards ecosystem-based marine spatial management. Mediterr. Mar. Sci. 13, 49-88. doi: 10.12681/mms.23

Sandström, M. 1996. Recreational benefits from improved water quality: A random utility model of Swedish seaside recreation. Working paper series in economics and finance, working Paper No. 121, August 1996, Stockholm School of Economics, Stockholm, Sweden.

Soutukorva, Å. 2001. A Random Utility Model of Recreation in the Stockholm Archipelago. Beijer International Institute of Ecological Economics, Discussion paper 135. The Royal Swedish Academy of Sciences, Stockholm.

Soutukorva, Å. \& Söderqvist, T. 2005. Gone fishing to the Stockholm-Roslagen archipelago - results from surveys on anglers' travels, catches and habits. Beijer Occasional Paper Series, Beijer International Institute of Ecological Economics, The Royal Swedish Academy of Sciences, Stockholm.

SwAM, 2012. Marine tourism and recreation in Sweden. A study for the Economic and Social Analysis of the Initial Assessment of the Marine Strategy Framework Directive. SwAM Report 2012:2.

Söderqvist, T. \& Hasselström, L. 2008. The economic value of ecosystem services provided by the Baltic Sea and Skagerrak. The Swedish Environmental Protection Agency Report 5874.

Söderqvist, T., Ahtiainen, H., Artell, J., Czajkowski, M., Hasler, B., Hasselström, L. et al. 2010. BalticSurvey - a survey study in the Baltic Sea countries on people's attitudes and use of the sea. Report on basic findings. Swedish Environmental Protection Agency Report 6348.

Söderqvist, T. \& Soutukorva, Å. 2006. An Instrument for assessing the quality of environmental valuation studies. Report. Swedish Environmental Protection Agency (Naturvårdsverket) http://www.naturvardsverket.se/bokhandeln/pdf/ 620-1252-5.pdf

TEEB, 2010. The Economics of Ecosystems and Biodiversity (TEEB). Ecological and Economic Foundations. Edited by Pushpam Kumar. Earthscan, London and Washington.

TEEB, 2012. Why Value the Oceans? - A discussion paper (February 2012). Edited by Yannick Beaudoin \& Linwood Pendleton.

TEEB, 2013. TEEB for Oceans and Coats. Information Brochure.

Tegeback, A. \& Hasselström, L. 2012. Costs associated with a major oil spill in the Baltic Sea. BalticMaster project report.

Tinch \& Mathieu, 2011. UNEP-WCMC (2011) Marine and coastal ecosystem services: 
Valuation methods and their application. UNEP-WCMC Biodiversity Series No. 33. $46 \mathrm{pp}$

Toivonen, A-L., Appelblad, H., Bengtsson, B., Geertz-Hansen, P., Guðbergsson, G., Kristofersson, D., Kyrkjebø, H., Navrud, S., Roth, E., Tuunainen, P. \& Weissglas, G. 2000. Economic value of recreational fisheries in the Nordic countries. TemaNord 604, Nordic Council of Ministers.

Toivonen, A-L., Roth, E., Navrud, S., Gudbergsson, G., Appelblad, H., Bengtsson, B. \& Tuunainen, P. 2004. The Economic Value of Recreational Fisheries in Nordic Countries. Fisheries Management and Ecology 11: 1-14.

Turner, R.K., Hadley, D., Luisetti, T., Lam V.W.Y. \& Cheung, W.W.L. 2010a. An introduction to socio-economic assessment within a Marine Strategy Framework. Department for Environment, Food and Rural Affairs (Defra), London.

Turner, R.K., Morse-Jones, S., Fisher, B. 2010b. Ecosystem valuation - A sequential decision support system and quality assessment issue. Annals of the New York Academy of Sciences. Issue: Ecological Economics Reviews 1185:79-101.

Turner, K., Schaafsma, M., Elliott, M., Burdon, D., Atkins, J., Jickells, T., Tett, P., Mee, L., van Leeuwen, S., Barnard, S., Luisetti, T., Paltriguera, L., Palmieri, G. \& Andrews, J. 2014. UK National Ecosystem Assessment Follow-on. Work Package Report 4: Coastal and marine ecosystem services: principles and practice. UNEP-WCMC, LWEC, UK.

UK National Economic Assessment (UK NEA) 2011. The UK National Ecosystem Assessment. Technical Report. UNEP-WCMC, Cambridge.

UNEP, 2009. Marine Litter: A Global Challenge. Nairobi: UNEP. 232 pp.

UNEP-WCMC, 2011. Marine and coastal ecosystem services: Valuation methods and their application. UNEP-WCMC Biodiversity. Series No. 33. 46 pp.

USEPA, 2009. Valuing the protection of ecological systems and services: a report of the EPA Science Advisory Board. EPA-SAB-09-012, United States Environmental Protection Agency, Washington, DC.

Vahtera, E., Conley, D.J., Gustafsson, B.G., Kuosa, H., Pitkänen, H., Savchuk, O.P., Tamminen, T., Viitasalo, M., Voss, M., Wasmund, N., Wulff, F. 2007. Internal ecosystem feedbacks enhance nitrogen-fixing cyanobacteria blooms and complicate management in the Baltic Sea. Ambio. 36(2-3):186-94.

Zaucha, J. 2014. The key to governing the fragile Baltic Sea. Maritime Spatial Planning in the Baltic Sea Region and Way Forward. VASAB.

Wattage, P. 2011. Valuation of Ecosystem in Coastal Ecosystems: Asian and European Perspectives. Working Paper 8, Ecosystem Services Economics (ESE) Working Paper Series, UNEP.

Östberg, K., Håkansson, C., Hasselström, L. \& Bostedt, G. 2013. Benefit transfer for environmental improvements in coastal areas: general versus best-fitting models. Canadian Journal of Agricultural Economics 61:239-258 


\section{Dansk sammenfatning}

MARECOS (Marine Ecosystem Services) er et tværfagligt studie, der har haft til formål at tilvejebringe information vedrørende kortlægning og værdisætning af økosystemtjenester, som kan anvendes i forbindelse med udformning af regulering på det marine område såvel nationalt, som regionalt og internationalt. Denne rapport indeholder forslag til, hvordan opgørelser af økosystemers tilstand baseret på EU's Havstrategidirektiv (EU Marine Strategy Framework Directive, MSFD), samt opgørelser baseret på anvendelse af HELCOM's indikatorer for Østersøen, kan anvendes i forbindelse med kortlægning og værdisætning af økosystemtjenester. Rapporten indeholder:

- Definitioner og beskrivelser af centrale begreber i forhold til opgørelse af økosystemtjenester, Forslag til, hvordan marine økosystemtjenester kan opgøres.

- Eksempler på, hvordan MSFD deskriptorerne og indikatorerne relateret til opgørelse af miljøtilstand kan kædes sammen med udvalgte økosystemtjenester, samt hvordan disse data kan anvendes i forbindelse med opgørelser af økosystemtjenester.

- Præsentation og diskussion af resultater fra værdisætningsstudier, som kan anvendes i forbindelse med opgørelser af økosystemtjenester i praksis.

- En diskussion af, hvor der er behov for yderligere viden i forhold til værdisætning af økosystemtjenester, samt i forhold til deskriptorer og indikatorer for god miljøtilstand.

- Et case-studie, der demonstrerer, hvordan rekreation (som repræsenterer en kulturel økosystemtjeneste) kan værdisættes.

Rapporten beskriver de potentialer, der ligger i at sammenkæde data og viden relateret til vandkvalitet og tilstanden af marine økosystemer med værdien af de økosystemtjenester, som de marine økosystemer tilvejebringer. Rapporten indeholder dermed information af relevans for politikere og beslutningstagere involveret i reguleringen af det marine område. 


\section{Udvidet dansk sammendrag med konklusioner}

Formålet med Marecos studiet er at definere og diskutere forskellige klassifikationsmetoder i forhold til opgørelse af marine økosystemtjenester og deres værdi, samt at undersøge, hvordan eksisterende viden og data vedrørende økosystemprocesser, -funktioner, -deskriptorer og værdisætningsresultater kan anvendes i forbindelse med opgørelsen af marine $\varnothing$ kosystemtjenester. Som et eksempel på en vigtig økosystemtjeneste, der er blevet undersøgt i forskellig udstrækning i de nordiske lande, præsenteres et case studie omhandlende kystnær rekreation.

\section{Koncepter og tilgange til analysen af økosystemtjenester}

Der eksisterer adskillige forskellige tilgange til værdisætning af økosystemtjenester, og deres anvendelighed afhænger af den specifikke kontekst. En af konklusionerne i Marecos er, at der bør lægges vægt på, at den anvendte tilgang gør det muligt at afdække hvordan ændringerne påvirker den enkelte økosystem tjeneste, samt afvejningen mellem forskellige økosystemtjenster, når regulering eller andre drivkræfter ændres. Den tilgang, der anvendes i Marecos, er inspireret af koncepterne fra MAES og UKNEA. Hovedfokus i Marecos har været på afdækning af mulighederne for at beskrive og kvantificere sammenhængene mellem økosystemprocesser og -funktioner, økosystemtjenester og deres værdi.

\section{Valg af eksempler på økosystemtjenester}

For at simplificere analysen gennemgås tre udvalgte økosystemtjenester som eksempler på, hvordan data vedrørende økosystemprocesser og funktioner, deskriptorer og værdisætningsresultater kan sammenkædes. Tilgængeligheden af data i den nordiske del af Østersøen gennemgås ligeledes for de tre udvalgte økosystemtjenester. De udvalgte økosystemtjenester er:

1. Produktion af fisk til fødevarebrug.

2. Marine økosystemers evne til at regulere næringsstoffer, sedimentation og naturlig vandrensning.

3. Kystnær rekreation og turisme. Alle tre repræsenterer økosystemtjenester, som anses som vigtige i Østersøområdet og i de nordiske lande. 


\section{Sammenhænge mellem økosystemfunktioner, - processer og - tjenester - kompleksiteter og potentielle løsninger?}

Mulighederne for at anvende eksisterende data til at afdække sammenhængene mellem økosystemfunktioner og - processer, og økosystemtjenester illustreres for de treudvalgte økosystemtjenester. Det marine bentiske økosystem i det nordlige Atlanterhav anvendes som eksempel på, hvordan information om fremherskende bentiske habitater og økosystemtjenester kan danne grundlag for kortlægning af de bentiske økosystemers kapacitet til at understøtte produktionen af økosystemtjenester. Sammenhængene mellem funktioner, processer og tjenester i marine $\emptyset$ kosystemer er meget komplekse, og den nuværende forståelse af koblingerne mellem biodiversitet, økosystemprocesser, - funktioner og - tjenester er ufuldstændig og mindre veludviklet end forståelsen af terrestriske $\varnothing$ kosystemer. En forudsætning for, at tilstanden og fordelingen af marine $\emptyset$ kosystemtjenester kan kortlægges og opgøres, er derfor, at der forskes yderligere i at afdække, hvordan økosystem strukturer (så som arter og habitater) påvirker tilvejebringelsen af økosystemtjenester. Yderligere forskning er ligeledes påkrævet i forhold til at øge forståelsen af de potentielle værdier, som økosystemtjenesterne fra de marine økosystemer repræsenterer.

\section{Anvendelsen af indikatorer og deskriptorer}

HELCOM CORESET I og II projekterne resulterede bl.a. i udviklingen af en række centrale indikatorer. Tilsammen udgør de udviklede indikatorer et sæt status- og belastningsindikatorer, som kan anvendes til at følge udvikling frem mod målet om opnåelse af god økologisk tilstand (GES) i Østersøen. Indikatorerne er videnskabeligt baserede, og de afspejler ændringer i det marine miljø, som er forårsaget af menneskeskabte belastninger. Med udgangspunkt i eksempler på indikatorer illustreres det, hvordan disse kan anvendes i forbindelse med opgørelse af sundhedstilstanden af økosystemerne i Østersøen, og der gives eksempler på potentielle sammenhænge mellem de udvalgte økosystemtjenester, tilstanden i det marine miljø samt deskriptorerne fra EU's Havstrategi direktiv (MSFD). For at illustrere, hvordan anvendelsen af forskellige indikatorsæt kan påvirke resultaterne af analysen, gennemføres der en tilsvarende analyse baseret på HELCOM CORESET indikatorerne. CORESET indikatorerne er udviklet med henblik på opfyldelse af EU's Havstrategi Direktiv. De er særligt anvendelige til opgørelser omfattende hele Østersøen da der er bred enighed om indikatorerne blandt de baltiske aftaleparter samt EU medlemslandene. Det er vigtigt, at HELCOM opgørelsessystemet udvikles 
yderligere med henblik på at udvikle kortlægningen og opgørelser af de marine økosystemtjenester i Østersøen.

Der er ingen MSFD deskriptor, som er direkte forbundet til tilvejebringelsen af rekreative tjenester. I analysen har der derfor været fokus på at identificere de mest relevante intermediære tjenester, og dernæst på at identificere deskriptorer og indikatorer, der kan beskrive tilstanden af disse intermediære tjenester. De identificerede indikatorer kan anvendes til indirekte at sige noget om gevinsterne forbundet med rekreative aktiviteter. Indikatorerne kan også potentielt anvendes til opgørelse af andre kulturelle tjenester, $\mathrm{fx}$ æstetiske værdier.

Analysen er afgrænset til at fokusere på deskriptorer og indikatorer, der har en effekt i forhold til særligt vigtige intermediære økosystemtjenester, samt indikatorer, der repræsenterer økologiske slutpunkter for disse tjenester.

\section{Værdisætningsstudier - erfaringer samt anvendelighed $\mathrm{i}$ forhold til opgørelse af økosystemtjenester}

En forudsætning for at kunne gennemføre den økonomiske del af økosystemtjenesteopgørelsen er, at værdien af ændringer i produktionen af $\emptyset$ kosystemtjenester forbundet med skift mellem forskellige scenarier kan opgøres i monetære termer. Til trods for at der er gennemført flere studier med fokus på opgørelse af de monetære gevinster forbundet med ændringer i miljøtilstanden i Østersøen, så er den eksisterende viden om værdien af de marine økosystemtjenester i Østersøen fragmentarisk. I de fleste tilfælde er det relativt ligetil at knytte værdisætningsstudierne til GES deskriptorerne fra Havstrategi direktivet, HELCOM CORESET indikatorerne og de strategiske mål i handlingsplanen for Østersøen (Baltic Sea Action Plan, BSAP). Hvis detaljeringsgraden øges omkring beskrivelsen af miljømål, økologiske processer og kerneindikatorerne, bliver sammenhængene imidlertid mere komplekse.

De udførte værdisætningsstudierne er navnlig koncentreret omkring opretholdelse af biodiversitet, sunde fiskebestande, eutrofiering, forurening og affald. Ikke-hjemmehørende arter er undersøgt i meget begrænset omfang.

Når de miljømæssige ændringer der er påkrævet jvf. Havstrategi direktivet (MSFD) eller handlingsplanen for Østersøen (BSAP) afviger væsentligt fra de ændringer, der er analyseret i studierne, kan det være kompliceret at anvende resultaterne fra studierne til at sige noget om værdien af de planlagt ændringer. Det er imidlertid mange af studierne, der adresserer de potentielle ekstrapoleringsproblemer. En anden udfordring forbundet med 
anvendelsen af resultaterne fra værdisætningsstudier til at opgøre gevinsterne forbundet med implementering af MSFD eller BSAP er, at de fleste af studierne er knyttet til en specifik geografisk lokalitet og kontekst. Dette er en fordel i forhold til at sikre rumlig præcision, men det repræsenterer en udfordring, hvis den rumlige skala ønskes udvidet, fx hvis resultaterne fra ét afgrænset område ønskes anvendt i forbindelse med opgørelse af de samlede gevinster forbundet med opnåelse af god tilstand for en given deskriptor i hele Østersøen.

Situationen er mest lovende i forhold til opgørelse af gevinsterne forbundet med reduceret eutrofiering. Disse er blevet analyseret på både regionalt, nationalt og internationalt niveau i hele Østersøen, og de ændringer i eutrofieringsniveauet, der er blevet værdisat, stemmer rimeligt overens med målsætningen om at opnå god økologisk tilstand (GES).

Der er mange studier, som ikke adresserer den rumlige fordeling af $ø$ kosystemtjenester og værdien af disse, og en kortlægning af økosystem tjenesterne baseret på tilgængelige studier vil derfor ikke afspejle den sande rumlige variation i økosystemtjenesteværdier. Hvis økosystemtjenesteopgørelser anses som vigtige i forhold til udviklingen af politiske målsætninger, bør der derfor fremover lægges vægt på at inkludere rumlige aspekter i udformningen af værdisætningsstudier. Det gælder både i forhold til hvor økosystemtjenesterne er lokaliseret (kapacitetskortlægning), og hvor gevinsterne realiseres. En måde at gøre dette på kunne være at identificere såkaldte marine "hotspots", som angiver områder, der er særligt vigtige i forhold til menneskers velbefindende, fx. som følge af udbredt brug i forbindelse med rekreative aktiviteter, eller fordi de understøtter tilvejebringelsen af andre kulturelle økosystemtjenester. På trods af den begrænsede rumlige præcision ved de eksisterende studier vurderes det dog, at resultater fra eksisterende værdisætningsstudier og benefit transfer kan danne grundlag for udpegningen af "hotspot" områder i Østersøområdet, fx. i forhold til rekreation og fiskeri. Denne tilgang kan særligt være relevant i forhold til rumlig marin planlægning.

Der er ingen værdisætningsresultater blandt de fundne eksisterende studier, der relaterer til økologiske tærskler, det vil sige tilstande, hvor der er høj risiko for pludselige og dramatiske ændringer i økosystemet. Inkorporering af økologiske tærskelværdier i værdisætningsstudier kræver grundige overvejelser i forhold til, hvordan tærskeleffekterne beskrives; dette gælder særligt, hvis der er miljømæssig usikkerhed omkring tærskeleffekternes optræden. 


\section{Casestudiet}

Som en del af Marecos projektet blev der gennemført et casestudie til illustration af, hvordan et værdisætningsstudie af marine økosystemtjenester kan gennemføres. Studiet fokuserer på at afdække, i hvilken udstrækning værdien af kystnær rekreation afhænger af vandkvalitet, mængden af affald langs kysten og antallet af andre besøgende. Casestudiet udgør et pilotstudie til en større undersøgelse, som på et senere tidspunkt skal udsendes til et repræsentativt udsnit af husstande i Sverige og Danmark. Baseret på resultaterne af pilotstudiet blev der lavet adskillige væsentlige ændringer i spørgeskemaet til hovedundersøgelsen. Betalingsviljeestimaterne udledt på baggrund af pilotundersøgelsen præsenteres ikke i nærværende rapport, men rapporten inkluderer deskriptiv statistik for både det svenske og det danske sample i forhold til respondenternes brug af kystområder for rekreative formål.

\section{Resultater - analyseramme}

Analysen og eksemplerne i nærværende rapport, inklusive case studiet, viser og eksemplificerer potentielle udgangspunkter for fremtidige analyser af marine økosystemtjenester (ØT), med fokus på at identificere hvordan ØT tilgangen kan anvendes til at koble miljødata med økonomiske data. Hvis der tages udgangspunkt i den miljømæssige dimension og anvendes eksisterende indikatorer, kan økonomiske data kobles på. En sådan tilgang kan åbne muligheder for helhedsorienterede opgørelser. Desuden kan den danne basis for bredere bæredygtighedsanalyser, der tager udgangspunkt i kortlægning af miljøtilstanden, hvortil de økonomiske effekter af ændringer efterfølgende kan kobles på.

Analyserammen hviler på den implicitte antagelse, at formålet med implementering af tiltag er at forbedre den miljømæssige tilstand. Analyserammen kan potentielt oversimplificere analysen af økonomiske konsekvenser i og med at tiltagene - uanset deres miljømæssige effekt - altid vil have økonomiske konsekvenser. Som et eksempel, så kan restriktiv regulering af fiskeriet give anledning til stigende fiskebestande og derigennem påvirke produktionen af "fisk til konsum"-økosystemtjenesten; reguleringen vil dermed kunne give anledning til økonomiske gevinster på lang sigt. Tiltaget vil imidlertid også påvirke fiskeriet økonomisk på kort sigt, og det uanset om der viser sig at være langsigtede økonomiske gevinster eller ej. Dette eksempel illustrerer vigtigheden af, at der i forbindelse med opgørelse af økosystemtjenester rettes fokus mod såvel potentielle synergi-effekter som trade-off's således at mulige konflikter mellem tilvejebringelsen af forskellige økosystemtjenester kan afdækkes. 


\section{Konklusioner}

Kortlægning og opgørelse af tilstanden og udbredelsen af marine økosystemtjenester kan bidrage til at øge vores forståelse af den potentielle samfundsøkonomiske værdi af økosystemtjenester, men en forudsætning for at analyserne kan gennemføres er, at det lykkes at samle og integrere viden fra marin forskning med økonomiske analyser og data. Dette studie indeholder ikke en udtømmelig liste over sammenhænge mellem tilgængelige økonomiske og marine data som kan blive brugt i fremtidige analyser af produktionen af økosystem tjenester; fokus har i stedet været på at give eksempler. Eksemplerne kan danne udgangspunkt for yderligere analyser af, hvordan økosystemtjenestetilgangen kan bruges til at skabe koblinger mellem miljøet og økonomien, samt som inspiration til helhedsorienterede og mere brede bæredygtighedsorienterede analyser.

Der konkluderes at:

- Eksisterende moniteringssystemer, data og resultater kan anvendes til at sammenkæde viden om sundheden og tilstanden af de marine $ø$ kosystemer med de økonomiske værdier af de tjenester, som $\emptyset$ kosystemer leverer.

- Deskriptorerne og indikatorerne fra hhv. Havstrategi direktivet (MSFD) og HELCOM's BSAP kan anvendes til opgørelse den nuværende tilstand af økosystemerne, Deskriptorerne og indikatorerne kan også anvendes i forbindelse med afdækning af sammenhængene mellem økosystemers sundhedstilstand og drivkræfterne bag forandringer.

- Det er relevant at gennemføre flere værdisætningsstudier, der anvender God Økologisk Tilstand (GES) som policy scenarie, idet det dermed vil være muligt at koble værdiestimaterne direkte til målsætningerne i Havstrategi direktivet (MSFD).

- Gevinster bør opgøres på en måde, der sikrer at de kan kobles til målbare indikatorer for miljøtilstand. Det vil dermed være muligt at opgøre gevinsterne for forskellige niveauer af ændringer (inkl. GES).

Det ville være nyttigt med internationale studier, der opgør sammenlignelige værdiestimater på tværs af lande, og sådanne fremtidige studier bør være rumligt specifikke. Rumlig præcision er vigtig i forhold til at sikre, at opgørelserne afspejler den variation, der er i udbredelsen af økosystemtjenester, og de dertil knyttede værdier, på tværs af forskellige kystområder. Information omkring økologiske tærskler, og størrelsen af de værdiændringer, der er forbundet med overskridelse af disse, ville 
være værdifuld. Det er imidlertid ikke ligetil at opgøre sådanne værdier, idet det kan ligge udenfor eksisterende værdisætningsmetoders anvendelsesområde.

Det konkluderes således, at der i fremtidige værdisætningsstudier bør lægges yderligere vægt på de rumlige aspekter relateret til produktionen af økosystemtjenester, særligt hvis økosystemtjeneste opgørelserne vurderes at repræsentere væsentligt input til udviklingen af den fremtidige politik på det marine område. Rumlig information er vigtig i forhold til vurdering af, hvor kapaciteter og potentialer er højest, samt i forhold til mere specifikke analyser af den geografiske distribution af gevinster. En mulig vej frem kunne være at identificere såkaldte marine og kystnære "hotspots", som repræsenterer områder, hvor enten produktionen af økosystemtjenester eller værdien af de producerede økosystemtjenester er særligt høj sammenlignet med andre mere generiske områder. En sådan tilgang kunne i særdeleshed være relevant i forhold rumlig marin planlægning. 


\section{Appendix - The questionnaire used in the case study}

Note: After each question/answer option the name of the corresponding variable in the data set received from Userneeds is specified (in brackets).

\section{Questionnaire}

\section{Dear panellist}

This study is part of a larger research project conducted by researchers and students from Aarhus University. Results from the survey will be used for research purposes, and will also be used in our advice to the environmental authorities.

Your responses are guaranteed anonymity.

The study is about the choices you make when you go on trips in the countryside in Denmark.

We are interested in your personal opinion on the questions we ask, no matter how much you use nature, how much you care about outdoor recreation and how informed you are about this topic.

4. Are you...? (Gender)

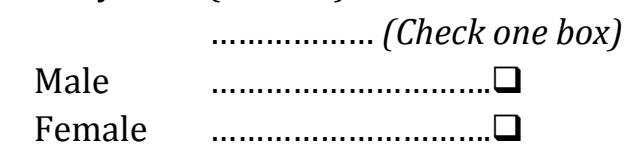

In order to be able to process your answers, we will ask you to provide your current address

This information will not be published.

2. What is the name of the street where you live? (Vej) 
3. In which of the following intervals is your house number? (Vejnummer)

\section{Specify your house number by checking one of the boxes:}

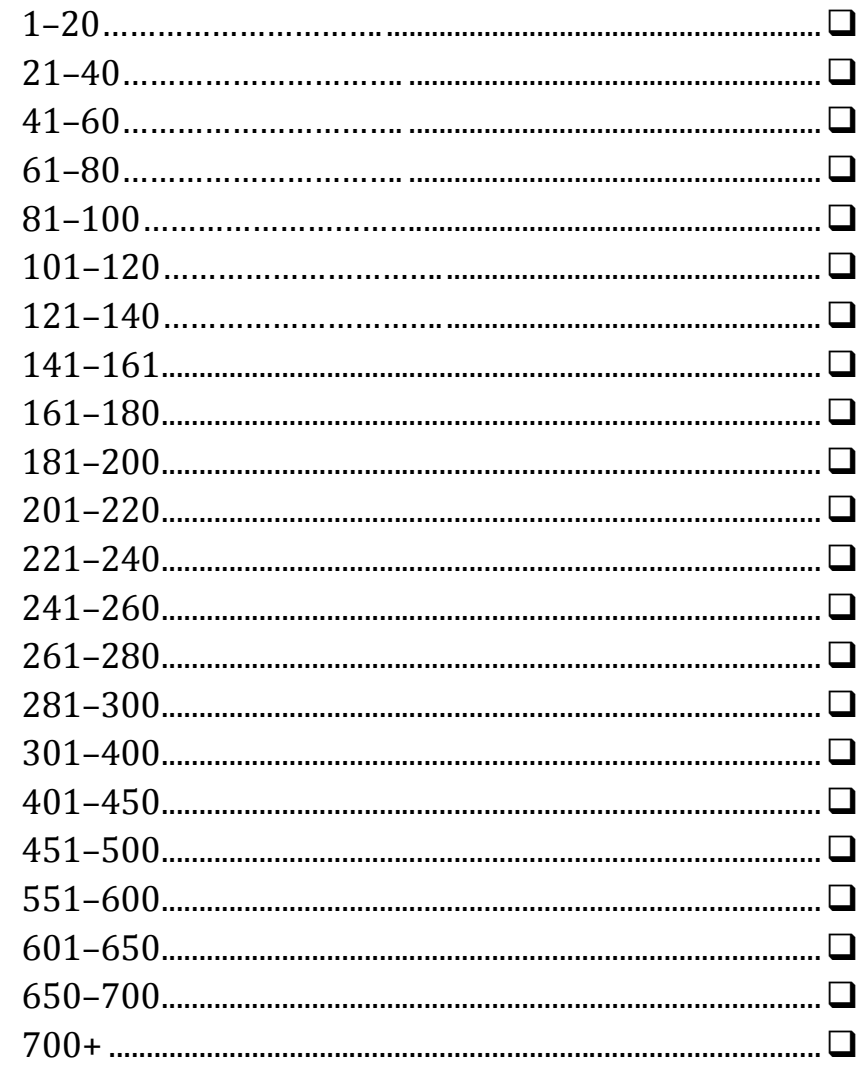

4. What is your zip code? (Postnummer)

I do not wish to state my address

5. In which region do you live? (RegionDK)
$\circ \square$ The Capital Region
$\circ \square$ Region Zealand
$\circ \square$ The Southern Denmark Region
$\circ \square$ The Central Denmark Region
$\circ \square$ The North Denmark Region
$\circ \square$ Foreign Country
o $\square$ Don't know 
6. What is your year of birth?

(Alder)

7. How many adults (i.e. persons over the age of 18) are there in your household (including yourself)? (Q43)
$\circ \square 1$
$\circ \square 2$
$\circ \square 3$
$\circ \square 4$ or more

8. How many children (i.e. persons under the age of 18) are there in your household? (Q44)
$\circ \square 1$
$\circ \square 2$
$\circ \square 3$
$\circ \square 4$ or more

9. What is your highest level of completed education? (Q45)

$\circ \square$ Primary school

$\circ \square$ Vocational education

$\circ \square$ Gymnasium

$\circ \square$ Short secondary education (up to 3 years)

$\circ \square$ Medium terms secondary education (3-4 years)

$\circ \square$ Long secondary education (5 years or more)

10. What is your current occupational status? (Q46)

$\circ \square$ Employed

$\circ \square$ Self-employed

$\circ \square$ Working spouse

o $\square$ Student

$\circ \square$ Unemployed

$\circ \square$ Retired 
11. In which interval is your personal monthly net income (i.e. after tax)? Please remember to include all types of income such as salary, pension and subsidies. (Q47)

$\circ \square$ Less than 10.000

$\circ \square 10.000-15.000$

$\circ \square 15.000-20.000$

$\circ \square 20.000-25.000$

$\circ \square 25.000-30.000$

$\circ \square$ More than 30.000

$\circ \square$ Don't wish to answer

12. If you are a student, in which interval do you then expect your personal monthly income before tax to be once you have completed your education? (Q48)

$\circ \square$ Less than 10.000

$\circ \square 10.000-15.000$

$\circ \square 15.000-20.000$

$\circ \square 20.000-25.000$

$\circ \square 25.000-30.000$

$\circ \square$ More than 30.000

$\circ \square$ Don't wish to answer

13. Which types of nature areas have you ever visited in Denmark?

$\circ \square$ Forest (Screen1_1)

$\circ \square$ Lake or river/stream Sø eller å (Screen1_2)

$\circ \square$ Beach/coast (Screen1_3)

$\circ \square$ Park (Screen1_4)

$\circ \square$ Other (Screen1_5)

$\circ \square$ None of the above (Screen1_6)

14. When did you last visit a nature area in Denmark? (Q5)
$\circ \square$ Today
○ Less than 1 week ago
$\circ \square$ 1-4 weeks ago
$\circ \square$ 1-6 months ago 
o $\square$ 6-12 months ago

$\circ \square$ More than a year ago

15. What type of area did you visit on your last trip to a nature area (in Denmark)? (check one or more boxes)

$\circ \square$ Forest (Q6_1)

$\circ \square$ Lake or river/stream (Q6_2)

$\circ \square$ Beach/coast (Q6_3)

$\circ \square$ Park (Q6_4)

$\circ \square$ Other (Q6_5)

16. What did you do? (Check one or more boxes)

$\circ \square$ Experienced nature (Q7_1)

$\circ \square$ Went for a walk (Q7_2)

o $\square$ Walked the dog (Q7_3)

$\circ \square$ Exercised/Went running (Q7_4)

o $\square$ Bicycled (Q7_5)

$\circ \square$ Horseriding (Q7_6)

$\circ \square$ Swimming/sunbathing (Q7_7)

$\circ \square$ Sailing/rowing (Q7_8)

$\circ \square$ Birdwatching (Q7_9)

$\circ \square$ Watched other animals (Q7_10)

$\circ \square$ Picknicking (Q7_11)

$\circ \square$ Picked mushrooms or berries (Q7_12)

o $\square$ Angling (Q7_13)

$\circ \square$ Hunting (Q7_14)

० $\square$ Relaxing (Q7_15)

$\circ \square$ Other (Q7_16)

17. How did you get to the nature area? (Q8)

(Check the main means of transport)

$\circ \square$ By foot

$\circ \square$ Bicycle

$\circ$ Car

$\circ \square$ Motorcycle / Moped 
$\circ \square$ Bus, S-train or train

o $\square$ Other

18. Where is the nature area you visited on your latest trip located?

(Remember we are only asking about nature area in Denmark)

Name of nature area:

Name of nearest town:

19. From where did the trip start? (Q10)

$\square$ From home

From summerhouse

$\square$ Other place

To assist you in assessing the distance in the questions below, we have inserted a link to google maps (see guide below). It is not necessary to use this link if you already know the distance. https://maps.google.dk/

\section{GUIDE TO GOOGLE MAPS}

In GOOGLE maps enter the address where the tour started from in the search box, and press the search button. Then click on "directions", which is located below the search box.

In the blank search field you write the name of the nature area you last visited.

A travel time and a distance will now appear. We ask you to write the calculated number of $\mathrm{km}$ into the questionnaire.

20. What is the distance from where the trip started to this area?'

km (Q11_TXT)

21. What is the distance from your home to this area?

km (Q12_TXT)

22. What is the distance from your home to the nature area you visit most frequently? (This is not necessarily the nature area that you last visited but it may be the same)

km (Q13_TXT) 
23. What is the distance from your home to the nearest coast? $\mathrm{km}(\mathrm{Q} 13 \mathrm{a}+\mathrm{TXT})$

24. What is the distance from your home to the nearest forest? km (Q13b_TXT)

25. How long did your latest visit to a nature area last? (Q14)

$\circ \square$ Less than 5 minutes

$\circ \square$ 5-15 minutes

$\circ \square$ 15-60 minutes

$\circ \square$ 1-2 hours

$\circ \square$ 2-3 hours

$\circ \square$ 3-4 hours

$\circ \square$ More than 4 hours

26. Were you alone or together with others on the trip? (Q15)

$\circ \square$ Alone

$\circ \square$ With others

27. How many others went with you (excl. yourself)?

$\circ \square$ No. of children (0-17 years): (Q15b_1)'

$\circ \square$ No. of adults: (Q15b_2)

28. How long time did you spend travelling to the nature area? (Q16)

o Less than 5 minutes

○ $\square$ 5-15 minutes

$\circ \square$ 15-30 minutes

$\circ \square$ 30-45 minutes

$\circ \square$ 45-60 minutes

$\circ \square$ More than 1 hour

29. Did you select the fastest route to the nature area? (Q17)

o $\square$ Yes

$\circ \square$ No 
FILTER. For Userneeds: If the respondent have answered "forest" in question 15 then he/she does not have to answer questions 30-36a (but they have to answer questions $36 \mathrm{~b}, \mathrm{~b}, \mathrm{~d}$ and therefore the introduction to question 36 should be presented to all respondents).

\section{We will now ask you to think about your latest visit to a forest in Denmark}

30. When did you last visit a Danish forest? (Q18)
$\circ \square$ Today
$\circ \square$ Less than 1 week ago
$\circ \square$ 1-4 weeks ago
$\circ \square$ 1-6 months ago
$\circ \square$ 6-12 months ago
$\circ \square$ More than a year ago

31. What is the name of the forest that you visited on your latest trip? Name of forest: (Q19_1)

Name of nearest town: (Q19_2)

32. From where did the trip start? (Q20)
$\square$ From home
$\square$ From summerhouse
$\square$ Other place

To assist you in assessing the distance in the three questions below, we have inserted a link to google maps (see guide below). It is not necessary to use this link if you already know the distance. https://maps.google.dk/

\section{GUIDE TO GOOGLE MAPS}

In GOOGLE maps enter the address where the tour started from in the search box, and press the search button. Then click on "directions", which is located below the search box. In the blank search field you write the name of the nature area you last visited. A travel time and a distance will now appear. We ask you to write the calculated number of $\mathrm{km}$ into the questionnaire.

33. What is the distance from where the trip started to this forest area?

km (Q21_TXT) 
34. What is the distance from your home to this forest area? km (Q22_TXT)

35. What is the distance from your home to the forest you visit most frequently? (This is not necessarily the forest that you last visited but it may be the same)

--------- km (Q23_TXT)

Name of the forest you visit most frequently: (Q23b)

36. How would you describe your most recent visit to a forest in Denmark?

a) What did you do during your visit?

$\circ \square$ I went for a walk in the forest (Q24a_1)

$\circ \square$ I was running/exercising (Q24a_2)

$\mathrm{O} \square$ I picked flowers/gathered firewood/ picked berried (Q24a_3)

$\circ \square$ I was walking the dog (Q24a_4)

$\mathrm{O} \square$ I was bicycling (Q24a_5)

$\circ \square$ I relaxed (Q24a_6)

$\circ \square$ None of these (Q24a_7)

b) Which season was it? (Q24b)

$\circ \square$ It was winter

$\circ \square$ It was spring

$\circ \square$ It was summer

$\circ \square$ It was autumn

c) Was there any litter in the forest? (Q24c)

$\circ \square$ There was no litter in the forest

$\circ \square$ There was some litter in the forest

$\circ \square$ There was a lot of litter in the forest

$\circ \square$ Don't know 
d) Were there other visitors in the forest? (Q24d)

$\circ \square$ There were no other visitors

$\circ \square$ There were some other visitors

$\circ \square$ There were many other visitors

$\circ \square$ Don't know

37. Did you travel by train/bus, car, bike or did you walk to the forest?

$\circ \square$ Train/bus/S-train (Q25_1)

$\circ \square$ Car (Q25_2)

$\circ \square$ Bike (Q25_3)

$\circ \square$ Walk (Q25_4)

38. How many trips to the forest do you go on during a year?

(Q25a)

We will now ask you to think about your latest visit to the coast.

FILTER. For Userneeds: If the respondent have answered "Beach/coast" in question 15 then he/she does not have to answer questions 39-45a (but they have to answer questions $45 \mathrm{~b}, \mathrm{~b}, \mathrm{~d}$ and therefore the introduction to question 45 should be presented to all respondents).

39. When did you last visit a beach or another area by the coast (in Denmark)? By "the coast" also include water areas by the fjords (Q26)

$\circ$ Today

$\circ \square$ Less than 1 week ago

$\circ \square 1-4$ weeks ago

$\circ \square$ 1-6 months ago

$\circ \square$ 6-12 months ago

$\circ \square$ More than a year ago

40. What is the name of the coastal area/beach that you visited on your latest trip to the coast?

Name of beach/coastal area:

Name of nearest town: 
41. From where did the trip start? (Q28)

$\square$ From home

$\square$ From summerhouse

$\square$ Other place

To assist you in assessing the distances below, we have inserted a link to google maps (see guide below). It is not necessary to use this link if you already know the distance. https://maps.google.dk/

\section{GUIDE TO GOOGLE MAPS}

In GOOGLE maps enter the address where the tour started from in the search box, and press the search button. Then click on "directions", which is located below the search box. In the blank search field you write the name of the coastal area you last visited. A travel time and a distance will now appear. We ask you to write the calculated number of km into the questionnaire.

42. What is the distance from where the trip started to this coastal area?

$$
\text { - Km (Q29_TXT) }
$$

43. What is the distance from your home to this coastal area (as mentioned it can also be a water area by a fjord)?

------- Km (Q30_TXT)

44. What is the distance from your home to the coastal area you visit most frequently? (as mentioned it can also be a water area by a fjord, and it is not necessarily the coastal area that you last visited but it may be the same)

------- Km (Q31_TXT)

45. How would you describe your most recent visit to the coast (as mentioned it can also be a water area by a fjord)?

a) What did you do?

$\circ \square$ I went for a walk along the coast/beach/habour (Q32a_1)

$\mathrm{O} \square$ I was swimming/bathing/sunbathing (Q32a_2)

$\circ \square$ I relaxed (Q32a_3)

$\circ \square$ I was fishingJeg fiskede (Q32a_4)

$\circ \square$ I sailed/paddeled/surfed (Q32a_5)

$\circ \square$ None of these (Q32a_6) 
b) Which season was it? (Q32b)

o $\square$ It was winter

$\circ \square$ It was spring

$\circ \square$ It was summer

$\circ \square$ It was autumn

c) Was there any litter on the beach/coast? (Q32c)

$\circ \square$ There was no litter on the beach/coast

$\circ \square$ There was some litter on the beach/coast

$\circ \square$ There was a lot of litter on the beach/coast

$\circ \square$ Don't know

d) Were there other visitors at the beach/coast? (Q32d)

$\circ \square$ There were no other visitors

$\circ \square$ There were some other visitors

$\circ \square$ There were many other visitors

$\circ \square$ Don't know

46. Did you travel by train/bus, car, bike or did you walk to the beach/coast?

$\circ \square$ Train/bus/S-train (Q32Transport_1)

$\circ \square$ Car (Q32Transport_2)

o $\square$ Bike (Q32Transport_3)

$\circ \square$ Walk (Q32Transport_4)

47. How would you describe the water at your latest visit to the coast? (Check one box) (Q33) 
The water was very clear and I think it was very suitable for bathing / swimming, fishing and rowing etc. It smelled fresh.

The water was quite clear and I think the water was suitable for bathing / swimming, fishing and rowing etc. There were some algae in the water and / or on the beach. The water smelled fresh. The water was quite turbid, and it smelled a bit rotten. The water was not tempting to swim in, but it was OK for rowing. There were algae on the beach and in the water.

The water was quite turbid and it smelled a bit rotten. The water was not tempting to swim in. There were algae on the beach and in the water.

48. How would you describe the water quality? (Q34)

(Check one box)

$\circ \square$ God kvalitet

$\circ \square$ Hverken god eller dårlig kvalitet

o Dårlig kvalitet

49. How many trips to the coast do you go on during a year? (remember it can also be an area by a fjord) (Q35)

We now ask you to imagine that it is a summer day and that you are considering going for a trip to a nature area.

You will be asked to choose between different trips to the coast (by the sea or by a fjord) or a trip to a forest.

You will be presented for a total of 8 choice situations. In each choice situation you will be presented for a chart like the one shown in the example below. (Note: The layout of the choice sets in the online version is not identical to the layout in the current document). 


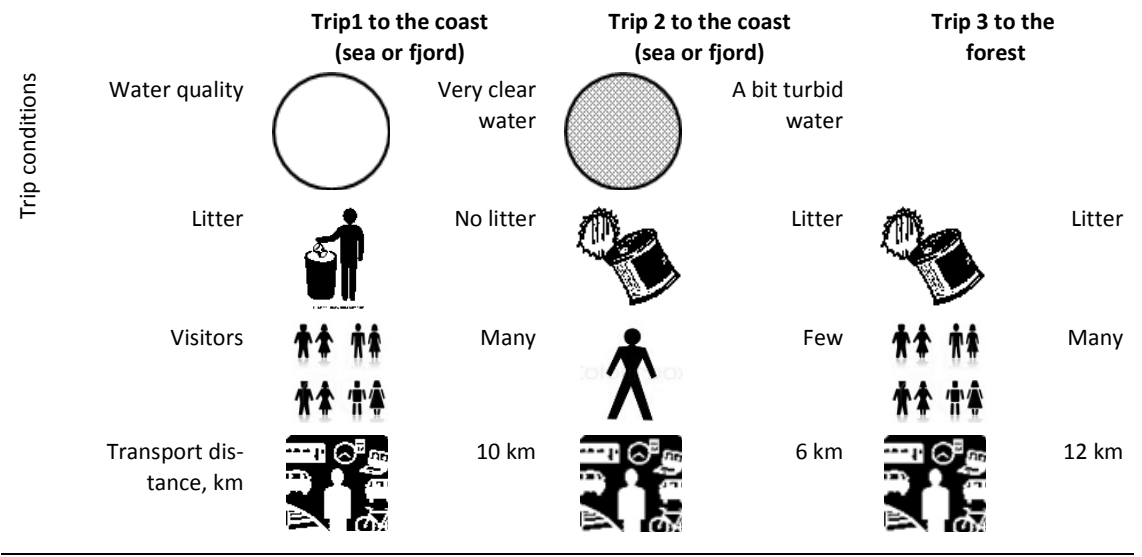

Which of the above trips do you prefer?

$\circ \square$ Trip 1 to the coast (sea or fjord)

$\circ \square$ Trip 2 to the coast (sea or fjord)

$\circ \square$ Trip 3 to the forest

$\circ \square$ None of the trips

If you in the example above choose "Trip 1 to the coast", it means, that you choose to go on a trip to a coast where there are many visitors, no litter and where the water is very clear. The distance to the coastal area is 10 $\mathrm{km}$ from your home.

For "Trip 2 to the coast" there are few visitors, litter and a bit turbid water. The distance from your home to the site is $6 \mathrm{~km}$.

The trip to a forest you can choose in this example is $12 \mathrm{~km}$ from your home, there is litter in the forest and there are many visitors.

You can also choose "None of the trips" where you either will stay at home or do something else.

On the next page you will find a more detailed description of the characteristics of the trips you are asked to choose between.

Description of the trip characteristics: 


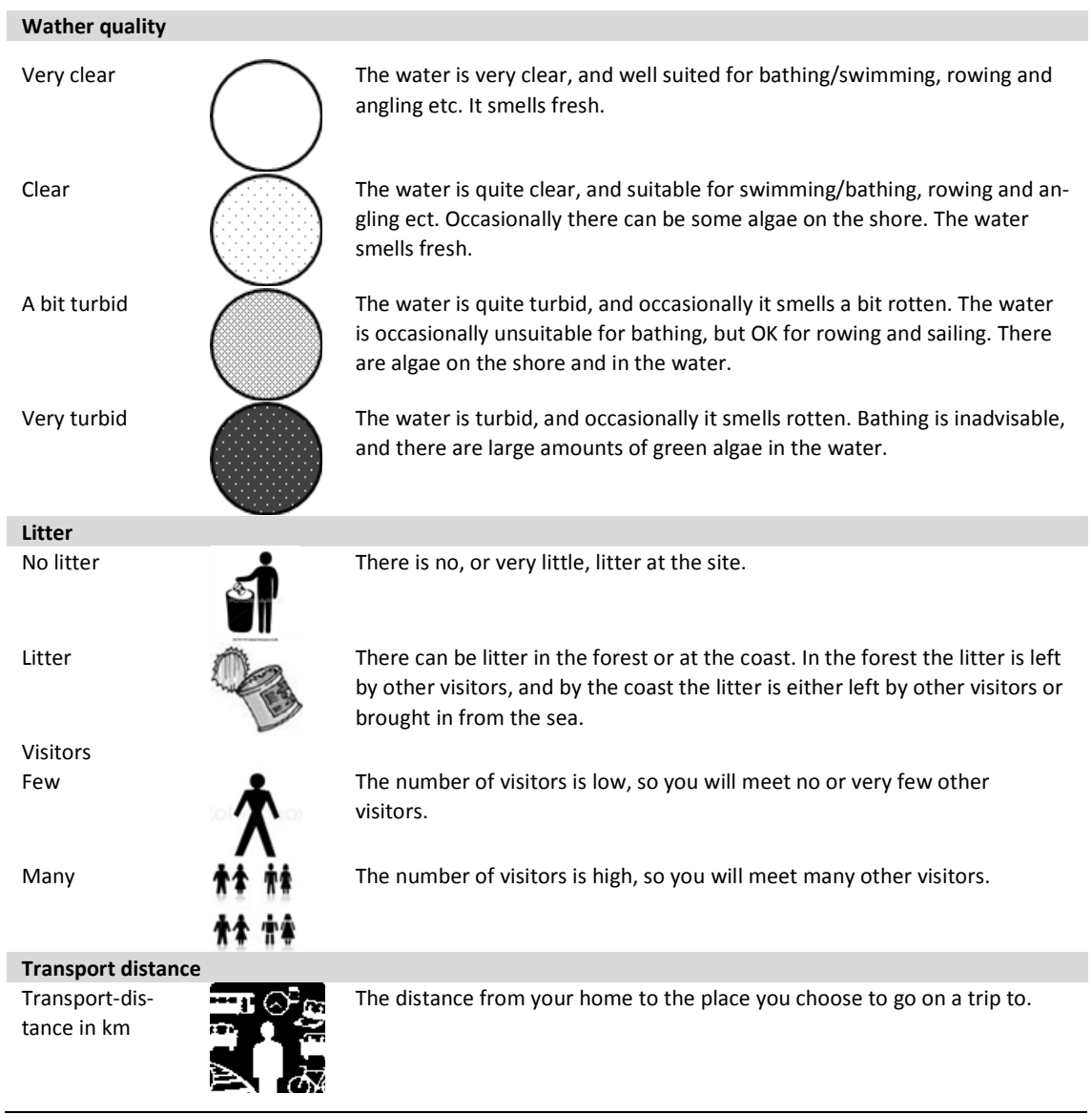

If you want to see this description of the characteristics again you can use the back-button.

\section{$1 / 8$}

Imagine now that it is a summer day, and that you are considering going on a trip to a nature area.

Which of the trips below would you choose?

For Userneeds - concerning the calculation of transport distances.

For the two trips to the coast the transport distance is calculated by increasing the distance reported by respondents in question 23 (Q13a_TXT) with the percentages specified in the choice sets.

For the trip to the forest the transport distance is calculated by increasing the distance reported by respondents in question 24 (Q13b_TXT) with the percentage specified in the choice sets. 
The transport distances are to be calculated as described above in all 8 choice situations in each of the 4 blocks.

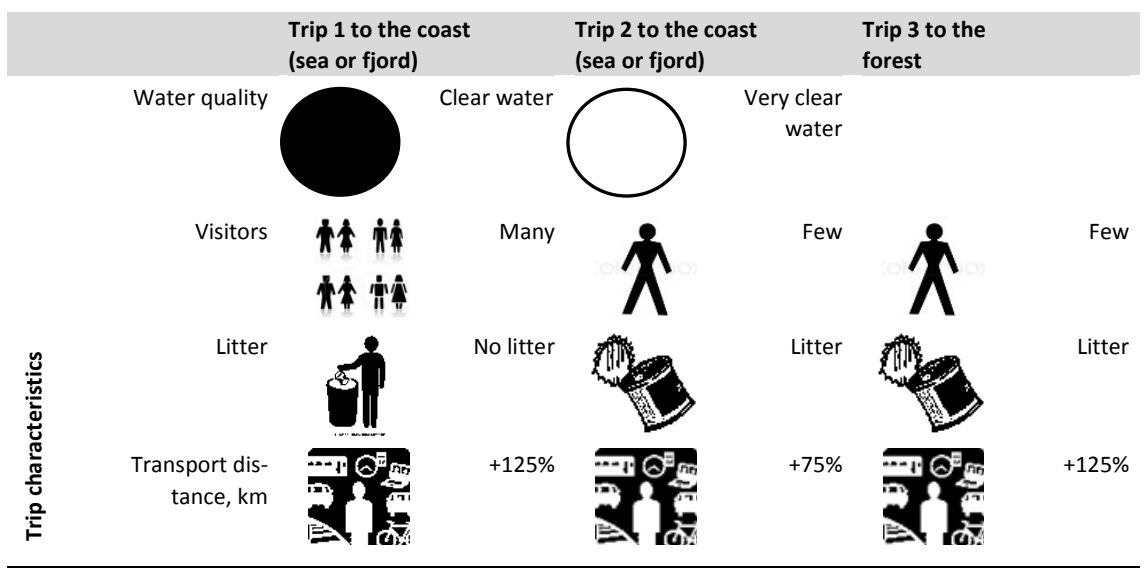

Which of the above trips do you prefer? (Blok1: V1Start; Blok2:

V2Start; Blok3: V3Start; Blok4: V4Start)

$\circ \square$ Trip 1 to the coast (sea or fjord)

$\circ \square$ Trip 2 to the coast (sea or fjord)

$\circ \square$ Trip 3 to the forest

$\circ \square$ None of the trips

Filter: Userneeds: The two following questions should only be answered if the respondent has chosen one of the trips to the coast or the forest.

How did you imagine that you would get to the coast/forest in the above choice situation?

o $\square$ By car (Blok1: V1a_1; Blok2: GroupV21a_1; Blok3: GroupV31a_1;

Blok4: GroupQ41a_1)

$\circ \square$ By bus/train (Blok1: V1a_2; Blok2: GroupV21a_2; Blok3:

GroupV31a_2; Blok4: GroupQ41a_2)

$\circ \square$ By bike (Blok1:V1a_3; Blok2: GroupV21a_3; Blok3: GroupV31a_3;

Blok4: GroupQ41a_3)

o $\square$ By foot (Blok1: V1a_4; Blok2: GroupV21a_4; Blok3: GroupV31a_4;

Blok4: GroupQ41a_4) 
Imagine that you are going on the trip you chose in the choice situation above. If this trip was possible, would you then go on fewer or more trips to the coast or the forest during one year, compared to the number of trips you make now?

(Blok1: V1b; Blok2: GroupV21b; Blok3: GroupV31b; Blok4: GroupQ41b)

$\circ \square$ Less trips

$\circ \square$ More trips

$\circ \square$ Same number of trips

o $\square$ Don't know

$2 / 8$

Imagine once again that it is a summer day, and that you are considering going on a trip to a nature area.

Which of the trips below would you choose?

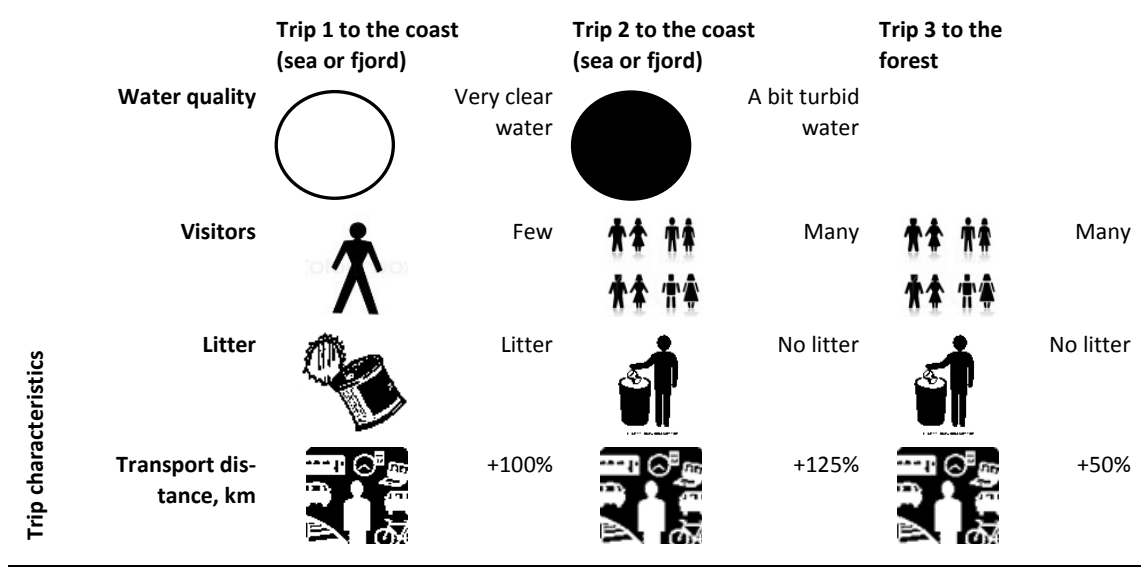

Which of the above trips do you prefer?

(Blok1: V12; Blok2: V22; Blok3: V32; Blok4: V42)

$\circ \square$ Trip 1 to the coast (sea or fjord)

$\circ \square$ Trip 2 to the coast (sea or fjord)

$\circ \square$ Trip 3 to the forest

$\circ \square$ None of the trips

Filter: Userneeds: The two following questions should only be answered if the respondent has chosen one of the trips to the coast or the forest. 
How did you imagine that you would get to the coast/forest in the above choice situation?

$\circ \square$ By car (Blok1: GroupV12a_1; Blok2: GroupV22a_1; Blok3:

GroupV32a_1; Blok4: GroupV42a_1)

$\circ \square$ By bus/train (Blok1: GroupV12a_2; Blok2: GroupV22a_2; Blok3:

GroupV32a_2; Blok4: GroupV42a_2)

$\circ \square$ By bike (Blok1: GroupV12a_3; Blok2: GroupV22a_3; Blok3:

GroupV32a_3; Blok4: GroupV42a_3)

$\circ \square$ By foot (Blok1: GroupV12a_4; Blok2: GroupV22a_4; Blok3:

GroupV32a_4; Blok4: GroupV42a_4)

Imagine that you are going on the trip you chose in the choice situation above. If this trip was possible, would you then go on fewer or more trips to the coast or the forest during one year, compared to the number of trips you make now?

(Blok1: GroupV12b; Blok2: GroupV22b; Blok3: GroupV32b; Blok4: GroupV42b)
$\circ \square$ Less trips
$\circ \square$ More trips
$\circ \square$ Same number of trips
$\circ \square$ Don't know

$3 / 8$

Imagine once again that it is a summer day, and that you are considering going on a trip to a nature area.

Which of the trips below would you choose?

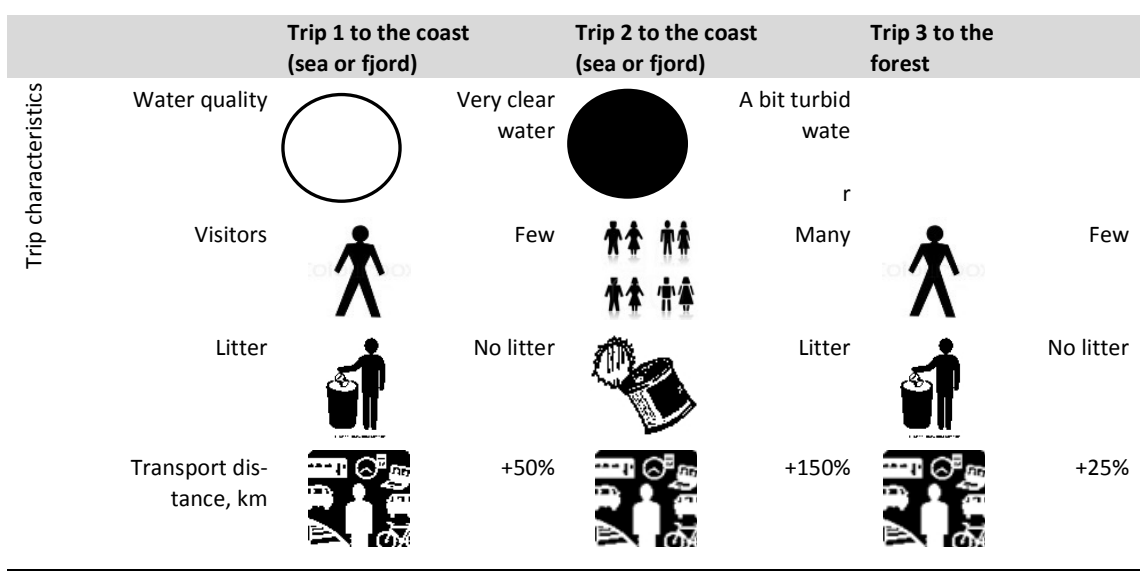


Which of the above trips do you prefer?

(Blok1: V13; Blok2: V23; Blok3: V33; Blok4: V43)

$\circ \square$ Trip 1 to the coast (sea or fjord)

$\circ \square$ Trip 2 to the coast (sea or fjord)

$\circ \square$ Trip 3 to the forest

$\circ \square$ None of the trips

Filter: Userneeds: The two following questions should only be answered if the respondent has chosen one of the trips to the coast or the forest.

How did you imagine that you would get to the coast/forest in the above choice situation?

o $\square$ By car (Blok1: GroupV13a_1; Blok2: GroupV23a_1; Blok3:

GroupV33a_1; Blok4: GroupV43a_1)

○ By bus/train (Blok1: GroupV13a_2; Blok2: GroupV23a_2; Blok3: GroupV33a_2; Blok4: GroupV43a_2)

o $\square$ By bike (Blok1: GroupV13a_3; Blok2: GroupV23a_3; Blok3: GroupV33a_3; Blok4: GroupV43a_3)

$\circ \square$ By foot (Blok1: GroupV13a_4; Blok2: GroupV23a_4; Blok3:

GroupV33a_4; Blok4: GroupV43a_4)

Imagine that you are going on the trip you chose in the choice situation above. If this trip was possible, would you then go on fewer or more trips to the coast or the forest during one year, compared to the number of trips you make now?

(Blok1: GroupV13b; Blok2: GroupV23b; Blok3: GroupV33b; Blok4: GroupV43b)

$\circ \square$ Less trips

$\circ \square$ More trips

$\circ \square$ Same number of trips

$\circ \square$ Don't know

$4 / 8$

Imagine once again that it is a summer day, and that you are considering going on a trip to a nature area.

Which of the trips below would you choose? 


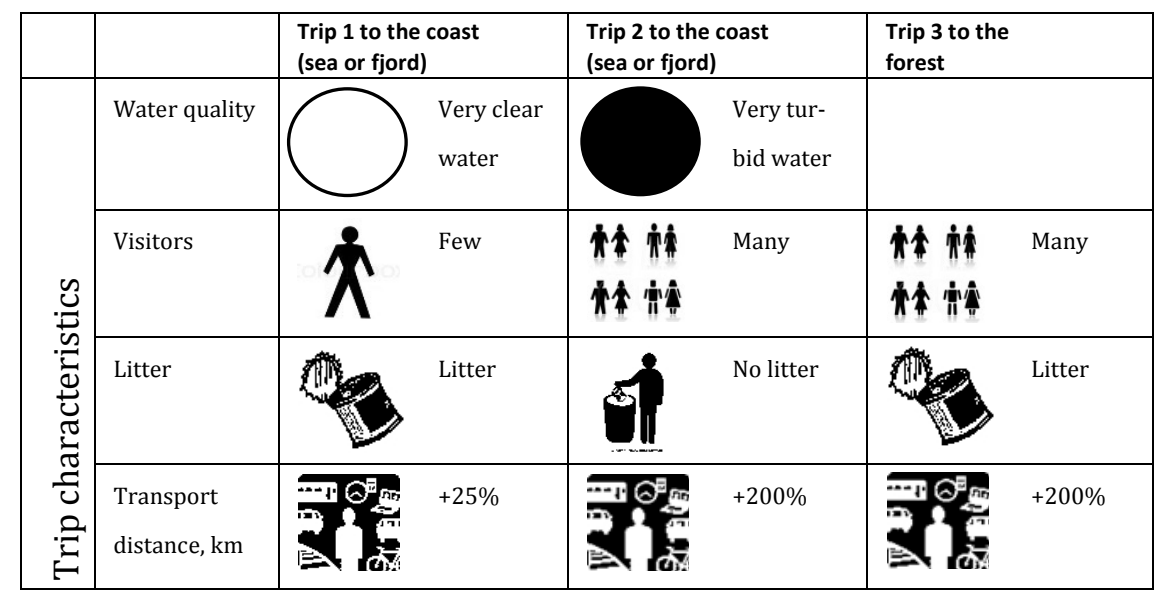

\section{Which of the above trips do you prefer?}

(Blok1: V14; Blok2: V24; Blok3: V34; Blok4: V44)

$\circ \square$ Trip 1 to the coast (sea or fjord)

$\circ \square$ Trip 2 to the coast (sea or fjord)

$\circ \square$ Trip 3 to the forest

$\circ \square$ None of the trips

Filter: Userneeds: The two following questions should only be answered if the respondent has chosen one of the trips to the coast or the forest.

\section{How did you imagine that you would get to the coast/forest in the} above choice situation?

o $\square$ By car (Blok1: GroupV14a_1; Blok2: GroupV24a_1; Blok3:

GroupV34a_1; Blok4: GroupV44a_1)

o $\square$ By bus/train (Blok1: GroupV14a_2; Blok2: GroupV24a_2; Blok3:

GroupV34a_2; Blok4: GroupV44a_2)

○ $\square$ By bike (Blok1: GroupV14a_3; Blok2: GroupV24a_3; Blok3:

GroupV34a_3; Blok4: GroupV44a_3)

$\circ \quad$ By foot (Blok1: GroupV14a_4; Blok2: GroupV24a_4; Blok3:

GroupV34a_4; Blok4: GroupV44a_4) 
Imagine that you are going on the trip you chose in the choice situation above. If this trip was possible, would you then go on fewer or more trips to the coast or the forest during one year, compared to the number of trips you make now?

(Blok1: GroupV14b; Blok2: GroupV24b; Blok3: GroupV34b; Blok4: GroupV44b)
$\circ \square$ Less trips
$\circ \square$ More trips
$\circ \square$ Same number of trips
$\circ \square$ Don't know

$5 / 8$

Imagine once again that it is a summer day, and that you are considering going on a trip to a nature area.

Which of the trips below would you choose?

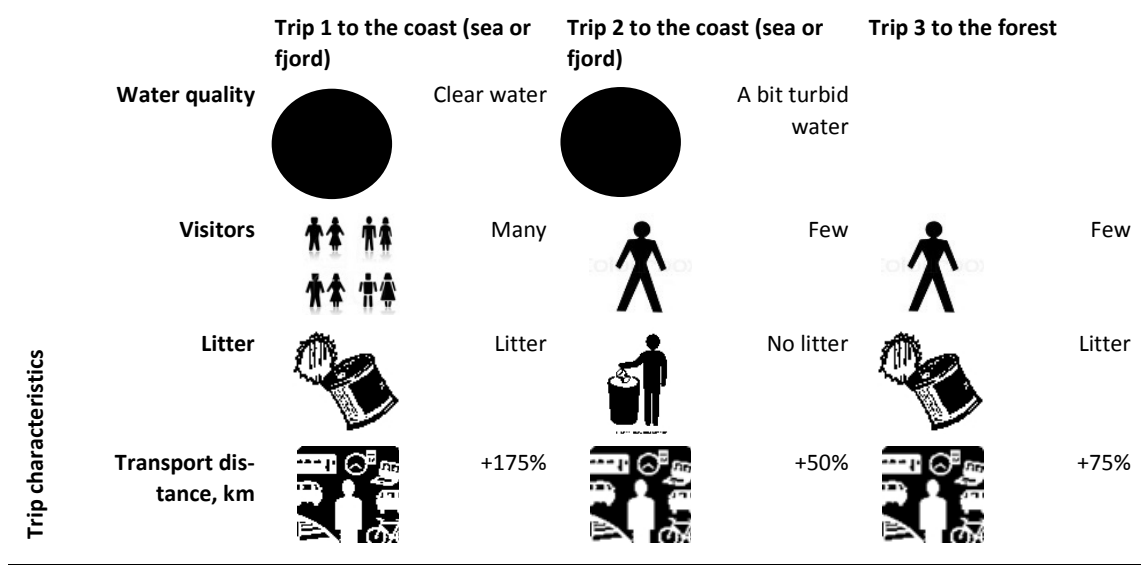

Which of the above trips do you prefer?

(Blok1: V15; Blok2: V25; Blok3: V35; Blok4: V45)

○ Trip 1 to the coast (sea or fjord)

- Trip 2 to the coast (sea or fjord)

- Trip 3 to the forest

- None of the trips 
Filter: Userneeds: The two following questions should only be answered if the respondent has chosen one of the trips to the coast or the forest.

How did you imagine that you would get to the coast/forest in the above choice situation?

o $\square$ By car (Blok1: GroupV15a_1; Blok2: GroupV25a_1; Blok3:

GroupV35a_1; Blok4: GroupV45a_1)

$\circ \square$ By bus/train (Blok1: GroupV15a_2; Blok2: GroupV25a_2; Blok3:

GroupV35a_2; Blok4: GroupV45a_2)

$\circ \square$ By bike (Blok1: GroupV15a_3; Blok2: GroupV25a_3; Blok3:

GroupV35a_3; Blok4: GroupV45a_3)

$\circ \square$ By foot (Blok1: GroupV15a_4; Blok2: GroupV25a_4; Blok3:

GroupV35a_4; Blok4: GroupV45a_4)

Imagine that you are going on the trip you chose in the choice situation above. If this trip was possible, would you then go on fewer or more trips to the coast or the forest during one year, compared to the number of trips you make now?

(Blok1: GroupV15b; Blok2: GroupV25b; Blok3: GroupV35b; Blok4: GroupV45b)

$\circ \square$ Less trips

$\circ \square$ More trips

$\circ \square$ Same number of trips

$\circ \square$ Don't know

$6 / 8$

Imagine once again that it is a summer day, and that you are considering going on a trip to a nature area.

Which of the trips below would you choose? 


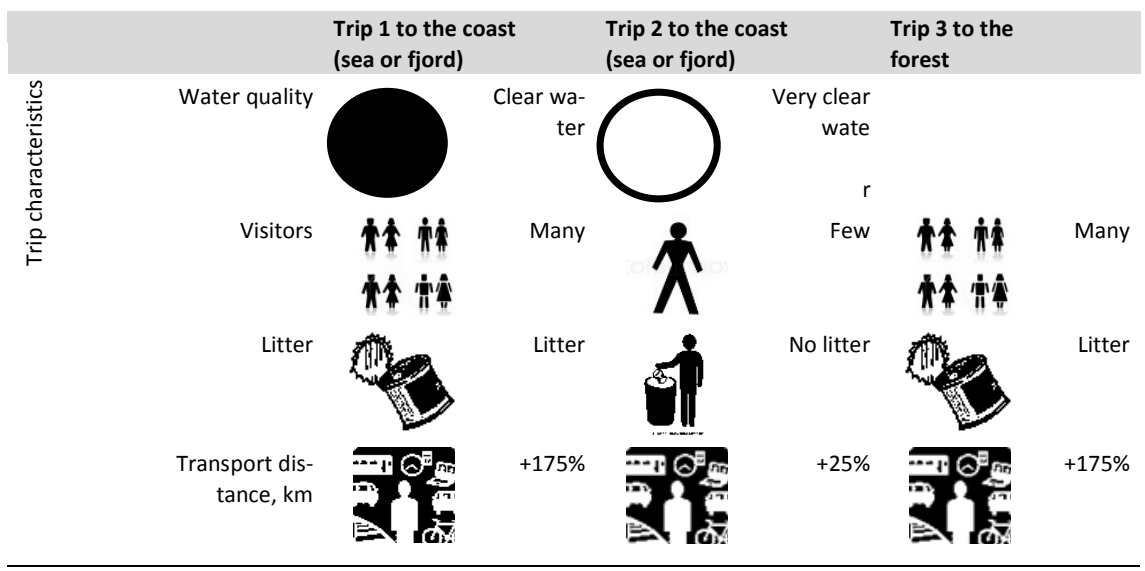

Which of the above trips do you prefer?

(Blok1:V16; Blok2: V26; Blok3: V36; Blok4: V46)

$\circ \square$ Trip 1 to the coast (sea or fjord)

$\circ \square$ Trip 2 to the coast (sea or fjord)

$\circ \square$ Trip 3 to the forest

$\circ \square$ None of the trips

Filter: Userneeds: The two following questions should only be answered if the respondent has chosen one of the trips to the coast or the forest.

\section{How did you imagine that you would get to the coast/forest in the} above choice situation?

$\circ \square$ By car (Blok1: GroupV16a_1; Blok2: GroupV26a_1; Blok3:

GroupV36a_1; Blok4: GroupV46a_1)

o $\square$ By bus/train (Blok1: GroupV16a_2; Blok2: GroupV26a_2; Blok3:

GroupV36a_2; Blok4: GroupV46a_2)

o $\square$ By bike (Blok1: GroupV16a_3; Blok2: GroupV26a_3; Blok3:

GroupV36a_3; Blok4: GroupV46a_3)

$\circ \square$ By foot (Blok1: GroupV16a_4; Blok2: GroupV26a_4; Blok3:

GroupV36a_4; Blok4: GroupV46a_4) 
Imagine that you are going on the trip you chose in the choice situation above. If this trip was possible, would you then go on fewer or more trips to the coast or the forest during one year, compared to the number of trips you make now?

(Blok1: GroupV16b; Blok2: GroupV26b; Blok3: GroupV36b; Blok4: GroupV46b)
$\circ \square$ Less trips
$\circ \square$ More trips
o $\square$ Same number of trips
$\circ \square$ Don't know

$7 / 8$

Imagine once again that it is a summer day, and that you are considering going on a trip to a nature area.

Which of the trips below would you choose?

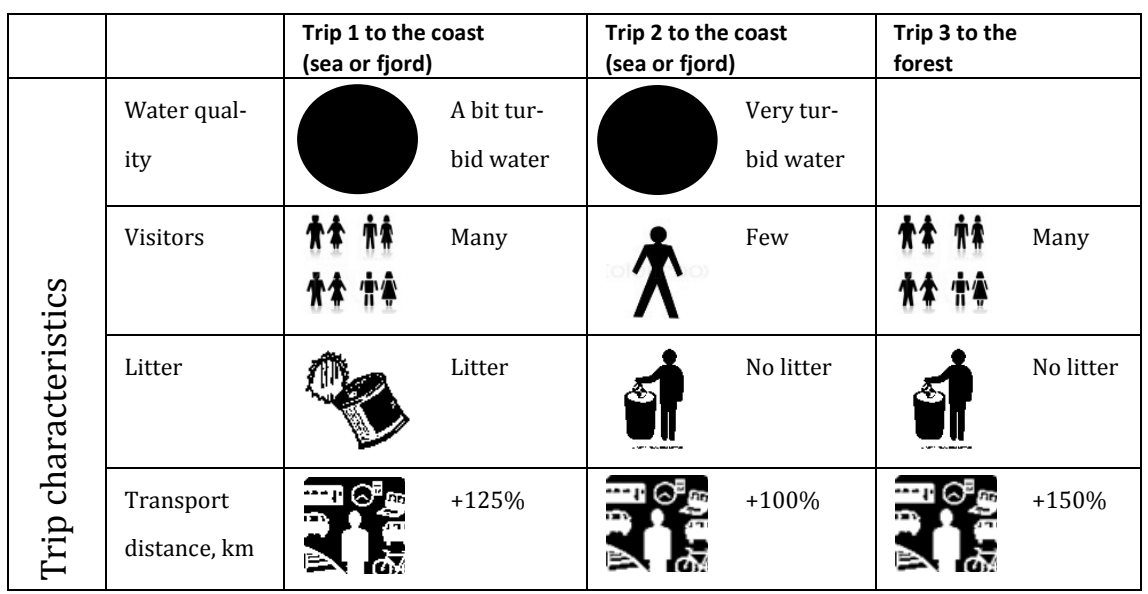

Which of the above trips do you prefer?

(Blok1: V17; Blok2: V27; Blok3: V37; Blok4: V47)

$\circ \square$ Trip 1 to the coast (sea or fjord)

$\circ \square$ Trip 2 to the coast (sea or fjord)

$\circ \square$ Trip 3 to the forest

$\circ \square$ None of the trips

Filter: Userneeds: The two following questions should only be answered if the respondent has chosen one of the trips to the coast or the forest. 
How did you imagine that you would get to the coast/forest in the above choice situation?

o $\square$ By car (Blok1: GroupV17a_1; Blok2: GroupV27a_1; Blok3:

GroupV37a_1; Blok4: GroupV47a_1)

o $\square$ By bus/train (Blok1: GroupV17a_2; Blok2: GroupV27a_2; Blok3:

GroupV37a_2; Blok4: GroupV47a_2)

$\circ \square$ By bike (Blok1: GroupV17a_3; Blok2: GroupV27a_3; Blok3:

GroupV37a_3; Blok4: GroupV47a_3)

$\circ \square$ By foot (Blok1: GroupV17a_4; Blok2: GroupV27a_4; Blok3:

GroupV37a_4; Blok4: GroupV47a_4)

Imagine that you are going on the trip you chose in the choice situation above. If this trip was possible, would you then go on fewer or more trips to the coast or the forest during one year, compared to the number of trips you make now?

(Blok1: GroupV17b; Blok2: GroupV27b; Blok3: GroupV37b; Blok4: GroupV47b)
$\circ \square$ Less trips
$\circ \square$ More trips
$\circ \square$ Same number of trips
o $\square$ Don't know

$8 / 8$

Imagine once again that it is a summer day, and that you are considering going on a trip to a nature area.

Which of the trips below would you choose?

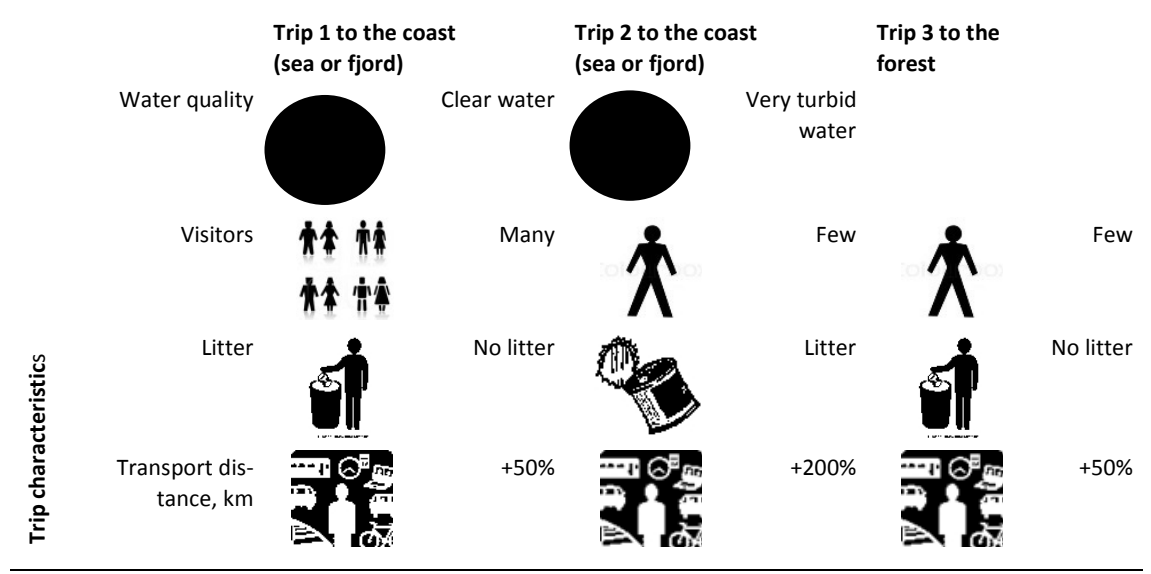


Which of the above trips do you prefer?

(Blok1: V18; Blok2: V28; Blok3: V38; Blok4: V48)

$\circ \square$ Trip 1 to the coast (sea or fjord)

$\circ \square$ Trip 2 to the coast (sea or fjord)

$\circ \square$ Trip 3 to the forest

$\circ \square$ None of the trips

Filter: Userneeds: The two following questions should only be answered if the respondent has chosen one of the trips to the coast or the forest.

How did you imagine that you would get to the coast/forest in the above choice situation?

o $\square$ By car (Blok1: GroupV18a_1; Blok2: GroupV28a_1; Blok3:

GroupV38a_1; Blok4: GroupV48aa_1)

o $\square$ By bus/train (Blok1: GroupV18a_2; Blok2: GroupV28a_2; Blok3:

GroupV38a_2; Blok4: GroupV48aa_2)

$\circ \square$ By bike (Blok1: GroupV18a_3; Blok2: GroupV28a_3; Blok3:

GroupV38a_3; Blok4: GroupV48aa_3)

○ By foot (Blok1: GroupV18a_4; Blok2: GroupV28a_1; Blok3:

GroupV38a_4; Blok4: GroupV48aa_4)

Imagine that you are going on the trip you chose in the choice situation above. If this trip was possible, would you then go on fewer or more trips to the coast or the forest during one year, compared to the number of trips you make now?

(Blok1: GroupV18b; Blok2: GroupV28b; Blok3: GroupV38b; Blok4: GroupV48ab)

$\circ \square$ Less trips

$\circ \square$ More trips

o $\square$ Same number of trips

o $\square$ Don't know

50. How important were the following characteristics in relation to the choices you made in the previous questions?

(Only check one box in each row) 


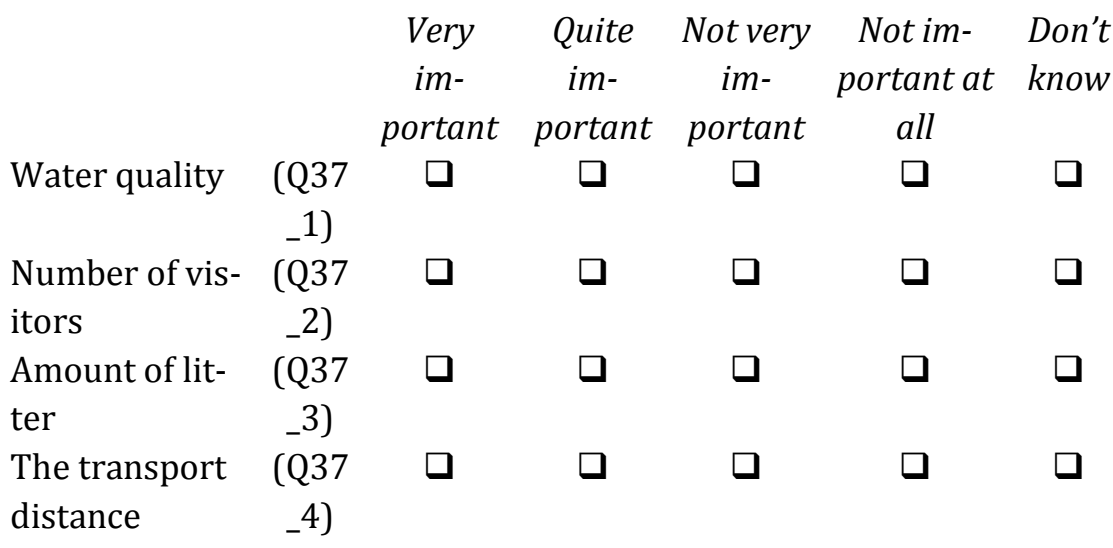

51. How would you describe the 8 choices? Check one box (Q38)

\begin{tabular}{|l|c|}
\hline The choices were very difficult & $\square$ \\
\hline The choices were difficult & $\square$ \\
\hline Neither nor & $\square$ \\
\hline It was fairly easy to choose & $\square$ \\
\hline It was very easy to choose & $\square$ \\
\hline Some choices were difficult others were easy & $\square$ \\
\hline
\end{tabular}

For Userneeds: Question 52 should only be asked to respondents who choose "None of the trips" in all 8 choice situations.

52. Why did you choose "None of the trips" in all the choice questions? (Q39)

For Userneeds: Question 53 should only be asked to respondents who choose "Trip to the forest" in all 8 choice situations.

\section{Why did you choose "Trip to the forest" in all the choice} questions? (Q39_TXT)

\section{Number of trips to the coast in the future}

Imagine that the water quality is improved to "Good quality" in all coastal areas and fjords in Denmark. Would you go on more trips to the coast than you do now if the water quality is improved?

Yes, Number of trips: (Q40; Q40_TXT)

No. 
55. Do you think that it is plausible that the water quality can become good in all coastal areas and fjords? (Q41)

\begin{tabular}{|l|c|}
\hline Plausible & $\square$ \\
\hline Fairly plausible & $\square$ \\
\hline Fairly unplausible & $\square$ \\
\hline Unplasible & $\square$ \\
\hline Plausible in some places, unplausible in other places & $\square$ \\
\hline
\end{tabular}


Ved Stranden 18

DK-1061 Copenhagen K

www.norden.org

\section{Marine Ecosystem Services}

Marine Ecosystem Services (MARECOS) is an interdisciplinary study that provides relevant information for national, Nordic and international ecosystem services assessments and valuation in the implementation of marine policy.

This report aims to provide suggestions on how ecosystem condition assessments, being based on the Marine Strategy Framework Directive (MSFD), and the HELCOM indicator based assessments for the Baltic Sea, could be used for the assessment of ecosystem services.

By describing the potentials of linking data and knowledge describing the status of marine ecosystems and water quality to the values of the services and goods provided, the report offers useful information for policy and decision makers in the domain of the marine and aquatic policies around the Baltic and in the Nordic countries.

TemaNord 2016:501

ISBN 978-92-893-4444-9 (PRINT)

ISBN 978-92-893-4445-6 (PDF)

ISBN 978-92-893-4446-3 (EPUB)

ISSN 0908-6692

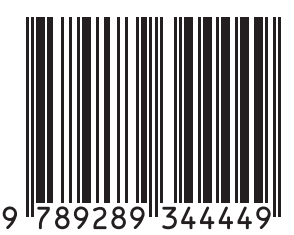

